\title{
Social class differences in eating and drinking behaviour: An international study
}

Citation for published version (APA):

Hupkens, C. L. H. (1998). Social class differences in eating and drinking behaviour: An international study. [Doctoral Thesis, Maastricht University]. Ponsen \& Looijen. https://doi.org/10.26481/dis.19980213ch

Document status and date:

Published: 01/01/1998

DOI:

10.26481/dis.19980213ch

Document Version:

Publisher's PDF, also known as Version of record

\section{Please check the document version of this publication:}

- A submitted manuscript is the version of the article upon submission and before peer-review. There can be important differences between the submitted version and the official published version of record.

People interested in the research are advised to contact the author for the final version of the publication, or visit the DOI to the publisher's website.

- The final author version and the galley proof are versions of the publication after peer review.

- The final published version features the final layout of the paper including the volume, issue and page numbers.

Link to publication

\footnotetext{
General rights rights.

- You may freely distribute the URL identifying the publication in the public portal. please follow below link for the End User Agreement:

www.umlib.nl/taverne-license

Take down policy

If you believe that this document breaches copyright please contact us at:

repository@maastrichtuniversity.nl

providing details and we will investigate your claim.
}

Copyright and moral rights for the publications made accessible in the public portal are retained by the authors and/or other copyright owners and it is a condition of accessing publications that users recognise and abide by the legal requirements associated with these

- Users may download and print one copy of any publication from the public portal for the purpose of private study or research.

- You may not further distribute the material or use it for any profit-making activity or commercial gain

If the publication is distributed under the terms of Article $25 \mathrm{fa}$ of the Dutch Copyright Act, indicated by the "Taverne" license above, 
CIP-gegevens Koninklijke Bibliotheek, Den Haag

Hupkens, Christianne L.H.

Social class differences in eating and drinking behaviour. An international study / Christianne L.H. Hupkens - [S.I.s.s.n.]

Thesis Universiteit Maastricht - With ref. - With summary in Durch ISBN 90-5651-047-9

Subject headings: diet, alcohol, social class

(C) Hupkens, Christianne L.H.

Ontwerp en boekverzorging:

Martijn Geerdes, Delft

Distributie:

EburonP\&L.

Postbus 2867

$2601 \mathrm{CW}$ Delft

Druk:

Ponsen \& Looijen, Wageningen

Financial support by the Netherlands Heart Foundation for the publication of this thesis is gratefully acknowledged. 


\section{Social class differences in eating and drinking behaviour}

An international study

\section{PROEFSCHRIFT}

ter verkrijging van de graad van doctor aan

de Universtiteit Maastricht,

op gezag van de Rector Magnificus, Prof. dr. A.C. Nieuwenhuijzen Kruseman volgens het besluit van het College van Decanen,

in het openbaar te verdedigen

op vrijdag 13 februari 1998 om 16.00 uur

door

Christianne Louise Hubertine Hupkens 
Promotor:

Prof dr. M.J. Drop

Co-promotor:

Dr. R.A. Knibbe

Beoordelingscommissie:

Prof. dr. G.J. Kok (voorzitter)

Dr. ir. R.A. Bausch-Goldbohm (TNO Voeding, Zeist)

Prof. dr. W.A. van Staveren (Landbouwuniversiteit, Wageningen)

Dr. H.C.W. de Vet

Prof. dr. J. van der Zee 


\section{Contents}

$1 \quad$ Introduction

2 Alcohol consumption in the European Community: uniformity and diversity in drinking patterns.

Addiction, 1993, 88, 1391-1404.

3 Social class differences in women's fat and fibre consumption: a cross-national study.

Appetite, 1997, 28, 131-149.

4 Social class differences in food consumption: the explanatory value of permissiveness and health and cost considerations. Submitted.

5 Social class differences in the food rules mothers impose on their children: a cross-national study. Social Science and Medicine, accepted.

6 Eat it or leave it. Class differences in how mothers handle children's dislikes. Submitted.

7 General discussion

Summary

Samenvarting

Appendix 1

Dankwoord / Acknowledgements 
Voor miln (groot)ouders 


\section{Introduction}

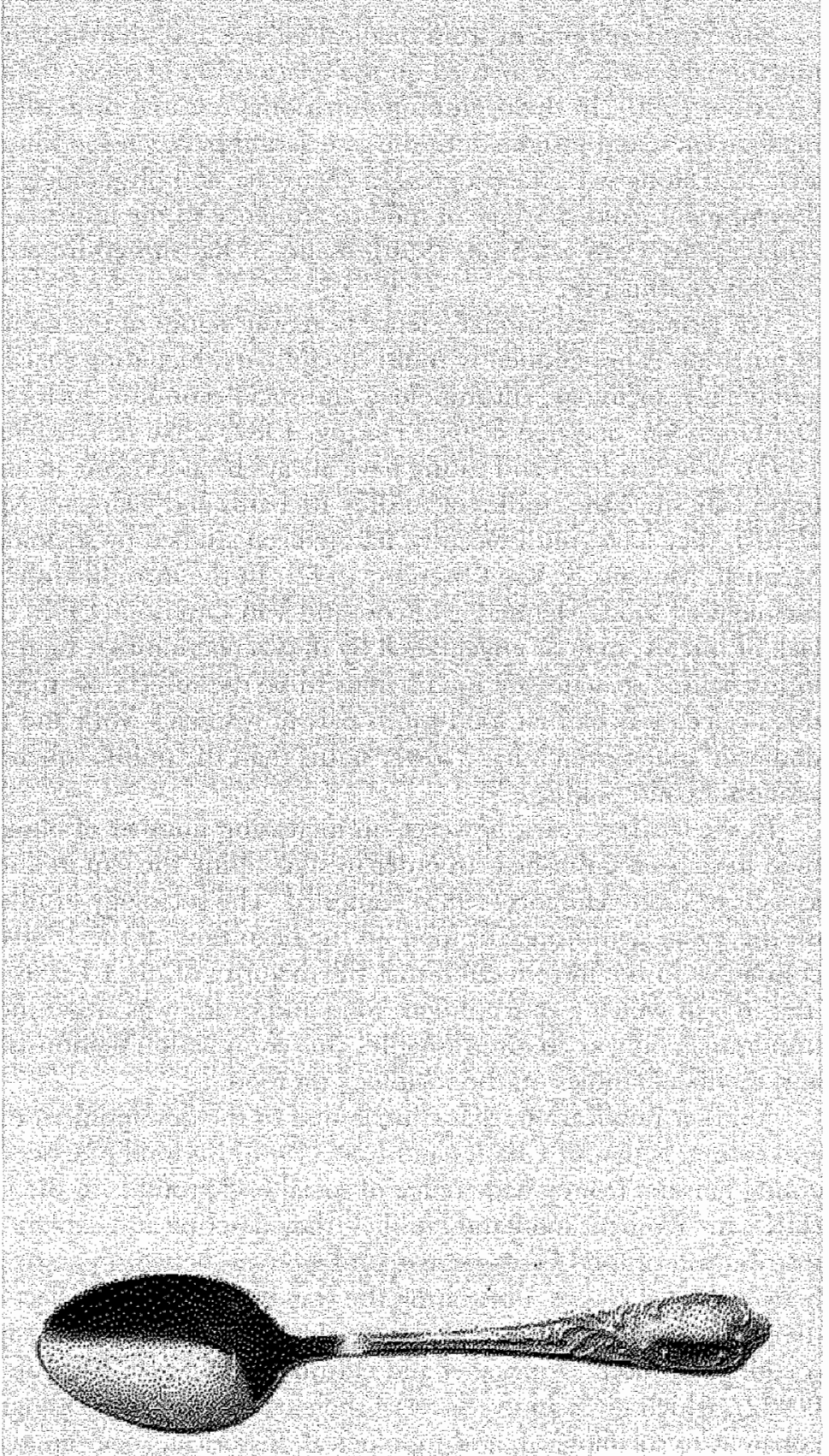




\section{Sociological studies on eating behaviour}

Since its development from medical science and pharmacy in the 19th century, nutritional science has focused on the relationship between food and health (Van Otterloo, 1990). In the beginning nutritional research primarily explored nutritional inadequacies, and insights into the association between food intake and disease advanced along with the progress in chemistry and physiology. Parallel to the development from shortage of food to affluence in the industrialised countries in the 20 th century (Van Otterloo, 1990), the focus has shifted from deficiencies towards diseases of affluence.

Yet, although nutritional science bears the stamp of the natural sciences, the field of nutrition is pre-eminently multi-disciplinary, including social sciences like psychology, sociology, anthropology and socio-economic history (Van Oosten-Van Der Goes, Van Staveren \& Den Hartog, 1982; Sobal \& LaChaussee, 1993; Murcort, 1995). Whereas food and eating have always been a theme in anthropology (especially since the studies of Audrey Richards and Margaret Mead in the 1930s and 1940s), they have, until recently, hardly been studied by sociologists (Murcott, 1988; Mennell, Murcott \& Van Otterloo, 1992). In the introduction of their book on the sociology of food, Mennell, Murcott and Van Otterloo (1992) illlustrated that this lack of interest may be engendered by the conviction that food and eating in the industrialised societies are too obvious to be the subject of study. Another reason for this neglect may be that food forms part of women's work and mainly belongs to the domestic sphere which has a lower status than the public spheres of, for instance, economics and politics.

In the last few years, however, an increasing number of books on the sociology of food have been published. In order to start filling the gap in knowledge on social aspects of food, Murcott (1983) compiled 'The sociology of food and eating. Essays on the social significance of food' in the beginning of the 1980s. Although Murcott comments in the introduction that the majority of the 16 essays are based on 'research in which a concern with food and eating was either incidental or assumed importance only as an afterthought', this compilation demonstrates the possibilities and merits of studies on the sociology on food.

Another publication, that contributed to the development of a sociology of food and eating, is that of Charles and Kerr (1988) on food practices among women with young families from a wide range of social backgrounds in the United Kingdom (UK). In 'Women, food and families' they describe and explain the uneven distribution of food between men and women, berween parents and children and between social classes, illustrating the way food practices reflect and create social divisions. Another impetus to the development of this sub-discipline is "The sociology of food: eating, dier and culture' of Mennell, Murcott and Van Otterloo (1992), which gives an overview of the current state of sociological knowledge apparent in sociological, anthropological, historical, socio-biological and nutritional fields of study. 
In the Dutch-and Flemish-speaking regions three noteworthy books on the social and historical aspects of food have recently been published. Van Otterloo (1990) and Jobse-Van Patten (1995) explored developments in eating behaviour since 1840 and the Middle Ages respectively in the Netherlands, and Scholliers (1993) described eating habits of the rich and the poor during the last two centuries in Belgium.

The growing interest for the sociology of food is also furthered by the British Economic and Social Research Council (ESRC), which has funded a research programme named 'the Nation's Diet: the social science of food choice'. 'This sixyear programme started in 1992 and covers 16 projects that are executed by several research groups of different social disciplines. The programme intends to illuminate why we eat what we do, and the projects focus for instance on how food consumption varies between families, ethnic groups and income groups, on changes in food habits when people get married and when they grow older, on psychological determinants of children's food preferences, and on trends towards eating out, takeaway meals and convenience food. Besides exploring the themes of the constituent projects separately, the researchers intend to examine the surplus value of this multidisciplinary programme (Murcott, 1995).

Similarly, the nutritional sciences can benefit from a multi-disciplinary approach. Because the perspectives of sociologists and anthropologists, that is the symbolic nature of food and eating practices and the meaning of these practices in their social and cultural setting, differ from those of nutritionists, who are primarily interested in bodily functioning and state of health (Lupton, 1996), the views and results of sociology and anthropology can yield insight into food choice and changing eating behaviours.

One of the main dilemmas within contemporary nutritional science is that the large majority of the people still do not eat healthily, notwithstanding the increasing knowledge on the relation between nutrients and health and in spite of the growing number of nutrition education campaigns. Thus, it appears to be hard to translate nutritional findings to the public at large, giving rise to many questions. Do people know the latest nutritional guidelines? If so, what do think of them? Are they interested in healthy food? Which other considerations play a role when people selecr food? What circumstances influence food habits? This kind of information is especially valuable for the further development of nutrition education and food policies.

\section{Social stratification and eating behaviour}

The present project aims to combine nutritional and sociological perspectives. Besides studying what people eat and drink, the project also explores why they do so. Its main sociological theme is the social distribution of food choices and regimes. 
Like age and sex, social class appears to be a key variable in food consumption patterns: in the industrialised countries people of the higher social strata generally have healthier diets than people of the lower social strata (Charles \& Kerr, 1988; Mennell, Murcott \& Van Otterloo, 1992). Thus, the study of eating behaviour in different social classes may give insight into the underlying mechanisms of food choice.

Moreover, socio-economic health differences have always been a theme within public health research (Mackenbach, 1994). Since the publication of the Black Report by the Working Group on Inequalities in Health in the UK in 1980 (Townsend, Davidson \& Whitehead, 1988), researchers have shown an increasing interest in this topic. In 1990, for instance, the journal Social Science and Medicine dedicated an edition to this topic under the title 'Health Inequities in Europe' (Volume 31, Number 3), which included 20 articles from 18 countries ranging from Norway to Spain, and from Ireland to Turkey. The majority of the publications on this topic show that people of the higher social classes are healthier than people of the working classes: generally higher class people suffer from fewer diseases and they have a longer life expectancy than lower class people (Mackenbach, 1994; Kunst, Cavelaars, Groenhof, Geurts \&c Mackenbach, 1996).

Empirical data has shown that these health differences have even been increasing in the last few decades (Davey Smith, Bartley \& Blane, 1990; Mackenbach, 1992; Mackenbach, 1994; Phillimore, Beattie \& Townsend, 1994; Rijksinstituut woor Volksgezondheid en Milieu, 1997). At present the social class difference in life expectancy at birth in the Netherlands appears to be 3.5 years, and the difference in healthy life expectancy is about 11.5 years for both men and women. According to a Durch team of scientists and policymakers, interventions to diminish socioeconomic health differences are the key to improve the general state of health of the population (Rijksinstituut voor Volksgezondheid en Milieu, 1997).

Four possible explanations for socio-economic health differences were elaborated in the Black Report: (1) artefact explanation, (2) natural or social selection, (3) materialist or structuralist explanation, and (4) cultural or behavioural explanation (Townsend, Davidson \& Whitehead, 1988). According to the cultural/behavioural explanation, lower class people have less healthy lifestyles, like smoking and unhealthy eating habits, which may influence their heal th negarively. This explanation is usually judged to be the most important, and is especially favoured by the medical profession and health educators (Blane, 1985). However, this explanation is also often criticised for its view that such behaviours are largely under individual control, and it is disputed whether lifestyles can be separated from their context, i.e. material and structural circumstances like purchasing power, access to education and working conditions. The authors of the Black Report preferred the explanation that structurally determined differences in the spheres of production and consumption cause social class differences in health. This materialist or structuralist explanation implies that people who have less material resources at their disposal 
have worse living and working conditions, like poor housing and heavy work, which may lead to a worse health status (Blane, 1985).

The present project may contribute to the explanation of socio-economic health differences by exploring class differences in eating behaviour. Moreover, as far as possible this project takes the broader context of this behaviour into account. Although the underlying biological mechanisms of the effects of food on health have not yet been elucidared, which makes it difficult to quantify the contribution of food to morbidity and mortaliry, dietary constituents like fat and vegetables appear to be associated with main causes of death like cardiovascular diseases and cancer (James, Ferro-Luzzi, Isaksson \& Szostak, 1988; Rijksinstituut voor Volksgezondheid en Milieuhygiëne, 1993; Hautvast, 1993; Willett, 1994). Therefore, class differences in diet may contribute to the explanation of socio-economic health differences.

\section{Theoretical perspectives on social stratification and eating behaviour}

Of the sociological approaches to food and eating, it is especially the theories of Elias, Mennell and Bourdieu that provide insight into the association between social stratification and food consumption (see Murcotr (1988) and Mennell, Murcott and Van Otterloo (1992) for an overview of sociological perspectives on food and eating).

In his book 'The civilising process' (originally published in German in 1939), Norbert Elias (1982) explored the development of manners among the secular upper classes in Europe since the Middle Ages. Elias related changes in forms of cultural expression to broader processes of structural changes in society, and he argued that when life became more predictable, from the $16 \mathrm{th}$ century onwards, foresight and self-regulation became more important for social and economic success. Generally, external constraints became internalised as unconscious and automatic self-restraint (Lupton, 1996). Although Elias did not pay much attention to food, his discussion of table manners is particularly renowned (Mennell, Murcott \& Van Otterloo, 1992).

Stephen Mennell (1985) applied Elias's theory of the "civilising process' to the 'civilising of appetite' in order to account for changing food preferences and emerging cuisines. He explored why a 'haute cuisine' had developed in France but not in England, and he illuminated the association of the development of these different cuisines with the social development of the two nations. Distinctions between the upper and lower social classes are an important feature of the civilising process. In the Middle Ages there were great inequalities in the social distribution of food, and until the late 17th century the upper classes often distinguished themselves from the lower by the sheer quantity of food they consumed. Once food supplies were more plentiful and reliable, social distinction came to be expressed 
more through quality and refinement of food than through quantity. According to Mennell's theory, the process of distinguishing goes on continually, and while external constraints diminish, internalised self-control increases especially in the higher social strata (Mennell, 1985).

To give a contemporary example, as most working class families could afford meat only on special occasions in the recent past, they nowadays consume this 'luxury food item on a daily basis. Moreover, they favour meat because of its 'filling' character, which is deemed especially appropriate for people who do heavy manual work. Higher-middle class people could afford a daily portion of meat much earlier, and they now emphasize gastronomy and a good health, and consequently favour refined dishes and quality rather than quantity: they nowadays consume smaller portions of meat of a better quality. Moreover, they consume meat less frequently, and they more often have fish, cheese or eggs instead (Van Otterloo, 1995).

According to Mennell's theory, the working class lags behind the higher social class. After some time the working class reproduces higher-middle class preferences and values, but they never converge, as people of the higher social strata continue to distinguish themselves.

Like Elias, Pierre Bourdieu (1989) showed that people's preferences and choices are linked with their position in the social order. In 'La distinction. A social critique of the judgement of taste' (first published in French in 1979), he defined social positions by the amount of economic and symbolic (mainly educational) capital. Based on a study on taste and lifestyles (including food, but also music, literature, cinema, arts, clothes and furniture) in France, he characterised the lifestyle of the working class by the 'taste of necessity', and the lifestyle of the middle and highermiddle class by the 'taste of luxury'. The latter used among other things eating habits to distinguish themselves in their values, rules and choices from the working class. French working class people (lacking economic and symbolic capital) favoured heavy and fatty meals in large quantities and well-cooked vegetables, while their middle class counterparts (possessing both economic and symbolic capital) preferred refined and light meals and raw vegetables, that were more expensive, but also healthier. In addition, Bourdieu stated that people in professional occupations accepted a new cultural norm of restraint, as they were concerned with moderarion and a slender body, while the working classes, because of their material limitations, displayed 'an ethic of convivial indulgence': taking advantage of good times while they lasted (Lupton, 1996).

These theories stress the association between social positions and lifestyles, confirming the correspondence between the cultural/behavioural explanation and the materialist/structuralist explanation of socio-economic health differences. This accords with the view of the authors of the Black Report, who referred to the artificial distinction between these two explanations (Blane, 1985; Townsend, Davidson \& Whitehead, 1988).

Although both Mennell and Bourdieu give many examples of eating habits and 
food preferences that trickled down the social scale, it can be argued whether people of the lower classes indiscriminately adopt all changes in eating behaviour from the middle classes (Warde, 1997). This may be true for trends and fashions in food consumption, but perhaps not for all norms, values and habits. The studies of Blaxter and Paterson (1982; 1983), Charles and Kerr (1988) and Stafleu (1994) on family food practices in lower class families, for instance, showed that working class mothers have their own norms and values regarding food practices, which may be reproduced from generation to generation.

With regard to the implications of these theories on bealthy lifestyles, three comments can be made. First, the theories show that emphasis on health has become a means of distinction only (fairly) recently. Taking health into account, which requires long-term planning and deferred gratification, is an aspect of the civilising process (Van Otterloo \& Gerritsen, 1991). While many contemporary examples indicate that higher-middle class people currently distinguish themselves from the lower classes by their more healthy lifestyles, health considerations appeared to be less influential in the past. Indulgence in the Middle Ages and smoking and being overweight in the first half of the 20 th century were preferred in the higher classes, but not because these habits were deemed healthy. In the 1950s mortality as a result of lung cancer and cardiovascular diseases was higher among people of higher socioeconomic status, while now more lower class people die of these diseases (Kunst, Looman \& Mackenbach, 1990).

Secondly, also nowadays higher class people do not always display the mose healthy habits. Compared to lower class people, more higher class people consume alcoholic drinks (Cahalan, Cisin \& Crossley, 1969; Hulshof, Löwik, Kok et al., 1991; Kunst et al., 1996) for instance, while the health benefits and disadvantages of alcohol consumption are not yet clear. Finally, people of the higher classes may demonstrate healthy habits, that are popular for reasons other than health. As mentioned above, Bourdieu's (1989) study showed that especially higher class people are concerned with slimming. Probably, this may be a more important reason to adhere to a low fat diet than considerations with respect to health.

\section{An ethnographic study on social stratification, food and eating}

The present study has been inspired by the ethnographic study of Van Otterloo and Van Ogtrop on attitudes and practices regarding food in working class and higher-middle class families. That study was based on semi-structured interviews with 46 mothers of 6-12-year-old children in the Netherlands (Van Otterloo \& Van Ogtrop, 1989; Van Otterloo, 1995). In their work these researchers combined the insights of Mennell's concept on the civilising of appetite with those of Bourdieu's notion on class patterns in taste. The Dutch working class mothers generally 
reported a preference for sweet, fat and filling food, while their middle class counterparts favoured a wider variety of different types of food. Compared to working class mothers, middle class mothers served less meat, and especially lower fat meat, a greater variety of vegetables in larger quantities, and more brown and wholemeal bread instead of white bread. Similar to the class patterns in France reported by Bourdieu (1989), the preferences of the lower class could be typified as the 'taste of necessity', and those of the middle class as the 'taste of luxury'.

With regard to the reasons mothers mentioned for their food choice, working class mothers mentioned tastiness most often as their first consideration, whether or not combined with other criteria like cheap, easy to prepare and appropriate to please husband and children. The mothers also referred frequently to health as a motive, but not as often as they did to taste. To the contrary, middle class mothers mentioned health more often than taste as their primary consideration. Mothers were also interviewed on how they educated their children with regard to food. Working class mothers appeared to be more permissive than middle class mothers: they were more inclined to accept their children's (and their husband's) tastes, whereas middle class mothers expressed more often that their children's tastes should be adapted and moderated.

Van Otterloo and Van Ogtrop (1989) gave several related explications for these distinctions between the social strata. Irrespective of social class, all mothers like to please their family members' preferences, as they depend on their husband and children for the approval of their work, especially if they are full-time housewives. However, compared to middle class mothers, mothers of the lower strata discipline their children less strictly, as they have less chance and possibility to resist the pressures of the apperites of their family members, because of the more deprived situation in which they live. Like health considerations, permissiveness too can be viewed as an aspect of the process of civilisation, which takes place at unequal pace for the different social strata.

Extending Elias's theory that after some time lower class people follow trends that were initiated in the higher social strata, the researchers conclude that 'as working class families have only recently participated in affluence, this is a time to enjoy food and not to postpone the gratification of appetite in view of future health. Probably their time to learn discipline and self-control has not been long enough, but eventually it will come.'

\section{Research questions}

As indicated above, the research questions of the present study were based on the ideas and findings of the qualitative study of Van Otterloo and Van Ogtrop (1989). Our aim was to explore social class differences in eating and drinking behaviour in a larger population, and therefore we used quantitative survey data. Moreover, whereas 
most research on this topic has been performed in the UK (e.g. Blaxter \& Parerson, 1982; Murcott, 1983; Charles \& Kerr, 1988), we did our study in countries located on the continent. In short, we studied class differences (1) in the consumption of foods and drinks, (2) in the considerations that may underlie food choices, and (3) in the way mothers discipline their children in food matters. An overview of the hypotheses is presented in figure 1.1.

\section{Figure 1.1}

Hypotheses

Higher-middle class compared to lower class

\section{consumption of foods and drinks}

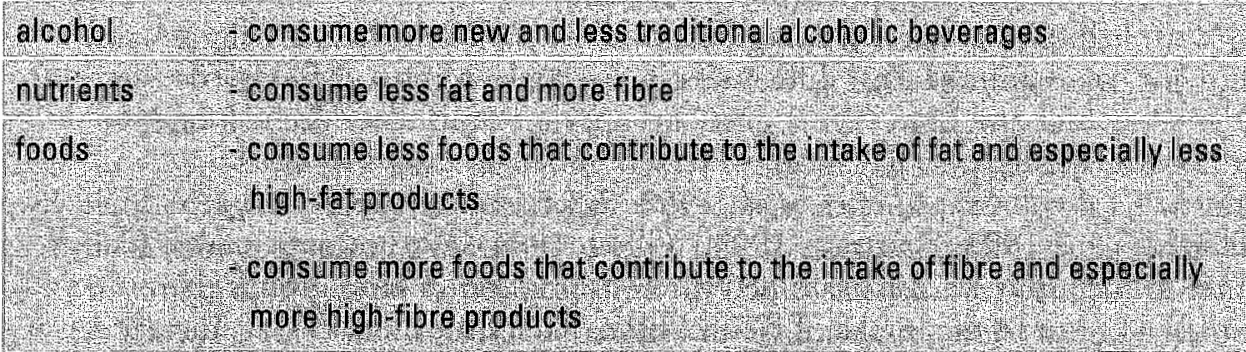

\section{considerations that may influence food choice}

considerations are less permissive, censider thealth more often and costs less often - these considerations partly explain olass differences in food consumption

\section{food rules}

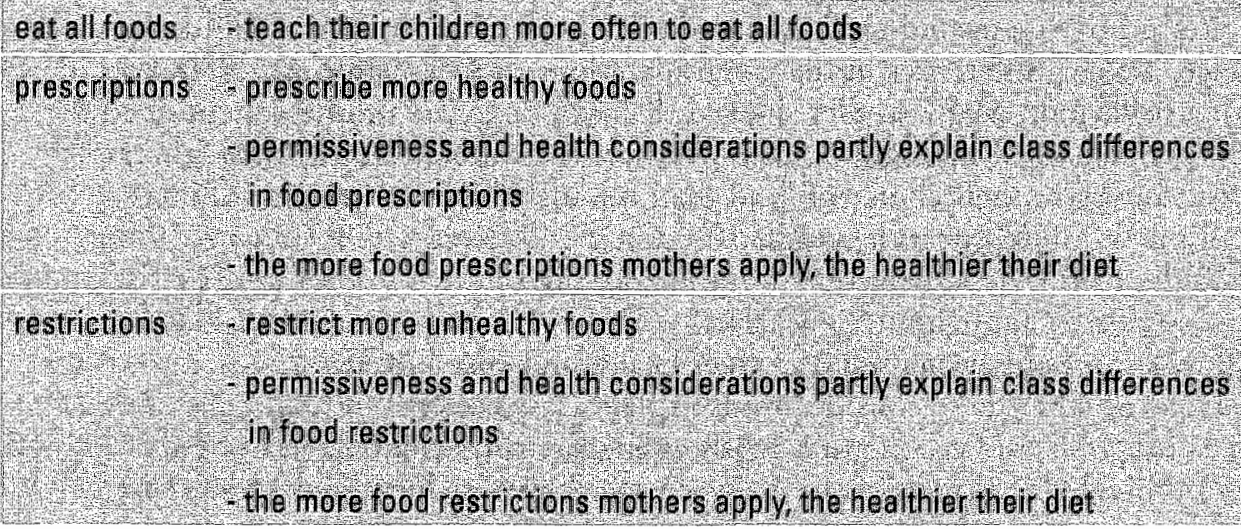

permissiveness and health considerations party explain class differences in food restrictions

the more food restrictions mothers apply the healthier their diet 
Two different data sources were used to explore these topics. In 1993/1994 we conducted a study on food consumption and eating behaviour among women in three ciries, located in a border region covering parts of the Netherlands, Belgium and Gemany. lin addition, we analysed data on drinking behaviour of both men and women in the 12 countries of the European Community (EC) in 1988, before the accession of Austria, Sweden and Finland to the European Union (EU). We used cross-national data, not to compare eating and drinking behaviour in different countries, but to compare class patterns in eating and drinking behaviour.

With regard to the first research topic (i.e. class distinctions in the consumption of foods and drinks), we studied whether higher class people favour 'modern' eating and drinking behaviour, whether or not these are deemed healthier, and whether working class people prefer more 'traditional' habits. Based on the EC data, we examined whether people of the higher social strata prefer 'new' alcoholic beverages, i.e. wine in the northern countries and beer in the Mediterranean countries, while people of the lower strata favour traditional beverages: beer in the northern countries and wine in the southern countries.

With help of the data on eating behaviour in the Netherlands, Belgium and Germany, we examined class differences in the consumption of foods, focusing on the intake of fat and fibre. These nutrients appear to influence the risk on cardiovascular diseases and cancer, which are the main causes of death in industrialised countries (James et al, 1988; Rijksinstituut voor Volksgezondheid en Milieuhygiëne, 1993; Haurvast, 1993; Willett, 1994). We not only analysed nutrient intake as such, but we also examined the consumption of food groups that contribute most to the intake of fat and fibre, like meat, milk, cheese, dietary oils and fars, bread, grain, and fruit and vegetables. In addition, we studied the choice for low-fat and high-fibre foodstuffs, like low-fat milk products and wholemeal bread. We hypothesised that working class women consume more foods that contribute to the intake of fat and especially more high-fat products, and that they consume less foodstuffs that contain fibre and especially less fibre-rich foods than higher class women.

Regarding the second topic, we studied considerations that may influence food choice, as class differences in these considerations may explain class differences in eating behaviour. Many studies showed that working class mothers mentioned the food preferences of their family members and costs more often as their primary consideration in their choice of food than middle class mothers did, while they mentioned health aspects less often (e.g. Charles \& Kerr, 1988; Calnan, 1990; DeVault, 1991). As indicated above, the majority of these studies were British and most studies were qualitative. With help of survey data we studied class differences in mothers' permissiveness and in their health and cost considerations, and we analysed whether these considerations explain class patterns in food consumption.

Thirdly, we studied the ways mothers educate their children in food matters, and we examined whether these vary between social classes. We tested whether higher 
class mothers apply stricter food rules, and whether lower class mother's are more permissive. We hypothesised that higher class mothers prescribe more healthy foods and restrict more unhealthy foods, and that they agree more often that their children should learn to ear all foods. If there appeared to be class differences in food rules, we examined whether these class differences could be explained by the mothers" permissiveness and their health considerations. Moreover, we studied whether mothers who apply stricter food regimens, have healthier eating habits themselves, in order to examine whether strict food rules are associated with a healthier diet.

\section{Design of the study}

\section{Study on drinking behaviour}

To study the consumption of alcoholic drinks in different European countries, we analysed data that were gathered in all countries of the EC by the 'Eurobarometer'. This half-yearly survey aims to monitor the atritudes of the population concerning the $\mathrm{EC}$ and its policies. Besides a basic questionnaire, each Eurobarometer includes additional questions. The $29^{\text {th }}$ Eurobarometer (conducted in 1988) covered special topics that were relevant for the EC programme 'Europe against Cancer", including the consumption of alcoholic drinks.

For this survey quota samples were drawn, that were stratified by sex, age and occupation in 1,350 regions covering the whole EC. In each country about 1,000 persons aged 15 years and over were questioned and in total 11,729 respondents were interviewed in their homes by professional interviewers. Respondents were asked how often they consumed wine, beer, aperitifs (i.e. fortified wines like port, sherry and vermouth) and distilled spirits, and whether they had consumed these beverages the day before the interview at breakfast, at lunch, at dinner or at other rimes. More detailed information on the design of the Eurobarometer is included in the 'Materials and Methods' section of chapter 2.

\section{Study on eating behaviour}

Besides this secondary analysis of alcohol consumption data, we initiated a survey on food consumption and eating behaviour in three European cities: Maastricht (the Netherlands), Liège (the French-speaking part of Belgium) and Aachen (Germany). These cities are located in a border region less than 50 kilometres apart in three linguistic areas. We chose mothers of 4-14-year-old children in complete families as respondents, because they generally are the 'gatekeepers', who are responsible for the purchase and preparation of food.

Unfortunately, it appeared to be impossible to draw a sample of working class and higher-middle class families including 4-14-year-old children with help of 
municipal data in Liège. As we wanted to follow a similar sampling procedure in each ciry; we applied another approach. We first selected typical working class and middle class districts in each city, based on the advice of a municipal official and on demographic data, if these were available. Secondly, we randomly selecred streets in these districts, and thirdly, trained female interviewers approached each address, where families with childen lived. If families met the inclusion criteria (complete families with at least one child aged between 4 and 14 years), the interviewers asked whether the woman within this family wanted to collaborate with the survey and whether she was willing to complete a questionnaire on eating behaviour. Between November 1993 and February 1994 a total of 849 women completed the questionnaire: 304 women in Maastricht (response rate: 79\%), 316 women in Liège (response rate: $78 \%$ ), and 229 women in Aachen (response rate: 67\%).

The questionnaire was in two parts: a food frequency questionnaire and a questionnaire on food pracrices. The questionnaire on food practices was based on the results of a qualitative study of Van Otterloo and Van Ogtrop (1989), and the semi-quantitative food frequency questionnaire was developed by Bausch-Goldbohm and Van Den Brandt for a prospective cohort study on diet and cancer in the Netherlands (Bausch-Goldbohm, Van Den Brandt, Van "t Veer, Sturmans \& Hermus, 1988). This food frequency questionnaire was improved with help of Belgian and German dietitians and researchers in order to adjust it for use in Liège and Aachen. The approach of this study is described more extensively in the 'Data and Methods' section of chapter 3.

\section{Operationalisation of social class}

Social class or socio-economic status refers to the position of people in the social order (Liberatos, Link \& Kelsey, 1988; Kunst \& Mackenbach, 1994; Kunst et al., 1996). That position is primarily determined by their educational level, occupational status and/or income level. Studies that compared these three measures for their power to predict health behaviour reported that educational level is usually the most consistent and reliable measure (Winkleby, Jatulis, Frank \& Fortmann, 1992; Pill, Peters \& Robling, 1995).

An expert committee in the Nerherlands (Van Berkel-Van Schaik \& Tax, 1990) also recommended using educational level as a measure for social class in epidemiological and social medical studies. Compared to occupational status and income, educational level has the advantage that it can be applied to everybody, and that it is less influenced by economic constraints. Finally, educational level appears to be more comparable internationally than occupational status (Valkonen, 1993; Kunst \& Mackenbach, 1994), even if international classifications are used, like the International Standard Classification of Occupations ISCO-88 (International Labour Office, 1990) or the EGP social class scheme (Erikson \& Goldthorpe, 1992). Therefore, we decided to use educational level as an indicator of social class in our study. 


\section{Outline of the thesis}

This thesis explores social class differences in eating and drinking behaviour, based on the results of two international studies. In chapter 2 the consumption of beer and wine in 12 countries of the EC is reported, and more specifically, the consumption patterns of women and men, young and old people, and less and more educated people are examined. With regard to social class differences, the study tests whether people of high educational level consume more new alcoholic beverages and less traditional beverages than people of low educational level.

Chapters 3 to 6 focus on class patterns in eating behaviour and food rules in working class and higher-middle class families, based on the data of mothers living in Maastricht, Liège and Aachen. In chapter 3 class patterns in the mothers' consumption of fat and fibre are examined, and chapter 4 investigates whether class patterns in these intakes can be explained by the mothers' permissiveness, and by their considerations on health and costs.

Chapters 5 and 6 address class patterns in food rules. Chapter 5 describes the foods mothers prescribe and restrict their children eating, and the explanatory value of the mothers' permissiveness and their health considerations. Chapter 6 reports whether or not mothers agree that their children should learn to eat all foods. In addition, this chapter describes the association between food rules and food consumption.

Chapter 7 contains an overview of the main findings. In addition, methodological considerations of the study, theoretical implications and implications for nutrition education and policy are elaborated. Finally, the thesis ends with suggestions for further research.

\section{References}

Bausch-Goldbohm, R.A., Van Den Brandt, P.A., Van ' $\mathrm{t}$ Veer, P., Sturmans, Fi \& Hermus, R.J.J.

(1988). Results of the methodological study for the design of a simplified, selfadministered questionnaire. In: E. Riboli \& R. Saracci (Eds. ), Diet, hormones and cancer: methodological issues for prospective studies. IARC Technical Report No. 4 (pp. 79-89). Lyon: International Agency for Research on Cancer.

Blane, $\mathrm{D}$.

(1985). An assessment of the Black Report's explanations of health inequalities. Sociology of Health and Illness, 7, 423-445.

Blaxter, M. \& Paterson, E.

(1982). Mothers and daughers. A three-generational study of health attitudes and behaviour: London: Heinemann. 
Blaxter, M. \& Paterson, E.

(1983). The goodness is out of it: the meaning of food to two generarions. In: A. Murcotr (Ed.). The sociology of food and eating. Essays on the social significance of food Bourdieu, $P$. (pp 95-105). Aldershot Gower.

(1989) Distinction. A social critique of the judgement of taste. London: Routledge \& Kegan Paul IOriginally published in French: Boundieu, P. (1979). La distinction. Critique sociale du jugement Paris: Les Editions de Minuit.]

Cahalan, D., Cisin, I.H. \& Crossley, H.M.

(1969). Anerican drinking practices. A national study of drinking behavior and altitudes. New Brunswick: Rutgers Center of Alcohol Studies.

Calnan, M.

(1990). Food and health: a comparison of beliefs and practices in middle-class and working class households. In: S. Cunningham-Burley \& N.P. McKeganey (Eds.), Readings it medical sociology (pp. 9-36). London: Routledge.

Charles, N. \& Kerr, M.

(1.988). Women, food and families. Manchester: University Press.

Davey Smith, G., Bartley, M. \& Blane, D.

(1990). The Black report on socioeconomic inequalities in health 10 years on. British Medical Journal, 301, 373-377.

DeVault, M.L.

(1991). Feeding the family: the social organization of caring as gendered work. Chicago:

Elias, N. the University of Chicago Press.

(1982). Het civilisatieproces. Saciogenetische en psychogenetische onderzockingen. Utrecht: Spectrum. [Originally published in German: Elias, N. (1939). Uber den Prozess der Zivilisation. Soziogenerische und Psychogenetische Untersuchungen. Bazel: Haus zum Falken.]

Erikson, E. \& Goldthorpe, J.H.

(1992). The constant fux: Oxford: Clarendon Press.

Hautvast, J.G.A.I.

(1993). The future of nutrition in Europe. European Jownal of Clinical Nutrition, 47. Suppl. 1, \$96-\$100.

Hulshof, K.F.A.M., Löwik, M.R.H., Kok, FJ., Wedel, M., Brants, H.A.M., Hermus, R.J.J. \& Ten Hoor $\mathrm{F}$.

(1991). Dier and other life-style factors in high and low socio-economic groups

(Dutch Nutrition Surveillance System). European Journal of Clinical Nutrition, 45, $441-450$.

International Labour Office

(1990). International Standard Classifacation of Occupations: ISCO-88. Geneva:

International Labour Office.

James, W.P.T., Ferro-Luzzi, A., Isaksson, B. \& Szostak, W.B.

(1988). Healthy mutrition. Preventing mutrition-related diseases in Europe. Copenhagen:

WHO Regional Publications, European Series No. 24. 
Jobse-Van Putten, J.

(1995). Eenwoudig maar voedzadm. Cuthumgeschiedenis wan de dagelijkse maaltijd in Nederland [Simple, but nourishing. Social history of the daily meal in the Netherlands]. Nijmegen: SUN.

Kunst, A.E., Looman, C.WN. \& Mackenbach, J.P.

(1990). Socio-economic mortality differences in the Netherlands in 1950 1984: a regional study of cause-specific mortality. Soctal Science and Medicine, 31, 141-152.

Kunst, A.E. \& Mackenbach, J.P.

(1994). The size of mortality differences associated with educational level in nine industrialized countries. American Journal of Public Healtb, 84, 932-937.

Kunst, A.E., Cavelaars, A.E.J.M., Groenhof, F., Geurts, J.J.M. \& Mackenbach, J.P. (1996). Socioeconomic inequalities in morbidity and mortality in Europe: a comparative study. Rotterdam: Erasmus University Rotterdam, Department of Public Health.

Liberatos, P., Link, B.G. \& Kelsey J.L.

(1988). The measurement of social class in epidemiology. Epidemiological Review, $10_{x}$ $87-121$.

Lupton, D.

(1996). Food, the body and the self. London: Sage Publications.

Mackenbach, J.P.

(1992). Socio-economic health differences in the Netherlands: a review of recent empirical findings. Social Science and Medicine, 34, 213-226.

Mackenbach, J.P.

(1994). Ongezonde verschillen. Over sociale stratificatie en gezonalheid in Nederland.

Assen: Van Gorcum.

Mennell, S.J.

(1985). All manners of food. Eating and taste in England and France from the Middle

Ages to the present. Oxford: Basil Blackwell.

Mennell, S., Murcort, A. \& Van Otterloo, A.H.

(1992). The sociology of food: eating, diet and culture. London: Sage Publications. Murcott, $A$.

(1983). The sociology of food and eating. Essays on the social significance of food

Aldershot: Gower.

Murcott, A.

(1988). Sociological and social anthropological approaches to food and eating. World Review of Nutrition and Dietetics, 55, 1-40.

Murcott, A.

(1995). Social science, food and eating: opportunities for multi-disciplinary research. Ernahrungs-Umschaw, 42, Beiheft, 217-21.8.

Phillimore, P, Beattie, A. \& Townsend, P.

(1994). Widening inequality of health in notthern England, 1981-91. British Medical Journal, 308, 1125-1128.

Pill, R., Perers, T.J. \& Robling, M.R.

(1995). Social class and preventive health behaviour: a British example. Journal of Epidemiology and Community Health, 49, 28-32. 
Rijksinstitutur wor Volksgezondheid en Milieuhygiëne

(1993). Wolksgezondheid Toekomst Verkenning. de gexondbeidstostand van de Nederlandse beiolking in de periade 1950-2010. Den Haag: Sdu Uitgeverij.

Rijksinstituut voor Volksgezondheid en Milieu

(1997). Volksgezondheid Toekonst Verkenning 1997. De som der delen. Utrech:

Dlsevier/De Tifidstroom.

Scholliers, $P$.

(1993). Arm en rijk atan tafel. Twebonderd jaar eewaltum in Belgzë (Poor and rich at table. Wwo hundred years of eating culture in Belgium]. Berchem: EPO.

Sobal, J. \& LaChausse, J.L.

(1993). Social science perspectives in nutrition. Appetite, $21,304$.

Stafleu, A.

(1994). Family resemblance in fat intake, nutrition atritudes and beliefs: a study among three generations of women (thesis). Wageningen: Grafisch Service Centrum.

Townsend, P., Davidson, N. \& Whitehead, $M$.

(1988). Inequalities in bealith. London: Penguin.

Vakonen, $T$.

(1993) Problems in the measurement and international comparisons of socioeconomic differences in mortality. Social Science and Medicine, 36, 409-418.

Van Berkel-Van Schaik, A.B. \& Tax, B.

(1990). Naar een standaardoperationalisatie van sociaal economische status voor epidemiologisch ev sociad-medisch onderzoek [Towards a standardised operationalisation of socio-economic status for epidemiological and social-medical research]. Rijswijk: Ministerie van Welzijn, Volksgezondheid en Cultuur.

Van Oosten-Van Der Goes, H., Van Staveren, W.A. \& Den Hartog, A.P.

(1982). Een verkenning in de sociale wetenschappen en voeding. In: A.P. Den Hartog (Ed.), Voeding als maatschappelijk verschijnsel (pp. 1-29). Utreche: Bohn, Scheltema \& Holkema.

Van Otterloo, A.H.

(1990). Eten en eetlust in Nederland (1840-1990). Een bistorish-socialogische studie

[Food and appetite in the Netherlands (1840-1990). A historic-sociological study].

Amsterdam: Bert Bakker.

Van Otterloo, A.H.

(1995). Taste, food regimens and fatness. A study in social stratification. In: I. De

Garine \& N.J. Pollack (Eds.), Social aspects of obesity (pp 111-126). Luxembourg:

Gordon and Breach Publishers.

Van Otterloo, A.H. \& Gerritsen, H.

(1991). Wat doet de consument met de voedingsboodschap? Voeding, 52, 246-250.

Van Otreloo, A.H. \& Van Ogtrop, J.

(1989). Het regime van wel, wet en zoet: praten met moeders over vaeding en gezondhe:d

[The regime of plenty, fat and sweet: talking with mothers on food and health].

Warde, A.

Amsterdam: VU Uitgewerij.

(1997). Consumprion, food and taste. Culinary antinomies and commodity culture.

London: Sage Publications. 
Willett, WC.

(1994). Diet and health: what should we ear? Siene, $264,532-537$.

Winkleby, M.A., Jatulis, D.E., Frank, E. \& Fortmann, S.P.

(1992). Socioeconomic starus and health: how education, income, and occupation contribute to risk factors for cardiovascular disease. American yow wat of public Health, $82,816-820$. 


\section{2}

Christianne L. H. Hupkens, Ronald A. Knibbe and Maria J. Drop

\section{Alcohol consumption}

in countries of the European Community

\section{uniformity and \\ diversity in \\ drinking patterns}

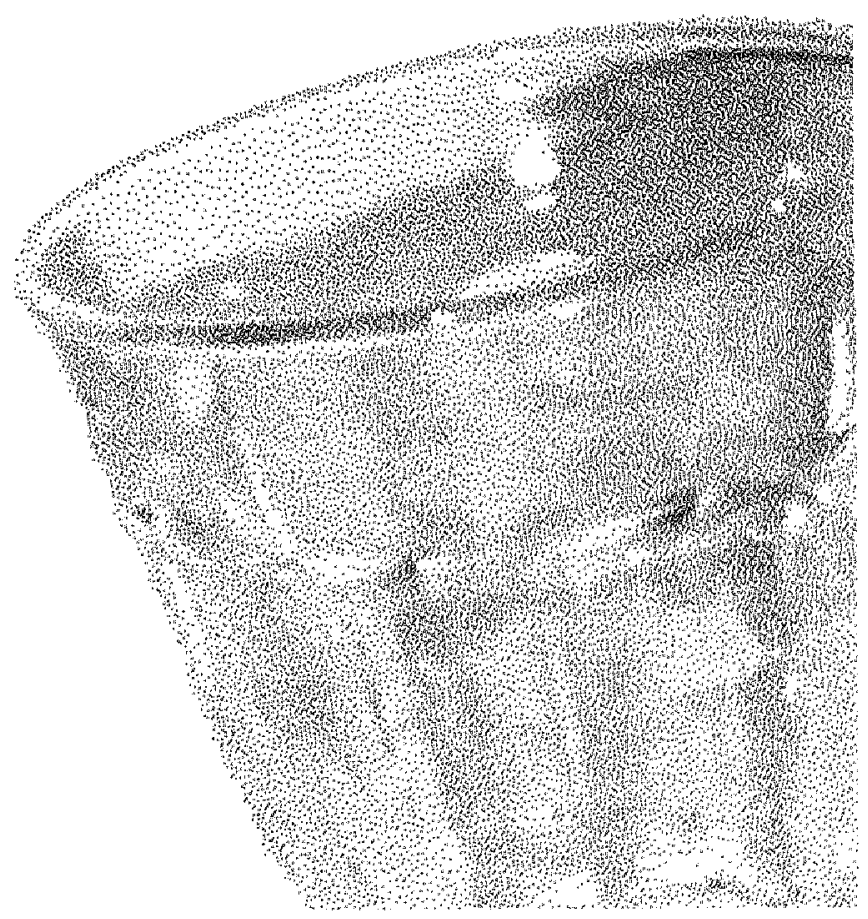




\section{Abstract}

Within the European Community (EC) drinking patterns in the southern countries can be characterised by daily consumption of wine at meals, and in the tiorthern countries by less frequent consumption of beer outside meals. Yet, as in past decades in the sauthern countries beer consumption and in the northern countries wine consumption strongly increased, the question is whether the distinction in drinking patterns still applies. This paper (1) describes for each country of the EC total alcohol consumption, (2) examines the frequency and the context of consumption of the new beverage type and (3) analyses whether subpopulations, defined by sex, age and educational level, differ in the adoption of the new beverage type.

In all countries wine is consumed more often at meals compared to beer. Older people consume wine in greater numbers and more frequently than younger people, who consume beer in greater numbers. People of higher educational level consume the new beverage type more often compared to people of lower educational level, who consume the traditional beverage type more frequently. Finally, males and femalles differ less in the frequency of consumption of the new beverage type than in the frequency of the traditional beverage type. 


\section{Introduction}

Alcohol consumption and alcohol related problems vary considerably between countries. Even within a relatively small area as Western Europe differences in the consumption of alcoholic beverages are substantial. These differences are likely to result partly from cultural dissimilarities. On the more fundamental level this means that cultures might differ in the norms concerning the type of beverage, the amount, the drinking companions and the drinking situations. These dissimilarities between cultures, which are embedded in everyday life, seem to explain part of the differences between countries in alcohol consumption and related problems.

Unfortunately, international research based on data gathered on an individual level is scarce. Only two studies with this design were recorded. Correlates of alcohol consumption in Switzerland, West Germany and the Netherlands were studied by Knibbe and Lemmens (1987). Péquignot, Crosignani, Terracini et al. (1988) analysed drinking habits in six areas in Italy, Spain, Switzerland and France. Comparative research is mainly based on consumption data per head of the population (De Lint, 1980; Davies \& Walsh, 1983; Casselman \& Knibbe, 1985; Walsh \& Grant, 1985; Pyörälä, 1990). These studies allow only a rough impression of the differences in alcohol consumption between countries. They do not offer opportunities for specifications in terms of frequency and context of consumption or for studies on drinking patterns within populations.

Yet, per capita data provide the opportunity to describe the consumption of alcoholic beverages through the years. Trends in the consumption of wine, beer and spirits in past decades show that wine is a new beverage type in the northern countries of the European Community (EC), while beer is a new beverage type in the Mediterranean countries (Produktschap voor Gedistilleerde Dranken, 1990). Changes in the consumption of spirits are much smaller compared to changes in the consumption of wine and beer. The increase in the per capita consumption of spirits between 1961 and 1988 was largest in Luxembourg $(+1,4$ litres of pure alcohol), the United Kingdom (UK) $(+1,0)$ and the Netherlands $(+0,9)$, and the smallest in West Germany $(+0,0)$ and Italy $(-0,2)$. As in none of the EC countries spirits are a traditional beverage (except in the Netherlands) or a new beverage, results regarding spirits as a separate beverage type will not be presented.

Denmark, West Germany, the Netherlands, the UK, Ireland and Belgium are typical beer countries. Between 1961 and 1988 per capita consumption of wine increased more than that of beer and spirits in these countries. In 1961 wine consumption was very low, except in West Germany, where not only beer but also wine is produced. Less than 30 years Jater the consumption of wine per head of the population doubled in West Germany, tripled in Belgium and Ireland, and increased sixfold in Denmark, the Nerherlands and the UK.

On the other hand, France, Italy, Greece, Spain and Portugal are traditional wine countries. Between 1961 and 1988 the consumption of wine decreased, the 
consumption of spirits slightly changed and the consumption of beer increased in these Mediteranean countries. In absolute numbers this increase in beer consumption is about as high as in some of the northern countries, but in relative numbers the increase in the Mediterranean countries is much higher. As a result, relatwe differences in beer consumption between the northern and the Mediterranean countries have diminished during this period. Except in France, where in 1961 beet consumption was rather high, the consumption of beer in the Mediterranean countries increased at least fourfold. The changes in wine and beer consumption between 1961 and 1988 in each country are clearly shown by figures 2.1 and 2.2 .

\section{Figure 2.1}

Per capita wine consumption in countries of the European Community in 1961 and 1988 (in titres).
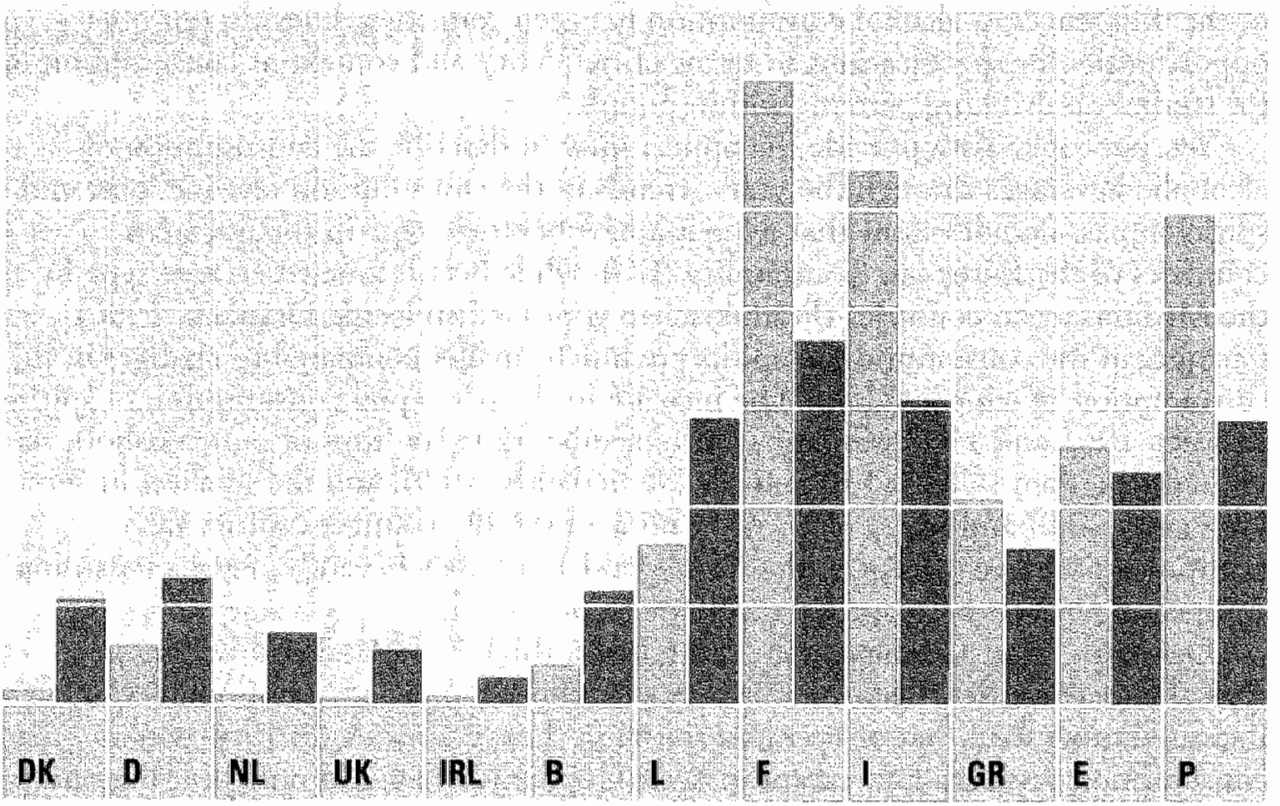


\section{Figure 2.2}

Per capita beer consumption in countries of the European Community in 1961 and 1988 (in litres)

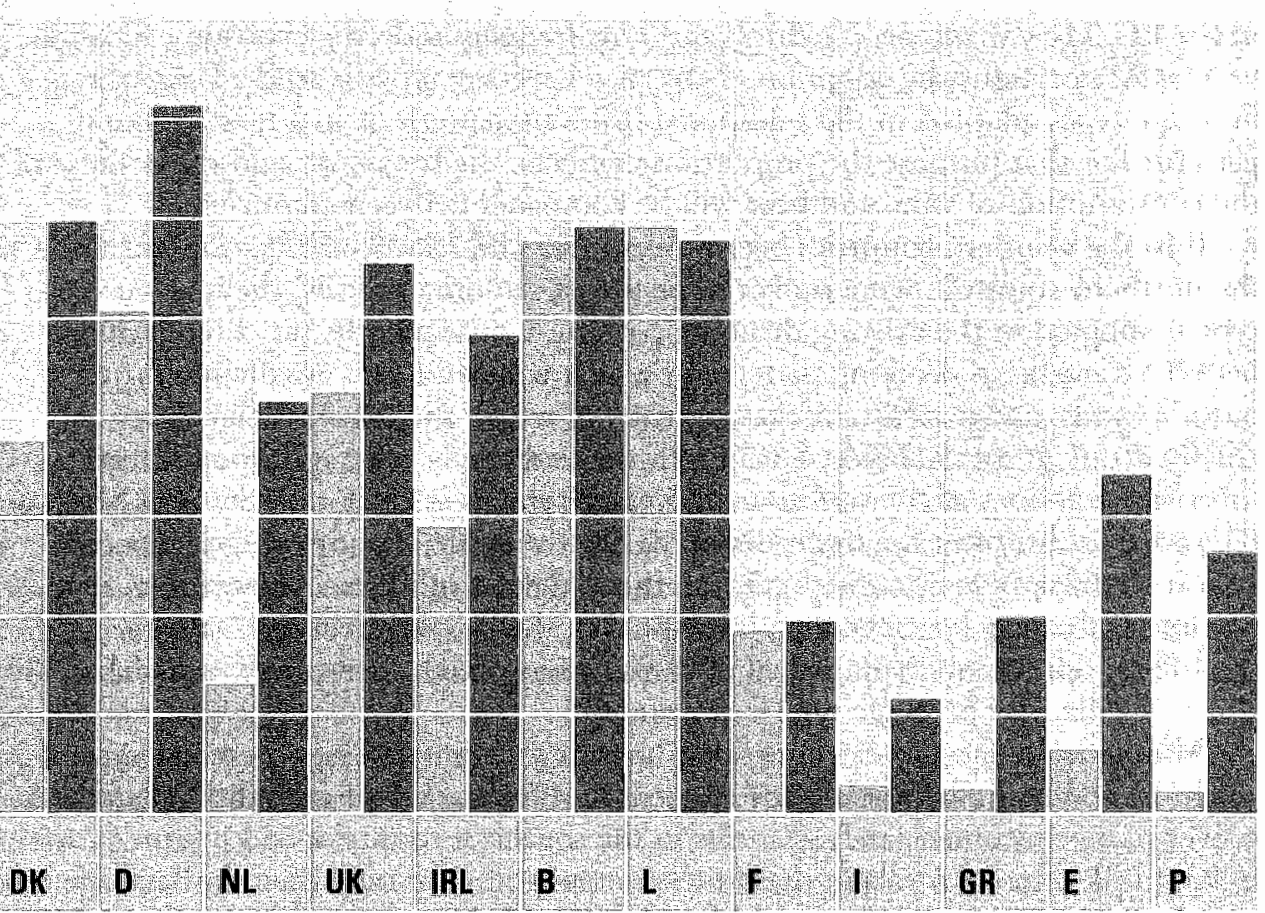

Source: Produktschap voor Gedistilleerde Dranken (1990)

DK: Denmark, D: Federal Repubic of Germany, NL: the Notherlands, UK: United Kingdom, IRL: Ireland, B; Belgium, L: Luxembourg, F: Franca, l: ltaly, GR: Greece, E: Spain, P: Portugal

Based on survey data gathered in 1988, this paper concentrates on a comparison of the EC countries on three aspects of drinking patterns; type of beverage, frequency and context of consumption, where context is defined as the extent, in which alcoholic beverages are consumed at meals. With regard to these three aspects it has been assumed that within the EC a distinction between countries in drinking patterns can be made. Traditionally the drinking patterns in Mediterranean countries can be characterised by the consumption of wine, which is consumed daily and is mainly drunk at meals (Lolli, Serianni, Golder \& Luzzatto-Fegiz, 1958; Sadoun, Lolli \& Silverman, 1965). In the northern countries of the EC the consumption of beer dominates, which is drunk less frequently and more often outside meals. In these countries beer is mainly consumed in leisure time (Sulkunen, 1976). Yet, as in 
nearly all countries of the EC the consumption of non-traditional beverage types strongly increased, it remains to be seen, wherher the distincrion between a northern and a southern drinking pattern still applies.

This paper starts with a descriprion of rotal alcohol consumption in each country of the EC. How many people drink and how frequently do they consume alcoholic beverages? Secondly, the adoption of the new beverage types is studied. Are the new beverage types adopted in the traditional drinking pattern or in a new drinking pattern? For that purpose the proportion drinkers, the frequency and the context of the consumption of wine and beer will be compared between countries.

If in the southern countries beer proves to be consumed mainly at meals and if in the northern countries wine proves to be drunk seldom at meals, the new beverage rype is adopted in the existing dirinking patrern. Consequently, the difference between a notthern drinking pattern, in which wine and beer are mainly drunk outside meals, and a mediterranean pattern, in which the two beverage types are chiefly drunk at meals, holds. Since in this case the new beverage type is drunk in the same situations as the traditional beverage type, it is likely that the new beverage type partly substitutes the traditional type. For example, if the Portuguese people appear to drink beer often with a meal, they mighr drink beer in some cases instead of wine. If the new beverage type is adopted in the existing drinking pattern, traditional norms concerning alcohol consumption might determine in which situations the new beverage type is consumed.

Alternatively, the norms concerning how to consume the new beverage type might be adopted of those countries where that beverage type is traditional. If beer proves to be consumed rarely at meals in the southern countries and if wine proves to be drunk often ar meals in the northern countries, not only the new beverage type but also new drinking habits would be adopted. In this case uniformity in drinking patterns increases: in all countries wine is mainly consumed in combination with a meal, while beer is consumed chiefly in other situations. Since the situations, in which the new and the traditional beverage types are consumed, differ, addition rather than substitution takes place. If the Portuguese, for example, appear to drink beer often outside meals, they might drink beer as well as wine.

Finally, the diffusion of new drinking habits is studied. Do subpopulations, defined by sex, age and level of education, differ in the extent in which they adopt a new type of alcoholic beverage? Considering the pattern of adoption of new habits the literature suggests that especially people of higher educational level and, to some extent, younger people are prone to adopt new habirs (Rogers \& Stanfield, 1968; Glenn, 1981; Bourdieu, 1986). Does this also apply to new beverage types in all countries of the EC?

All results will be presented for males and females separately. The boom of the women's liberation coincided with the period, in which the consumption of the new beverage type increased considerably. It might be that, compared with the norms regarding the traditional beverage type, the norms concerning the new beverage type differ less berween the sexes. 
In conclusion, this paper analyses three research questions, of which the first one is purely descriptive and the others are exploratory.

1 Do the proportions of drinkers and the frequency of consumption of alcoholic beverages differ between countries within the EC?

2 Are the new beverage types adopted in the existing or in a new drinking pattern?

3 Do subpopulations, defined by sex, age and level of education, differ in the adoption of the new beverage type?

\section{Materials and Methods}

\section{Sample}

The research questions were elaborated by means of an analysis of consumption data, which were gathered in all countries of the EC in 1988. In the EC every year a survey, named the 'Eurobarometer', is conducted in order to gather information on the attitudes of the population towards the EC and its policy. Each year additional questions about a specific subject are appended to the questionnaire of the Eurobarometer. Within the framework of the Programme 'Europe against Cancer' in 1988 some questions on the consumption of alcohol were included in the $29^{\text {th }}$ Eurobarometer.

Samples of the population, aged 15 years and over, were taken in every region of each country, for example in each of the 12 provinces of the Netherlands. So, the survey covered the whole territory of the EC. A two stage sampling method was used. In the first stage a random selection of sampling points within each region was made in such a way that urban and rural areas were represented proportionally. This selection resulted in 1,350 sampling points. In the second stage interviews were distributed in these sampling points. In Denmark, Luxembourg and the Netherlands persons were chosen at random from the population or electoral lists. In Belgium, France, Italy, the UK and Ireland individuals were selected by quota sampling. The quotas were established by sex, age and occupation on the basis of census data. In the Federal Republic of Germany, Greece, Spain and Portugal a combination of both methods was used. For each country the distribution of the sample regarding sex and age proved to be consistent with census data.

Because quota sampling dominated, non response figures are not available. However, the method of quota sampling is not completely random. For instance people, who are rarely ar home, are less represented in the sample. However, we think it safe to assume that the interviewed sample is representative for the category of 'average citizens', who are accessible at home and who agree to be interviewed. In each country about 1,000 persons were interviewed, except in Luxembourg, where 300 individuals were selected, and the UK, where 1,300 respondents were chosen. In total 11,729 respondents were interviewed in their homes by professional interviewers, between March 18 and April 29, 1988. The survey was conducred by 12 national institutes. 


\section{Data}

Two questions about the consumption of respectively wine, beer, aperitifs and distilled spirits were included in the questionnaire of the $29^{\text {th }}$ Eurobarometer. Firstly, respondents were asked how frequently they consumed each of the four beverage types. Five answer categories were precoded: every day or almost every day, 3 or 4 days in a week, 1 or 2 days in a week, less often or never. Secondly, respondents were asked whether they consumed each of the beverage types the day prior to the interview at breakfast, at lunch, at dinner or at other times. Because alcoholic beverages were rarely drunk at breakfast, this data was not used in the analysis.

To clarify which beverages belong to the aperitifs and which beverages belong to the distilled spirits, the interviewers gave examples of both beverage types. Aperitifs cover for example vermouth, port and sherry, and in general the fortified wines. As it is generally assumed that the fortified wines belong to the category of wine, we added the consumption of aperitifs to that of wine. In all countries the frequency and the context of the consumption of aperitifs bear a fixed proportion to those of wine. Aperitifs are consumed 3 or 4 times less often as wine and less often in combination with meals than wine. Thus, addition of aperitifs does not interfere with the comparison between countries of the frequency and the context of wine consumption. As a result of this addition, the frequency of wine consumption could not be expressed in terms of 'days per week'. Consequently, this frequency will be expressed in terms of 'drinking situations per week'. Correspondingly, the frequency of total alcohol consumption was calculated by adding the consumption frequencies of wine (including aperitifs), beer and spirits. This frequency will also be expressed in terms of 'drinking situations per week'.

\section{Methods}

The first research question describes total alcohol consumption in the countries of the EC. For that purpose the proportion abstainers and the frequency of alcohol consumption were calculated. Persons who neither drank wine, nor beer, nor spirtts were defined as abstainers. In order to get a good impression how often the drinking population consumed alcohol, the abstainers were left aside at the calculation of the frequency of alcohol consumption.

The second research question concerns the drinking pattern of the new beverage type. To that end three variables with respect to both wine and beer were computed: the proportion non-drinkers, the frequency and the context of consumption. As we were interested in those people, who drank alcoholic beverages but never drank wine, the percentage non-wine drinkers of the drinking population was calculated. The percentage non-beer drinkers was compured in the same way. The frequency of wine consumption was based on the population wine drinkers and the frequency of beer consumption on the population beer drinkers. The context of consumption was defined as the proportion of the total wine or beer consumption of yesterday, which 
is consumed at meals (lunch and/or dinner).

According to the third research question, differences in the consumption of the new beverage type between subpopulations, defined by sex, age and educational level, were elaborated. All results are presented for males as well as females. In order to reduce the number of figures, only the differences berween the consumprion figures of the youngest and the oldest age categories ( 15 to 25 years respectively 55 years or more) and categories of highest and lowest educational level (receiving fulltime education until the minimum age of 20 respectively the maximum age of 15) are reported. The consumption results of the intermediate categories were mostly situated between the results of the two extreme categories.

\section{Results}

\section{The proportion abstainers and the frequency of alcohol consumption}

For each country of the EC table 2.1 presents the percentage abstainers and the mean frequency of alcohol consumption. In the EC about $10 \%$ of all malles and more than $20 \%$ of all females reported that they never drank alcoholic beverages. In all countries females were almost twice as likely to report that they were abstainers than were males. In Greece and Portugal the differences between males and females were even larger: respectively four times and three times more females than males: were abstaining from alcoholic drinks. In Denmark and West Germany the proportions abstainers were by far the lowest, while in Portugal, Spain and Ireland these figures were the highest. On average males drank alcoholic beverages in 5 or 6 situations per week and females in abour 3 situations. Males in the southern countries drank alcoholic beverages more frequently than males in the northern countries. Females showed a similar pattern, with the exception of the Belgian females, who drank frequently compared to females in the other northern countries, and the Greek females, who drank less often compared to females in the southern countries. 
Table 2.1

Proportian abstainers and frequency of consumption in countries of the European Community

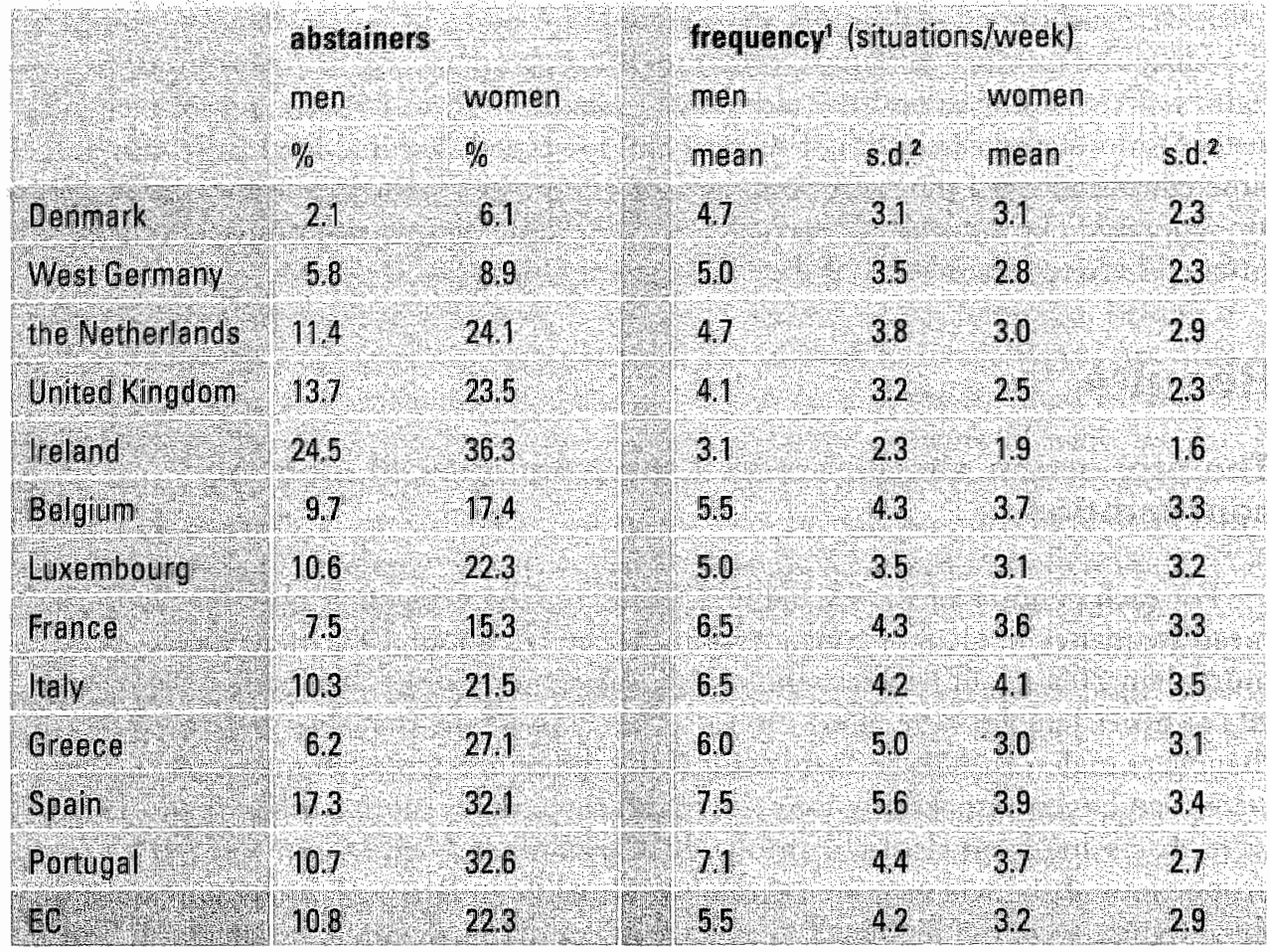

'abstaners excluded

${ }^{2}$ s.d.: standard deviation

\section{The drinking patterns of wine and beer}

\section{Non-wine drinkers and non-beer drinkers}

Table 2.2 shows the proportions males and females of all drinkers, who reported that they never drank wine or beer. In the EC $86 \%$ of the male drinkers reported to consume wine. As might be expected, the proportions wine drinkers were smaller in the northern countries than in the southern countries, wirh the exception of Denmark, where almost all male drinkers consumed wine, and Spain, where the proportion wine drinkers was rather small. On average $91 \%$ of all female drinkers were wine drinkers. The proporrion female wine drinkers did not vary considerably between countries and there was no clear distinction between the northern and the Mediterranean countries. With regard to sex differences, in all countries more female drinkers than male drinkers consumed wine, except in Italy and Greece. Compared with beer and spirits, wine appears to be a women's drink. Whereas sex differences 


\section{Table 2.2}

Proportion non-wine drinkers and non-beer drinkers in countries of the European Community

\begin{tabular}{|c|c|c|c|c|}
\hline & non- & kers? & non- & ers' \\
\hline & men & women & men & women \\
\hline & & $\%$ & $\%$ & \% \\
\hline Genmaik & 15 & 34 & 30 & 180 \\
\hline West Germaly & 118 & 47 & 5.2 & 22.6 \\
\hline the Netherlands & 23.4 & 104 & 145 & 58.3 \\
\hline United Kung dorm & 23.3 & 9.2 & 13.3 & 630 \\
\hline Ireland & 509 & 21,1 & 6.6 & 46.1 \\
\hline Belgum & 100 & 77 & 7.1 & 21.6 \\
\hline Luxembourg & 8.3 & 65 & 10.4 & 45.4 \\
\hline france & 39 & 41 & 28.6 & 592 \\
\hline laly & 8.2 & 135 & 204 & 35.5 \\
\hline Greece & 5.5 & 88 & 150 & 26.6 \\
\hline Spain & 18.5 & 142 & 13.2 & 29.9 \\
\hline Pormugal & 58 & 52 & 18.5 & 51.3 \\
\hline & 140 & 08 & 13.2 & 396 \\
\hline
\end{tabular}

'abstainers excluded

in proportions non-wine drinkers were small in the southern countries, differences were rather big in the northern countries.

In the $\mathrm{EC} 13 \%$ of all male drinkers reported that they never drank beer. Consequently, about as many male drinkers consumed beer as wine: $87 \%$. The proportions beer drinkers were higher in the northern countries than in the southern countries. Compared with wine, more female drinkers did not consume beer: $40 \%$. Although countries differed substantially in the proportion female beet drinkers, there appeared to be no clear distinction between the northern and the southern countries. Comparing the proportions male and female beer drinkers within countries, sex differences were larger in the northern countries than in the southern countries. In conclusion, the distinction in traditional beer countries and traditional wine countries with regard to the proportion drinkers applied rather strongly for males. Differences between males and females in the proportions wine and beer drinkers were larger in the northern countries than in the Mediterranean countries. 
The frequency of wine and beer consumption

Table 2.3 presents the mean frequency of wine and beer consumption of male and female consumers in the 12 countries. On average males in the EC drank wine in 3 and females in just more than 2 situations in a week. Both males and females in the Mediterranean countries consumed wine more frequently compared to males and females in the northern countries. Sex differences in the frequency of wine consumption were larger in the southern countries. In general Mediterranean males drank wine one and a half time as often as Mediterranean females, while northern males and females only slightly differed.

\section{Table 2.3}

Frequency of wine and beer consumption in countries of the European Community

\begin{tabular}{|c|c|c|c|c|c|c|c|c|}
\hline & wine? & Isitua & ns/wee & & beer ${ }^{2}$ & days: & eekl & \\
\hline & men & & womes & & men & & women & \\
\hline & mean & s.d. & mean & s.d. & mean & s.d. & nean & s.d. \\
\hline Denmark & 17 & 1.4 & 1.6 & 14 & 2.4 & 20 & 1.2 & 1.3 \\
\hline West Germany & 17 & 1.6 & 14 & 13 & 29 & 2.1 & 13 & 14 \\
\hline the Netherlands & 22 & 2,5 & 22 & 24 & 22 & 2.0 & 13 & 1.5 \\
\hline United Kuigdom & 1.7 & 1.6 & 1.6 & 1.6 & 22 & 1.8 & 12 & 13 \\
\hline lroland & 1.1 & 11 & 1.1 & 1.1 & 20 & 1.5 & 1.0 & 0.8 \\
\hline Belgian & 24 & 27 & 20 & 1,9 & 2.9 & 23 & 1.8 & 19 \\
\hline Luxembourg & 26 & 23 & 2.3 & 2.3 & 2.4 & 2.1 & 11 & 1.1 \\
\hline France. & 4.5 & 31 & 27 & 27 & 17 & 1,8 & 1.2 & 1.5 \\
\hline |taly & 4.9 & 27 & 3.5 & 28 & 1.6 & 1.7 & 1.2 & 1,4 \\
\hline Greere & 3.1 & 27 & 1.8 & 1.8 & 20 & 14 & 13 & 1.4 \\
\hline Spain & 4.7 & 3.3 & 27 & 26 & 3.2 & 19 & 1.9 & 1.9 \\
\hline Portugal & 4.8 & 25 & 3.1 & 24 & 2.4 & 12 & 1.2 & 12 \\
\hline & 30 & 28 & 21 & 22 & 23 & 20 & 13 & 15 \\
\hline
\end{tabular}

'Mon-wine drinkers exciluded non-beer drinkers excluded 
Regarding the frequency of beer consumption, males drank beer on average 2.3 days per week and females 1.3 days per week. It is noteworthy that both Spanish men and women consumed beer the most often and that lrish men and women drank beer less often than average. Except for Spain and Ireland, males in the southern countries drank beer less often compared with males in the northern countries. Belgian females drank beer almost as often as Spanish femalles. Females in the other countries consumed beer on about 1 day in a week. In each country, malles drank beer more often than females. Differences between males and females in the frequency of beer consumption were bigger in the northern countries.

In brief, males in the southern countries drank wine more frequently and beer less often than males in the northern countries. Females in the Mediterranean countries drank wine more often and beer as frequently as females in the northern countries. Males and females differed more in the frequency of consumption of the traditional beverage type than in the frequency of consumption of the new beverage type.

Table 2.4

Context of wine and beer consumption in countries of the European Community

\begin{tabular}{|c|c|c|c|c|c|c|}
\hline & $\begin{array}{l}\text { wine } \\
\text { lunch } \\
\%\end{array}$ & $\begin{array}{l}\text { dinner } \\
\%\end{array}$ & $\begin{array}{l}\text { other } \\
\text { times } \\
\text { \% }\end{array}$ & $\begin{array}{l}\text { beer } \\
\text { lunch } \\
\%\end{array}$ & $\begin{array}{l}\text { dinner } \\
\%\end{array}$ & $\begin{array}{l}\text { other } \\
\text { times } \\
\%\end{array}$ \\
\hline Denmark & 3.8 & 58.1 & 38.1.1. & 26.1 & 25.2 & 487 \\
\hline West Germany & 19.1 & 42.6 & 38.3 & 22.1 & 49.0 & 290 \\
\hline the Netherlands & 7.5 & 44.5 & 48.0 & 10.9 & 23.4 & 657 \\
\hline United Kingdom & 14.5 & 36.4 & 49.1 & 13.2 & 12,1 & 74.7 \\
\hline Iroland & 67 & 43.2 & 50.0 & 1,9 & 2.4 & 95.7 \\
\hline Belgium & 236 & 43.9 & 32.5 & 21.6 & 32.2 & 46.2 \\
\hline Luxembourg: & 44.8 & 30.5 & 24.7 & 26.3 & 34.9 & 38.8 \\
\hline France & 510 & 42.1 & 6.8 & 17.3 & 15.0 & 677 \\
\hline Italy. & 523 & 40.4 & 7.3 & 30.3 & $25: 2$ & 445 \\
\hline Greece & 47.2 & 26.6 & 26.2 & 38.8 & 30.0 & 313 \\
\hline Spain & 515 & 23.2 & 25.3 & 30.9 & 18.7 & 50.5 \\
\hline Portugal & 46.1 & 42.7 & 112 & 10.3 & 9.0 & 807 \\
\hline EE & 38.9 & 39.6 & 215 & 210 & 25.8 & 53.2 \\
\hline
\end{tabular}




\section{The context of wine and beer consumption}

The extent, in which wine and beer were consumed at lunch, dinner or other situations, is shown in table 2.4. With regard to wine as well as beer the context hardly differed between males and females and berween week- and weekenddays. Therefore the presented results are not split up by sex or by day of the week. Southern Europeans drank wine mainly in combination with meals. In these countries about half of all wine drinking situations coincided with lunch. Moreover Frenchmen, Italians and Porrugueses drank wine in $40 \%$ of all wine drinking situations at dinner and in only 10\% outside meals. Greeks and Spaniards drank wine in a quarter of all situations at lunch and equally often at other situations. Northern Europeans drank wine less often with meals than Southern Europeans, but they drank wine more at meals than outside meals. Moreover, they consumed wine more frequently at meals compared to beer. In the northern countries wine was principally consumed at dinner and less often at lunch. Belgians and Luxembourgers consumed wine less often at meals than the Southern Europeans, but more often than the Northern Europeans.

In all countries, except West Germany, beer was consumed less often at meals than wine. Contrary to our expectations, Germans, Belgians and Danes appeared to drink beer more frequently at meals than at other situations. Yet, Dutchmen, Britons and Irishmen drank beer in more than two thirds of all situarions outside meals. Southern Europeans also varied considerably in the extent, in which beer was drunk at meals. In general in both the northern and the southern countries wine is consumed more often at meals compared to beer. Yet, in the Mediterranean countries this tendency is stronger.

\section{Wine and beer consumption of subpopulations}

\section{Wine and beer consumption of younger and older people}

To study the hypothesis that, compared to older people, younger people consume the new beverage rype in larger numbers and more often, wine and beer consumption of respondents aged 15 to 25 years were compared with dara of respondents aged 55 years or more. Ratios between younger and older people of the proportions non-drinkers, the frequency and the context of consumption of both wine and beer are listed in tables 2.5a and 2.5b. For example, in Denmark 6.53 times as many younger men as older men appeared to be non-wine drinkers, younger males drank wine 0.69 times as frequent as older males and younger males consumed wine 0.37 times as often at meals compared to older males. In most countries the ratios of the proportion non-wine drinkers were greater than 1 . This means that more younger males and females reported that they did not drink wine compared to their older counterparts. "Thus, in all countries, except Belgium, more older males and females were wine drinkers than younger males and females. The ratios of the mean frequency of wine consumption were generally smaller than 1 ; so, younger people consumed wine less frequently than oider people. Concerning the 
context of wine consumption the ratios between the younger and the older males and females were mostly smaller than 1 . Thus, younger people drank wine less often at meals than older people. Only in the UK younger females drank wine twice as often at meals as older females.

Regarding the consumption of beer, more younger people drank beer compared to older people. This result was found in all countries, except in Belgitum. The ratios on the frequency of beer consumption differed berween the northern countries on the one hand and the southern countries on the orher. In the northern countries younger people consumed beer less often than older people (except the Dutchmen), as opposed to the southern countries, where younger people drank beer more frequently than older people. In general younger people consumed beer less often at meals compared to older people.

\section{Table 2.5a}

Ratios of three aspects of wine consumption between younger and older people in countries of the European Community

\begin{tabular}{|c|c|c|c|c|c|c|}
\hline & men & & & women & & \\
\hline & $\begin{array}{l}\% \\
\text { non-wine } \\
\text { drinkers }\end{array}$ & $\begin{array}{l}\text { mean } \\
\text { frequency }\end{array}$ & $\begin{array}{l}\% \\
\text { consumed } \\
\text { at meals }\end{array}$ & $\begin{array}{l}\% \\
\text { non-wine } \\
\text { drinkers }\end{array}$ & $\begin{array}{l}\text { mean } \\
\text { frequency }\end{array}$ & $\begin{array}{l}\% \\
\text { consumed } \\
\text { at meals }\end{array}$ \\
\hline Denmark & 6.53 & $0.69^{*}$ & $0.37 *$ & 1,19 & $073 \%$ & 0.92 \\
\hline West Germany & 1.51 & 0.62 * & 1.25 & 2.22 & 0.88 & 0.93 \\
\hline the Netherlands & $2.03 *$ & 0.68 & 0.65 & $4.52 *$ & 0.48 * & 1,47 \\
\hline United Kingdom & 1.08 & 0.91 & 105 & 1.98 & 106 & $1.97^{*}$ \\
\hline lreland & $1,43 *$ & 0.96 & 0.51 & $3.03 *$ & 0.71 & 0.96 \\
\hline Belgium & $0.39 *$ & $0.71 *$ & 0.98 & 0.50 & $0.61^{*}$ & 0.48 \\
\hline Luxembourg & 0.82 & 0.35 * & 0.87 & - & 0.73 & 1.06 \\
\hline France & 1.15 & $0.47 *$ & 0.96 & 1.44 & $0.56 \%$ & 0.93 \\
\hline laty & $2.91 *$ & $0.60 \%$ & 0.95 & 3.44 * & $0.65^{\circ}$ & $0.86^{*}$ \\
\hline Greece & 1.06 & 0.97 & 0.77 & 1.51 & 0.97 & 0.88 \\
\hline Spain & $3.17^{*}$ & $0.62^{*}$ & 0.67 * & $3.23^{*}$ & $0.55 *$ & $0.52^{*}$ \\
\hline Portugal & 6.54 * & $0.71 *$ & $0.88^{*}$ & $3.72 *$ & $0.52 *$ & $0.83^{*}$ \\
\hline & 1.54 & 0.64 & 0.83 & 243 & 0.69 & 0.90 \\
\hline
\end{tabular}

'ratio $>$ 1: more younger than older people do not drink wine

${ }^{2}$ ratio > 1: younger people drink wine more frequently than older people; absta inders exchuded

${ }^{3}$ ratio $>1$ : younger people drink wims more often at meals than older people

* significant difference between younger people and older people, Student $\$$ two-tailled te st: $p<0.05$ 
These results do not support the hypothesis, that in the northern countries mainly younger people drink wine and that they consume wine more frequently than older people. On the contrary, in each country older people drank wine in greater numbers and more often than younger people. Consequently it can be asked, whether older people are more uniform in the consumption of wine than younger people. In other words, does the frequency of wine consumption vary less among older people in all $\mathrm{EC}$ countries than among younger people? The amount of variation within a population can be expressed by the coefficient of variation, which is defined as the quotient of the standard deviation and the mean frequency. The coefficient of variation of wine consumption is 0.82 and 1.00 for the older males and females respectively and 1.05 and 1.07 for the younger males and females. Since the frequency of wine consumption varies less in the older population than in the younger population, older people are more uniform in the consumption of wine.

\section{Table 2.5h}

Ratios of three aspects of beer consumption between younger and older people in countries of the European Community

\begin{tabular}{|c|c|c|c|c|c|c|}
\hline $\begin{array}{ll}4 \\
4\end{array}$ & $\begin{array}{l}\text { men } \\
\text { o } \\
\text { pon beer } \\
\text { dininkers }\end{array}$ & $\begin{array}{l}\text { mean } \\
\text { frequency }\end{array}$ & $\begin{array}{l}\% \\
\text { consumed } \\
\text { atmeals }\end{array}$ & $\begin{array}{l}\text { women } \\
\% \\
\text { non-beer } \\
\text { drinkers }\end{array}$ & $\begin{array}{l}\text { mean } \\
\text { frequency? }\end{array}$ & $\begin{array}{l}\% \\
\text { consumed } \\
\text { at meals }\end{array}$ \\
\hline Denmark & 0.36 & $0.70^{\circ}$ & 0.37 * & 078 & $0.57 *$ & 0.57 \\
\hline West Gerpieny & $0.25^{*}$ & $060 *$ & 0.81 & 1.31 & 075 & 0.82 \\
\hline the Netherlands & $0,15 *$ & 153 & 1.82 & $0,54 \%$ & 1.06 & 0.62 \\
\hline United Kiggdoin & $0.30 \%$ & 1.13 & 0.77 & $0.62 \%$ & 100 & 1.59 \\
\hline reland & 102 & 0.92 & 1.06 & 0.29 & 144 & 3 \\
\hline Beiginar & 2.61 & $0,62 *$ & $060^{\circ}$ & $232 \%$ & 0.46 & 0.56 \\
\hline Luxeribourg & 0.65 & 0.81 & 0.91 & 1.06 & 0.37 & 0.56 \\
\hline rranos & $0.61 \%$ & 1.15 & 4.85 & 0.62 & 0.99 & 208 \\
\hline tely & $0.47 \times$ & $165^{*}$ & 153 & 0.36 & 107 & 0.87 \\
\hline Greece & $0.49 *$ & 11.12 & 1,22 & 0.62 & 137 & 101 \\
\hline Spain & $0.37 \%$ & $163^{*}$ & 0.95 & $0.51 \%$ & 146 & 0,86 \\
\hline Portugal & $0,26 *$ & $2,09 *$ & 0.81 & $0.42^{*}$ & 130 & \\
\hline S & 0.41 & 1.07 & 0.70 & 0.63 & 090 & 0.65 \\
\hline
\end{tabular}

'ratio $>1$ : more younger than oldar people do not drink beer

${ }^{2}$ ratio $>1$ : younger people drink beer more frequent|y than ohder people; abstainers excluded

"ratio 3 1: younger people drink beer more often at meals than older people

* significant difference between younger people and olider people, Student's twa-tailed totest: p< 0.05 
The hypothesis, that in the southern countries, where beer is the new beverage type, chiefly younger people drink beer and that they consume beer more often than older people, is supported. Moreover, also in the northern countries, where beer is the traditional beverage type, more younger people than older people consumed beer. Yet, they drank beer less often than elderly people. Are younger people all over the EC more uniform in the consumption of beer than older people? Younger males and females appear to have smaller coefficients of variation concerning the frequency of beer consumption ( 0.85 and 1.05 respectively) compared to the elderly males and females (0.97 and 1.14). Thus, younger people are more uniform in the consumption of beer than older people.

\section{Table 2.6a}

Ratios of three aspects of wine consumption between people of high and people of low educational level in countries of the European Community

\begin{tabular}{|c|c|c|c|c|c|c|}
\hline & $\begin{array}{l}\text { men } \\
\% \\
\text { non-wine } \\
\text { drinkers } 1\end{array}$ & $\begin{array}{l}\text { mean } \\
\text { frequency }\end{array}$ & $\begin{array}{l}\% \\
\text { consumed } \\
\text { at meals }\end{array}$ & $\begin{array}{l}\text { women } \\
\% \\
\text { noln-wine } \\
\text { drinkers }\end{array}$ & $\begin{array}{l}\text { mean } \\
\text { frequency }\end{array}$ & $\begin{array}{l}\% \\
\text { consumed } \\
\text { at meals }\end{array}$ \\
\hline Denmark & $0.55 \%$ & 1.18 & 0.96 & $0.14 \%$ & 1.37 & 0.92 \\
\hline West Germany & $0.18^{*}$ & 1.17 & 1.09 & 0.82 & $1.53^{*}$ & 0.92 \\
\hline the Netherlands & 0.46 * & 1.04 & 1,18 & 0.43 & 1.33 & 0.98 \\
\hline United Kringdom & $0.08^{*}$ & 1.24 & 1.01 & $0.23^{*}$ & $132 \%$ & $2.44 *$ \\
\hline Ireland & $0.19 *$ & $1.70^{*}$ & 3.00 & 0.52 & 1.32 & 1.20 \\
\hline Belgiun & $0.26 *$ & $1.59 *$ & $1.74 *$ & $0.11 \%$ & $137 *$ & $1.48 *$ \\
\hline Luxembourg & 0.49 & $1.46^{*}$ & 0.88 & 0.97 & 101 & 1.24 \\
\hline France & 104 & 0.76 & 0.99 & 1.13 & 0.93 & 1.00 \\
\hline Itally & 0.97 & 0.90 & 1.01 & 0.65 & 0.73 & $0,83^{*}$ \\
\hline Greece & 2.80 & 0.75 * & 1.11 & 0.95 & 0.87 & 0.80 \\
\hline Spain & 1.25 & 0.92 & 1.00 & 039 & 0.87 & 0.69 \\
\hline Portugal & -4 & 0.94 & 1,00 & 2.98 & $058^{\circ}$ & 106 \\
\hline & 0.47 & 0.79 & 0.92 & 0.50 & 0.95 & 0.90 \\
\hline
\end{tabular}

'ratio $>1$ : moke higher educated people thian lower educated people do not drink wine

${ }^{2}$ ratio $>$ in: higher educated people drink wine more frequently than llower educated people; abstainers exchuded

ratio $>1$ : higher educated people drink wine more often alt meals than lower educated people

* signifficant difference between higher and lower educated people. Student"s two-tailed t-test: $p<0.05$ 
Wine and beer consumption of people of higher and people of lower educational level

The consumption of beer and wine of people, who were at least 20 years old when they finished their full-time education, was compared with data of people, who received education until they were at most 15 years old. Ratios between people of higher educational level and people of lower educational level of the proportions non-drinkers, the frequency and the context of consumption are listed in tables $2.6 \mathrm{a}$ and $2.6 \mathrm{~b}$. The drinking patterns of the categories of higher educational level and of lower educational level differ between the northern and southern countries. In the northern countries more people of higher educational level consumed wine than people of lower educational level. Yet, in the southem countries differences in proportions non-wine drinkers between the more and the less educated were small. In contrast to the southern countries, people of higher educational level in the northern countries consumed wine more frequently and more often at meals compared to people of lower educational level.

\section{Table 2.6b}

Ratios of three aspects of beer consumption between people of high and people of low educational level in countries of the European Community

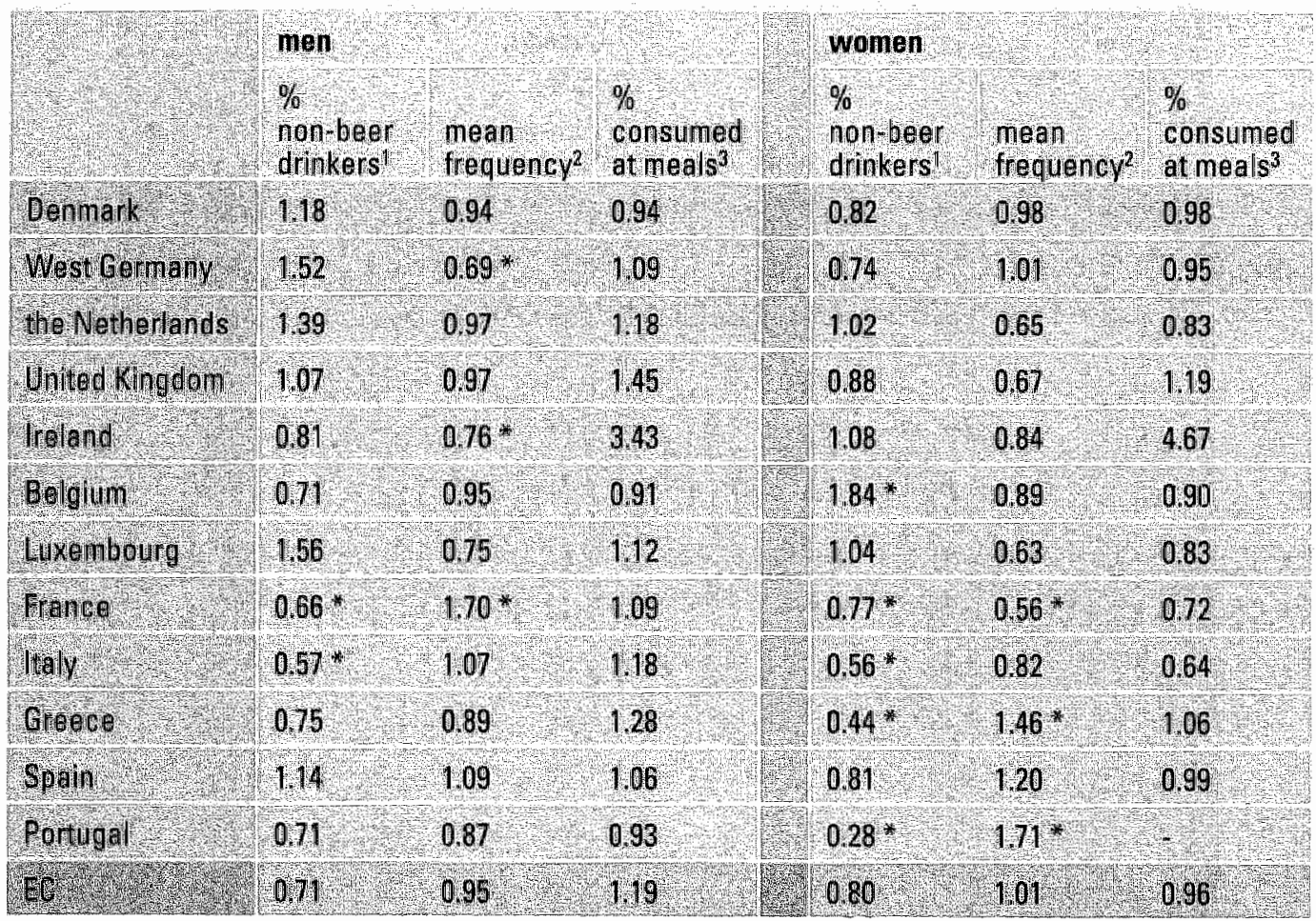

Tratio > 1: more higher educated people than lower educated people do not drink beer

"Ifatio $>1$ : higheir educated people drink beer more trequenty than lower educated people: abstainers excluded

${ }^{3}$ ratio > 1: higher aducated penple drink beer more often at meals than lower educated people

" significant difference between higher and lower educated people, Student"s two-tailed t-test: $p<0.05$ 
In the southern countries more people of higher educational level consumed beer, while in the northern countries more males of lower educational level consumed beer than males of higher educational level. A similar pattern is found for the Bejgian females. Females in the orher northern countries showed only small differences in proportions non-beer drinkers by level of education. To a certain extent the results on frequency of beer consumprion correspond with these results. In the southern countries Greek, Spanish and Portuguese females and Frenchmen of higher educational level consumed beer more frequently, while in the northern countries the higher educated drank beer less frequently compared with the lower educated. Concerning the context of consumption, there appears to be no clear distinction between the northern and the southern countries. There is, however, a distinction between the sexes. Females of higher educational level drank beer less frequently at meals compared with females of lower educational level, while males of higher educational llevel drank beer more often with meals compared to males of lower educational level. These results support the hypothesis, that chiefly people of higher educational level consumed the new beverage type. Moreover, people of lower educational level consumed the traditional beverage type in greater numbers and more often than people of higher educational level.

\section{Discussion}

The results on total alcohol consumption in the 12 countries of the EC are a clear indication that people in the southern countries consume alcoholic beverages more frequently than people in the northern countries. This implies that in the year 1988 the distinction between the mediterranean and the northern drinking pattern concerning the frequency of consumption still holds. The question remains whether this applies for wine, beer or both beverage types.

Consequently, the drinking patterns of wine and beer were studied. With regard to the proportion non-wine drinkers, non-beer drinkers and the frequency of wine and beer consumption, the difference between the northern countries and the southern countries applies strongly for males. In the northern countries males consume beer in greater numbers and more frequently compared to males in the southern countries, who for their part consume wine in greater numbers and more freguently. With respect to females, there appear to be no clear distinctions in the proportions drinkers and the frequency of consumption between the northern and the southern countries. Our data indicate that, regarding these aspects, the countries within the EC still substantially differ in their drinking patterns. There is, however, some uniformity concerning the context of the main beverage types. In both the northern and the southern countries wine is more often consumed at meals compared to beer, which is more often consumed outside meals. Consequently the drinking norms of the new beverage type appear mainly to be adopted of the 'original' countries. This outcome suggests that the new beverage type does not substitute, but is added to the 
traditional beverage type:

The hypothesis, that younger people consume the new beverage rype in larger numbers and more frequently compared to older people, is supported in the case of the Mediterranean countries, but not in the case of the northern countries. There appears to be a correlation between age category and the consumption of wine or beer. In each country older people drink wine in greater numbers and more often than younger people, while younger people consume beer in greater numbers and more frequenrly. Although the survey does not contain information on the number of glasses per drinking occasion, this amount can be roughly estimated from the data on the context of drinking. Since both age categories drink wine mainly at meals, both the younger and the older people probably consume a rather small amount. As older people consume wine more often than younger people, older people apparently drink more wine than younger people.

With regard to the context of beet consumption, younger people consume beer less frequently at meals than older people. In drinking situations outside meals, younger people might consume alcoholic beverages mainly with their friends. Consequently, the possibility that they drink more in these situations is greater than if they drink beer at meals with their family. So, both in the northern and in the southern countries younger people consume beer not only in greater numbers and more often, but probably also in greater amounts than older people. This interpretation corresponds with the finding of Péquignot et al. (1988), that in France, Italy, Spain and Switzerland younger age categories of both sexes consumed more beer than older age categories. Research in the Netherlands showed that the drinking patterns of younger people differ from those of older people. Younger people consumed alcoholic beverages less frequently, but they drank more per drinking situation compared to the elderly (Knibbe, Drop \& Muytjens, 1987).

The results concerning the drinking patterns of the categories of higher educational level and lower educational level are very clear. People of higher educational level consume the new beverage type in greater numbers and more often and the traditional beverage type less often compared to people of lower educational level. Moreover, people of higher educational level in the norchern countries consume wine more often at meals and in the southern countries they drink wine more often outside meals than people of lower educational levell.

These differences in the consumption of new alcoholic beverages indicate a diffusion of new habits initiated by the more educated people. Sulkunen (1989) showed in detail that changes in beverage preferences between 1965 and 1979 in France follow a process of hierarchical diffusion. In this respect our results fit with Bourdicu's central hypothesis that people in the higher strata, and more specifically people with much cultural capital but relatively litrle economic capital, are prone to invest in stylizing consumption behaviour (Bourdieu, 1986; Sulkunen, 1982). In this way they claim a competence which distinguishes them not only from people in the lower strata, but also from people who are nothing but rich. Bourdieu describes these processes for for example exoric foods, preferences in music and art. Applied to 
beverage preferences this means that in a context where most people still show traditional preferences, the preference for a new bexerage and the knowledge how and when to use this may function as a symbol of cultural comperence. Because of the prestige associated with these new habits, people with less cultural capital will adopt these new habits after some time. However, it should be noted that what from a national point of view can be described as a hierarchical diffusion, from an international point implies that the more educated people seek distinction by adopting 'exotic' proletarian habits.

Finally, sex differences in the frequency of consumption of the new beverage type are smaller than in the frequency of the traditional beverage type. People of higher educational level, who consume the new beverage type more often than people of lower educational level, may have accepted the women's emancipation mote strongly and consequently may differ less in drinking norms between the sexes. This may partly explain the smaller differences berween males and females in the consumprion of the new beverage type. An indication, that confirms this supposition, is the finding of Knibbe and Lemmens (1987) that in Switzerland, Germany and the Netherlands sex differences in the consumption were smallest among the higher educated. Moreover, ideas about women's emancipation might be diffused to such an extent that, irrespective of educational level, traditional norms about sex differences apply less to the use of the new beverage types.

\section{References}

Bourdieu, $P$.

(1986). Distinction, A social critique of the judgement of taste. London: Routledge and Kegan Paul.

Casselman, J. \& Knibbe, R.A.

(1985). Alcoholgebruik en alcoholproblemen in België en Nederland, Gezondheid \& Samenteving, 6, 256-264.

Davies, P. \& Walsh, D.

(1983). Alcohol problems and alcobol control in Europe. New York: Croom Helm.

De Lint, J.

(1980). Het alcoholgebruik in België en Nederland. In: H. de Baere \& J. Casselman

(Eds.), Het alcoholprobleem (pp. 36-42). Alphen a/d Rijn: Stafleu.

Glenn, N.D.

(1981). Cohort analysis. Sage university paper series on quantitative applications in the social sciences 07-005. Beverly Hills: Sage publications.

Knibbe, R.A., Drop, M.J. \& Muyrjens, A.

(1987). Correlates of stages in the progression from everyday drinking to problem drinking, Social Science and Medicine, 24, 463-473. 
Knibbe, R.A: \& Lemmens; P.H.

(1987). Korrelate des Alkoholkonsums in der Schweiz, Deutschland und den Niederlanden, Drogalkobol, $11,27-41$.

Lolii, G.s Serianti, Eu, Golder, G.M. 8e Luzzatio-Fegiz P.

(1958). Aloobal in Italian culume Food and wine in relation to sobriety amang thatian and Inalian Americans. New Haven: Yale Center of Alcohol Studies.

Péquignor, G; Crosignani, P., Tertacini, B., Ascunce, N., Zubiri, A, Raymond, L., Estère, J. 8. Tuyns, A.J.

(1988). A comparative stucly of smoking, drinking and dietary habits in population samples in France, Italy, Spain and Switzerland. III Consumption of alcohol. Rezue d'Epidemiologie et de Sante Publique, 36, 177-185.

Produkrschap voor Gedistilleerde Dranken

(1990). World drink trends. Intemational bevenage alcohol consmption and production trends. Henley-on-Thames: NTC Publications.

Pyöräla E E

(1990). Trends in alcohol consumption in Spain, Portugal, France and Italy from the 1950 s until the 1980 s, British Jownal of Addiction, $85,469-477$.

Rogers, E.M. \& Stanfield, J.D.

(1968). Adoption and diffusion of new products: emerging generalizations and hypotheses. In: E.M. Bass, C.W. Kung \& E.A. Pessemier (Eds.), Applications of the sciences in marketing managenent (pp. 227-250). New York: Wiley.

Sadoun, R., Lolli, G, \& Silverman, $M$.

(1965), Drinking in French culture. New Brunswick: Rutgers Center of Alcohol Studies.

Sulkunen, P:

(1976). Drinking patterns and the level of alcohol consumption: an international overview. In: R.J. Gibbins, Y. Israel, H. Kalant, R.E. Popham, W. Schmidt \& R.G. Smarc (Eds.), Research advances in alcohol and drug problems, Vol. 3 (pp. 223-281). New York: Wiley.

Sulkunen, P.

(1982). Sociery made visible - on the cultural sociology of Pherre Bourdieu. Acta Sociologica, 25, $103-115$.

Sulkunen, P.

(1989). Drinking in France 1965-1979. An analysis of household consumption data. British Joumat of Addiction, $84,61-72$.

Walsh, B. \& Grant, M.

(1985). International trends in atcohol production and consumption: implications for public health. World Health Statistics Quarterly, 38, 130-141. 


\section{Christianne L.H. Hupkens}

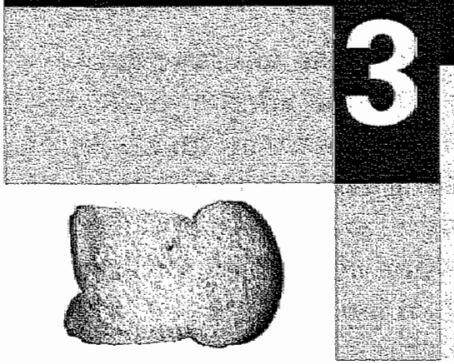

Ronald A. Knibbe and Maria J. Drop

Social class differences in women's

fat and flbre consumption

a cross-national study

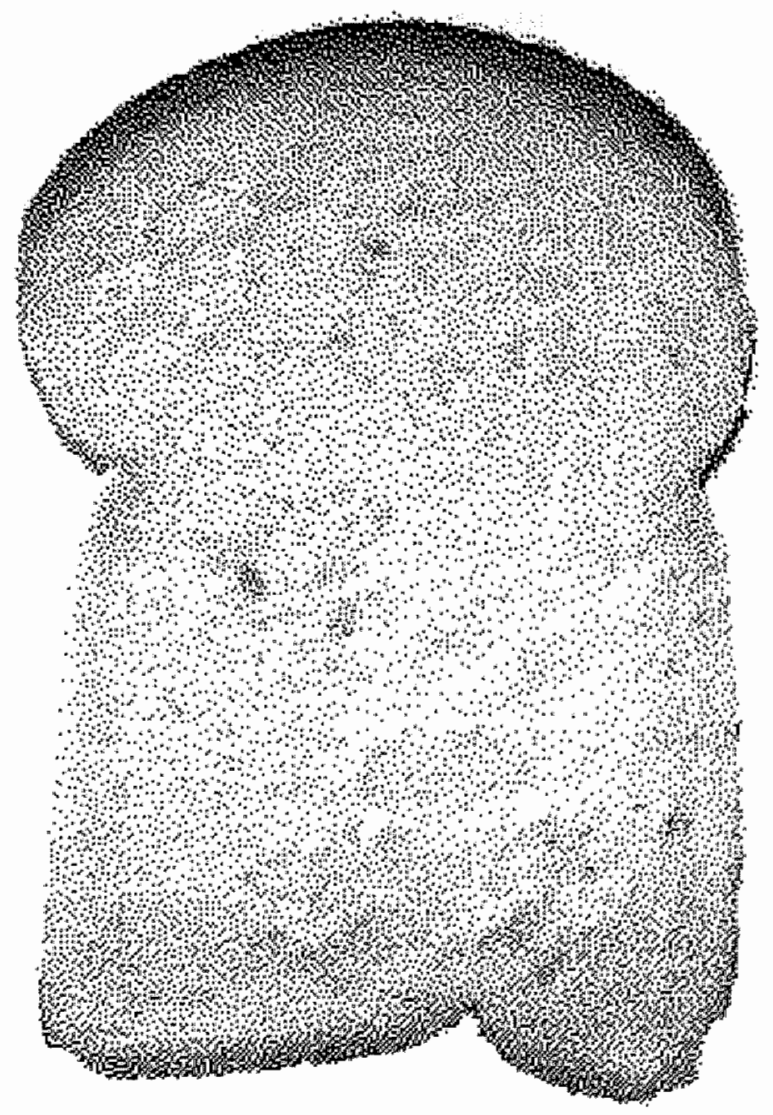




\section{Abstract}

This study focuses on social class variation in the intake of fat and fibre in Maastricht, Liège and Aachen, based on food frequency questionnaires of 849 women from nuclear families with schoolgoing children. In Maastricht and Liège higher-middle class women consumed less fat than working class women, while in Aachen no class difference was apparent. The intake of fibre was highest among the higher-middle class women, alt though this tendency was not significant in Aachen.

Analysis of food groups that contribute to the intake of fat and fibre revealed that not all food groups showed this pattern. Higher-middle class women consumed less bread, less potatoes and more cheese than working class women. Moreover, they chose more often high-fat cheese and fats. Yet, working class women consumed more meat, milk and fats, and less grain, fruit and vegetables.

In general, social class variations in fat and fibre inrake were uniform across the cities, although in Aachen class differences were small or absent. In conclusion, these results suggest that the diet of higher-middle class women is more in accordance with the dietary recommendations regarding fat and fibre than the diet of working class women. 


\section{Introduction}

During the last few decades social inequalities in health have been extensively studied in many western countries. Class differences in possible causes of morbidity and mortality (like health behaviour and working condicions), in the state of public health, and in the consequences of health (like incapacity for work) are often reported (e.g. Townsend, Davidson \& Whitehead, 1988; Davey Smirlh, Bartley \& Blane, 1990; Lagasse, Humblet, Lenaerts, Godin \& Moens, 1990; Kirchgässler, 1990; Helmert, Shea, Herman \& Greiser, 1990; Lahelma \& Valkonen, 1990; Mackenbach, 1992; Helmert, Mielick \& Classen, 1992; Kunst \& Mackenbach, 1994; Joosten, 1995).

Class differences in eating habirs may partly explain social inequalities in health. In studies of food consumption parterns, social class appears to be a key variable, besides age and sex. In general, people of the higher-middle social class are reported to have a healthier diet than people of the working class (Mennell, Murcott \& Van Otrerloo, 1992). Milk and meat provide examples that show clear class differences, with a higher consumption of skimmed milk and lean meat in the higher educational or professional groups, and a higher consumption of the high-fat alternatives in the lower educational or occupational categories (Prättälä, Berg \& Puska, 1992; Hulshof, Löwik, Kok et al., 1991; Kromhout, Doornbos \& Hoffmans, 1988; Lepage, 1985). However, when it is not foodstuffs, but the intake of nutrients like fat and fibre that is studied, class differences tend to be less apparent (Prättälä, 1995). Yet, when class differences are found, the higher-middle social classes show a lower intake of fat and a higher intake of fibre.

In a study on determinants of fat consumption among random samples of the adult population in two Belgian cities (Ghent in Flanders, the Dutch-speaking part, and Charleroi in Wallonia, the French-speaking part), a higher consumption of fat was reported among lower class men, while no difference according to social class was found among women (De Craene, De Backer, Kornitzer et al., 1990). Results of a national food consumption survey in the Netherlands showed that lower social class was associated with a higher energy percentage of far intake, but the class differences were small. In that survey a class difference in the intake of dietary fibre was reported for men, but not for women (Hulshof et al., 1991). In a West German food consumption survey, more highly educated women showed a lower consumption of fat and a higher consumption of fibre than women of low educarional level (Heseker, Adolf, Eberhardt et al., 1992).

Also qualitative studies convincingly demonstrated that the food practices and choices among higher-middle class women were more in line with the latest nutrirional views than the food habits of working class women (Calnan, 1990; Van Otterloo \& Van Ogtrop, 1989; Charles \& Kerr, 1988). Van Otterloo (1990) suggested that these social class differences in eating habits may be interpreted by Elias's theory on the civilization process. This theory describes that during the past 
centuries behaviour became increasingly controlled by internalization of norms (Elias, 1982). One aspect of this process is the civilizing of appetite. Only recently working class families can afford the food items they prefer. As in the past they could afford meat only on special occasions, and no white bread at all, they nowadays buy these 'luxury' food items. In contrast, higher-middle class people could afford expensive food items much earlier. They now emphasize gastronomy and a good health, and consequently favour refined dishes and quality rather than quantity. According to this theory, the working class lags behind the higher social class. After some time higher-middle class' preferences and values may be reproduced by the working class. Yet, higher-middle class people continue to distinguish themselves from working class people, and thus they also keep changing their eating habits.

Trends in food consumption in the Scandinavian countries between 1970 and 1990 support this theory (Prättälä, 1995). In Finland, Norway and Sweden the higher social classes started to consume less fat and especially less saturated fat, and more fruit and vegetables, and the lower classes followed five to ten years later. During this process class differences altered, but they did not vanish. Prättälä presumed that social class differences in eating habits become more subtle and complex: 'instead of differences in the use of single foods, social classes are likely to differ in the way they talk about food, set their tables and combine foods into dishes and meals'.

The fact that higher class people generally live a healthier and longer life and have healthier lifestyles may also be viewed in the light of Weber's notions on the positive relation between class and status on the one hand and life chances and lifestyles on the orher. According to his theory, lower class people are to a greater extent determined and controlled in their life chances and lifestyles, whereas people with better class and status positions and consequently more power generally have better conditions of living or in other words life chances. Moreover, they are to a lesser extent restricted by necessities, and thus they have more freedom to determine their lifestyle. Nowadays they particularly seem to prefer a healthy lifestyle, featuring for instance healthier diets, greater opportunities for relaxation, greater resources in dealing with stress and higher levels of participation in sports than lower class people (Luischen \& Cockerham, 1995).

Inspired by Weber's concepts of class and 'stand' (Bourdieu, 1989, p. xii), Bourdicu performed a study on taste and lifestyles in France. He also concluded that people's preferences and choices were linked with their position in the social order, and he characterised the lifestyle of the working class by the 'taste of necessity', and the lifestyle of the middle and higher-middle class by the 'taste of luxury'. The latter used among other things eating habits to distinguish themselves in their values, rules and choices from the working class. Bourdieu illustrated this by describing the eating habits of the French. Generally speaking, working class people favoured heavy and fatty meals in large quantities and well-cooked vegetables, while higher-middle class people preferred refined and light meals and raw vegetables, that were more expensive, but also healthier. 
The study reported here explores social inequalities in eating habits of women within families, including at least one school-going child, aged between 4 and 14 years. This subpopulation was selected for three reasons. First, a qualitative survey on food habits in the Netherlands showed that women were more interested in healthy food when they had children than before (Van Otterloo \& Van Ogtrop, 1989). We were interested whether mothers of different social levels still vary in their eating habits, despite their shared concern for health. That qualitative study also showed that the food patterns of women became more regular after they had children, and as a consequence they may have fewer difficulties to recall their food habits. Finally, mothers fulfill a central role in the provision of food for their family.

Yer, this does not mean that mothers function as gatekeepers in food matters (Charles \& Kerr, 1988; Murcotr, 1985; Murcotr, 1983). Charles and Kerr (1987) reported a class gradient in the extent women were autonomous in their food choice, as working class women took the food preferences of their husband more often into account than higher-middle class women. As most women consider the preferences and wishes of their husbands in their selection of food, food choices appear to differ between complete families and lone-parent families (Murcott, 1993; Van Otterloo \& Van Ogtrop, 1989; Charles \& Kerr, 1986). Despite the increase of alternative ways of living, couples with children are still the most frequent mode of cohabitation of all households with children. Based on data gathered in 1991, in the Netherlands $16 \%$, in Belgium $20 \%$ and in Germany $17 \%$ of families with children were loneparent famillies (Eurostat, 1995). As the number of lone-parent families in the sample might be too small to justify conclusions, only complete families were included in the present study.

This study focuses on social class variation in eating habits within a border region to investigate whether class differences are comparable in different countries. Following the theories of Elias and Bourdieu, higher-middle class people adopt new eating habits first, while working class people still prefer traditional food. Two contrasting suppositions can be elaborated on cultural variation of social class differences. If new eating habits are uniform in western countries, class differences in eating habits will be comparable in these countries. Opposed to this view, new eating habits may vary between these cultures. To give a hypothetical example: French cheese (which is generally full-fat) might become popular in the Netherlands, because it is foreign, while lean sorts of cheese might be trendy in Germany, because of health reasons. If in both countries these trends start in the higher-middle class, class differences in full-fat cheese will be contradictory in these countries. In conclusion, if new habits are uniform across countries, class differences in these habits are probably comparable, and if new habits differ berween countries, class differences might be disparate. In the three countries health promotion campaigns are recommending to consume less far and more fibre for several years. As we presume that new habits are mainly inspired by these health considerations, we expect that class differences will be uniform across the cities.

In order to study these views, a cross-cultural survey was conducted in 
Maastricht, Liège and Aachen. These cities are located in three linguistic areas, that is the Netherlands, the French-speaking part of Belgium, and Germany. Yer, geographically the towns are situated less than 50 kilometres apart within the Euregion Rhine-Maas, which consists of the Belgian provinces Limburg and Liège, the southern part of Dutch Limburg, and the region around Aachen in Germany. Historically, the national boundaries have been no barrier for frequent contacts berween people in this border region. Up till now, many people visit cultural events and shops or have friends and relatives on the other side of the border.

In their description of the development of culinary cultures Mennell, Murcotr and Van Otterloo (1992) reported that the Dutch and German style of cooking generally show an emphasis on 'thrift and simplicity more reminiscent of England than of France or Belgium', although in the case of Germany it seems hardly possible to speak of a national culinary culture, because of the importance of regional culinary preferences and dishes. On the other hand, Belgian cuisine resembles the French cuisine, and Belgians just like French are famous for their propensity to dine heartily. Thus, food traditions vary between cultures and consequently eating habits are diverse (Kromhout, Keys, Aravanis et al., 1989). For instance, consumption figures collected in European countries show that meat consumption is higher in Belgium (102 kg per capita per year) than in Germany (97 $\mathrm{kg}$ ) and the Netherlands $(89 \mathrm{~kg})$. Also vegetables and potatoes are consumed in larger amounts in Belgium (103 $\mathrm{kg}$ respectively $99 \mathrm{~kg}$ ) compared to the Netherlands $(99 \mathrm{~kg}$ and $87 \mathrm{~kg}$ ) and Germany ( $83 \mathrm{~kg}$ and $74 \mathrm{~kg}$ ). On the other hand, the consumption of milk products is highest in the Netherlands $(136 \mathrm{~kg})$, followed by Germany (91 kg) and Belgium (81 kg) (Eurostat, 1994). Despite the cultural variation in the amounts and types of food consumed, the literature cired above shows that in western countries less healthy eating habits appear to be more common in the lower social strata.

With respect to food habits, this study focuses on the consumption of dietary fat and fibre, as these nucrients seem to be related to cardiovascular diseases and cancer (Willetr, 1994; Hautvast, 1993; James, Ferro-Luzzi, Isaksson 8x Szostak, 1988). Moreover, the recommendations to consume less fat and more fibre are well-known in the general population of all three countries. Yet, if people choose their daily food, they mostly do not select nutrients, but specific foodstuffs. In the selection of food items, the intention to ingest one or more specific nutrients may play a role, but in general other considerations, like preferences and habits, have a larger impact. In order to study the consistency between nutrients and foodstuffs, a selection of food groups, that may reflect the choice between food items with less or more fat or less or more fibre, was analysed too. These involve meat and meat products, milk and milk products, cheese, oils and fats, bread, grain, fruit, vegetables and potatoes. "The consumption of these food items may be in line with the total intake of fat and fibre, e.g. a higher consumption of meat in the working class may correspond with a higher intake of dietary fat. Yet, if higher-middle class women consume more edible fats and oils, which counteracts their lower fat intake from meat, the classes might 
not differ in the intake of fat, but in their sources of fat. Evidently, this information is important for health education programmes.

In conclusion this paper focuses on three research questions:

1 Is there a class difference in the intake of fat and in the consumprion of meat products, milk products, cheese; and oils and fats?

2 Do social classes differ in the intake of fibre and in the consumption of bread, grain, fruit, vegetables and potatoes?

3 To what extent are these class differences similar in different cultural settings, namely in Maastricht, Liège and Aachen?

\section{Data and Methods}

\section{Survey}

Data on dietary and eating habits were collected from 849 women in Maastricht $(\mathrm{N}=304)$, Liège $(\mathrm{N}=316)$ and Aachen $(\mathrm{N}=229)$ between November 1993 and February 1994, except for the period between 23 December and 9 January because of Christmas. The inclusion criteria were: (i) having a family with at least one child aged 4-14 years, who lives at home, and (ii) living together with a partner, as we were interested in complete families. When the interviewers met non-native-speaking women, they quickly checked the woman's dietary habits. In general, foreign women were included in the sample, unless they mentioned a couple of food items, that were not incorporated in the food frequency questionnaire, or when the interviewers noticed language problems.

In general, social class is based on education, occupation, and/or income. Studies that compared these three measures for their power to predict health behaviour, reported that education is usually the most consistent and reliable measure (Pill, Peters \& Robling, 1995; Winkleby, Jatulis, Frank \& Fortmann, 1992). An expert committee in the Nerherlands also recommended to use educational level as a measure for social class in epidemiological and social-medical studies. Compared to occupational status and income, educational level has the advantage that it can be applied to everybody, and that it is less susceptible to economical constraints (Van Berkel-Van Schaik \& Tax, 1990).

In order to reach enough women with a low and a high educational level, working class and higher-middle class districts, populated by families with schoolgoing children, were selected in each city. The selection of districts was based on demographic data (if available), and on the advice of a municipal official.

Trained female interviewers, students and graduates of the Universities of Maastricht, Liège or Aachen, started the sample by approaching a random address and asking whether there were children between the ages of 4 and 14 living there. If the family met the criteria, the interviewers asked whether the woman wanted to answer a questionnaire on dietary and eating habits. If so, the interviewers explained 
how to complete the questionnaire. In addition, they made an appointment with the woman to collect the questionnaire about one week later at her home. At each contacted address, whether this family met the criteria or not, the interviewers asked whether one of the neighbours had children aged 4-14 years. In this way the interviewers garhered addresses and distribured questionnaires, which they collected later To obtain data about the sampling procedure and the non-response, the interviewers kept accounts of all addresses they contacted during the distribution and collection of the questionnaires.

Table 3.1 shows data on the response in working class districts and higher-middle class districts in Maastricht, Liège and Aachen. The response was highest in Maastricht (79\%) and Liège (78\%) and lowest in Aachen (67\%). In all three cities the higher-middle class districts showed the highest response. Non-response might possibly be selective. For instance, as generally in the working class areas more people have a low educational level, more people may have problems with reading or writing and may refuse to collaborate for this reason. Another possibiliry might be that they are less interested in the subject. Consequently, results on class differences in the present study may be underestimated.

\section{Table 3.1}

Response and non-response in lower class and higher-middle class districts in Maastricht, Liège and Aachen

\begin{tabular}{|c|c|c|c|c|c|}
\hline PrY, & $\begin{array}{l}\text { women who } \\
\text { met criterial }\end{array}$ & $\begin{array}{l}\text { non } \\
\text { res } \\
\mathrm{N}\end{array}$ & \% & $\begin{array}{l}\text { resp } \\
\mathrm{N}\end{array}$ & $\begin{array}{l}\text { ise } \\
\%\end{array}$ \\
\hline Malastrolit & & & & & \\
\hline tower class & 206 & 50 & 24 & 156 & 76 \\
\hline Gigher nidd dloclass & 180 & 32 & 18 & 148 & 82 \\
\hline$(6 \mathrm{ta})$ & 386 & 82 & 21 & 304 & 79 \\
\hline Lrege & & & & & \\
\hline Lower class & 216 & 59 & 27 & 157 & 73 \\
\hline Wigher niddle olass & 191 & 32 & 17 & 159 & 83 \\
\hline (otal & 407 & 91 & 22 & 316 & 78 \\
\hline Aachon & & (2) & & & 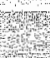 \\
\hline lower class & 173 & 65 & 38 & 108 & 62 \\
\hline higher niddels class & 135 & 37 & 27 & 98 & 73 \\
\hline (totel. & 308 & 102 & 33 & 206 & 67 \\
\hline
\end{tabular}

\footnotetext{
1 im Aachen response figures are based on $90 \%$ of the questionnaires collected. Infoimation aboult the collection of the remaining questionmaires is not available, as one student did not report the number of people she approachad. In total 229 questionnaires were collected: 121 in lower class districts and 108 in higher-midde class districts.
} 


\section{Questionnaire}

The questionnaire involved two parts: a food frequency questionnaire and a questionnaire on food practices. Food frequency questionnaires are ofen used in large-scale studies, as it is a simple and quick method, that can be completed by the subjects themselves. Food frequency questionnaires may be less reliable to measure absolute nutrient intakes than other methods, like dietary history, food records, and recalls (Cameron \& Van Staveren, 1988). However, also these methods are still under discussion (e.g. Hunter, Rimm, Sacks et al, 1992). Nevertheless, food frequency questionnaires are able to rank individuals according to their nutrient and food intake (Block, 1982; Willett, Sampson, Stampfer et al., 1985). As we were interested in the presence or absence of class differences in food consumption rather than the exact magnitude of these differences, we selected a semiquantitative food frequency questionnaire, of which the ability to rank subjects was validated. This questionnaire was developed by Bausch-Goldbohm and Van Den Brande for a large cohort study on diet and cancer in the Netherlands to assess habitual consumption of approximately 150 food items during the past year (Bausch-Goldbohm, Van Den Brandt, Van 't Veer, Sturmans \& Hermus, 1988).

The validity of that questionnaire was tested among 109 women and men with a dietary record, kept over 3 three-day periods, four to five months apart, as a reference. The correlations for the consumption of fat and fibre, adjusted for energy intake, were 0.52 and 0.74 respectively (Goldbohm, Van Den Brandt, Brants et al., 1994). During the first five years of the cohort study the questionnaire was repeared annually in independent samples, consisting of 200 men and 200 women. The women showed test-retest correlations, from which the effect of change over the five years was removed, of 0.60 for fat intake and 0.69 for fibre intake. Based on these findings, the researchers concluded that a single measurement of this questionnaire was a good indicator of nutrient intake over a period of at least five years (Goldbohm, Van 't Veer, Van Den Brandt et al, 1993). As we were interested in a selection of five nutrients, namely dietary fat, saturated fat, mono- and disaccharides, dietary fibre and alcohol, the original questionnaire was shortened in consultation with Bausch-Goldbohm.

The questionnaire on food practices was based on the results of a qualitative study of Van Otterloo and Van Ogtrop (1989). In collaboration with Van Otterloo, questions were formulated on for example meal patterns, the preparation of meals, food regimes, health considerations and preferences. In addition, questions about age, marital state, familly composition, religion, education, occupation and working situation were included.

The Dutch questionnaire was translated into French and German. The translated food frequency questionnaire was checked by Belgian and German dieticians and researchers for three reasons: (i) to include common Belgian or German food items, (ii) to exclude typical Durch foods, and (iii) to improve the description of the food items, for instance by using local wordings or local brands as examples. Moreover, in 
collaboration with Belgian and German social scientists, questions about religion, education, occupation and working situation were formulated. Next, the translation of the questionnaire as a whole was checked by interviewers, who lived in Liège or Aachen. Finally, in each city the questionnaire was tested in a pilot-study.

If the respondents encountered questions about the questionnaire or the study, they were encouraged to phone a researcher at the local university. Moreover, when the interviewers collected the questionnaires, they asked whether the woman had any problems and they checked the questionnaire on those questions that were known to cause difficulties.

\section{Data}

\section{Social class}

Based on the arguments discussed above, social class is indicated by the highest completed education of the woman. Moreover, in the present study educational level of the women appeared to be a better predictor of food consumption than their partner's educational level, their own or their husband's occupational status, and income source (a dichotomous variable: eirher salary or state benefit). This conclusion was based on stepwise regression analyses of these five proxies of social class on the food consumption variables, that are used in the present paper. Most often women's educational level was included first.

Educational level of the woman correlated positively with her occupational status (Maastricht: 0.72, Liège: 0.73, and Aachen: 0.52) and with the highest completed education of her partner (Maastricht: 0.67, Liège: 0.68, and Aachen: 0.60). According to the educational structure in each country, seven educational levels were used in the Dutch and German questionnaire and six levels in the Belgian version. Next, educational level was classified into three categories: lowest (i.e. elementary and lower vocational training for 12-16 years old), middle, and highest educational level (i.e. higher vocational training for $18+$ years old and university). In total eight women, who skipped the question about their educational background, were excluded from the analyses. Next, the food frequency questionnaires of women, who showed a very large energy intake ( $>5000 \mathrm{kcal} / \mathrm{day}$ ) were examined. One woman in Maastricht and two women in Liège who showed very high frequencies and huge portions were excluded, as they probably reported not only their own consumption, but also the intake of their husband and children.

The homogeneity of the districts according to educational level varied berween the cities. As a consequence, the distribution according to educational level in the three samples differed. As we expected, women with a low educational level were overrepresented in the lower class districts and highly educated women in the highermiddle class districts (table 3.2). The only exception was Liège, where in the highermiddle class districts most women had a middle educational level. Moreover, table 3.2 shows that the districts in Aachen were the least homogeneous, as in the highermiddle class districts $12 \%$ of the women had a low educational level, while in the working class districts $21 \%$ of the women had a high educational level. 


\section{Table 3.2}

Number of low, middle and high educated women in lower class and higher-middle class districts in Maastricht, Liege and Aachen

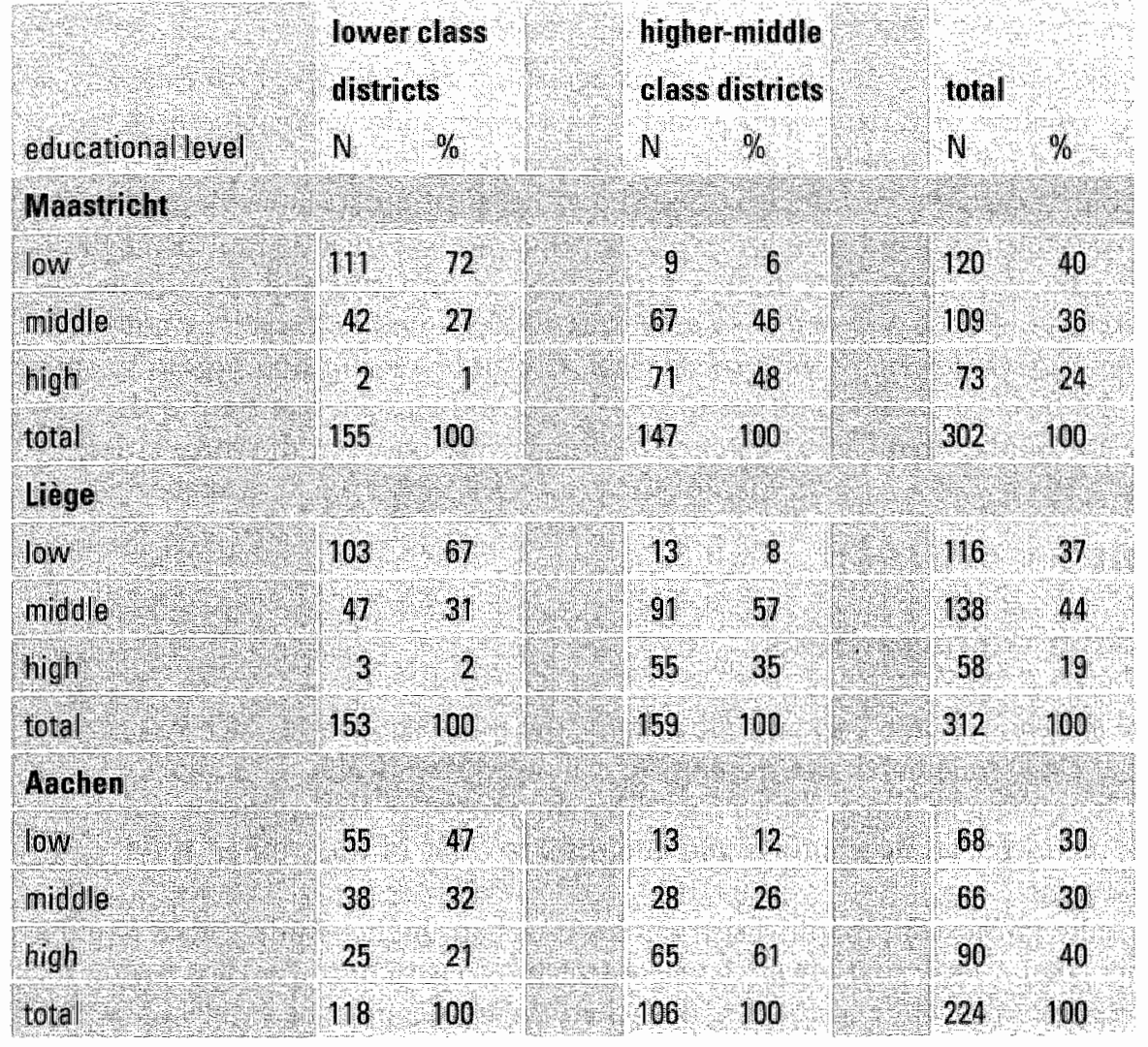

\section{Food items}

Mean daily intake of all foods was computed by multiplying consumption Frequency, number of serving units and weight of a tunit. Nutrient intake was calculated using the computerized Dutch food composition table (Nevo tabel, 1993) extended with information from the Belgian and German food composition tables for those food items not included in the Dutch table (Nubel, 1992 ; Heseker \& Heseker, 1993).

We were not only interested in the consumption of nutrients but also in the consumption of foods. Therefore groups of food items have been selected that contributed considerably to the intake of fat and fibte and that may reflect the choice between products, which contain less or more fat or fibre. In the three cities on average more than $70 \%$ of the intake of fat was derived from meat products, milk 
products, cheese and oils and fats and more than $75 \%$ of dietary fibre intake originated from bread, grain, fruir, vegetables and poratoes. Appendix 1 shows these food groups and examples of the products they represent.

\section{Analysis}

First, class differences in population characteristics were analysed for each city separately. Analysis of variance with social class as independent variable, or in the case of dichotomous variables chi-square tests were performed. Of these demographic variables, working situation showed the strongest association with social class (table 3.3), and therefore working situation was included in the analysis of variance on dlass differences in the consumption of nutrients and food items. Next, variation of class differences in intake across cities was examined by analysis of variance of the whole sample with social class, city and working situation as main effects. Significant interaction effects of social class and city are reported in the text, as this result implies that class differences in intake vary berween the three cities.

\section{Results}

\section{Population characteristics}

Table 3.3 shows some background data for the three samples as a wholle and for each social class. In general, the women were about 36 years old, the majority had 2 or 3 children living at home, on average their children were about 8 years old, most of the women were autochthonous and about 40 to $50 \%$ of the women had a paid or unpaid job.

Especially in the samples of Maastricht and Aachen, higher-middle class women were older than middle and lower class women. In Maastricht lower class women had fewest children, while in Liège and Aachen these categories had the largest number of children. In general, working class mothers had the oldest children. In Liege a relarively large part of the lower class women were foreign. Liège has many enterprises which attracted many immigrants, especially from lraly. Of the 43 foreign women in the Belgian sample, 22 were Italian, 10 had another European nationality and 11 women originated from another continent. The proportion of working women differed considerably between classes. In Maastricht and Liège higher-middle class mothers more often had a job than middle and lower class mothers. 
Table 3.3

Population characteristics of the samples in Maastricht, Liège and Aachen by social class

\begin{tabular}{|c|c|c|c|c|}
\hline variables & total population & $\begin{array}{l}\text { social cla } \\
\text { lower }\end{array}$ & middle & higher-middle \\
\hline \multicolumn{5}{|l|}{ Maastricht } \\
\hline age of women (years) & $36.6[5.4]$ & $34.5[5.6]$ & $37.3\lceil 5.11$ & $39.1[4.1]$ \\
\hline number of children & $2.1[0: 8]$ & $1.9[0.7]$ & $2.2[0,8]$ & $2.4[0.8]$ \\
\hline age of children (years) & $8.0[3.6]$ & $8.4[3.5]$ & $8.2[3: 8]$ & $7.2|3.5|$ \\
\hline Dutch nationality ( $\%)$ & 99.0 & 99.2 & 99.1 & 98.6 \\
\hline working women $(\%)$ & 47.7 & 29.2 & 53.2 & 69.9 \\
\hline \multicolumn{5}{|l|}{ Liêge } \\
\hline age of women (years) & $36.4[5.4]$ & $36.0[6.0]$ & $36.4[15.31$ & $3711(4.1)$ \\
\hline number of children & $2.4[1.0]$ & $2.5[1.0]$ & $2.4[1,0]$ & $2.3[0.7]$ \\
\hline age of cliildren (vears) & $9: 4[4: 0]$ & $10.7[3: 9]$ & $8.9[3.9]$ & $7.8[3.4]$ \\
\hline Bolgian nationality $(\%)$ & 86.2 & 75.9 & 920 & 93.1. \\
\hline working women $(\%)$ & 49.5 & 31.3 & 52.2 & 80.4 \\
\hline \multicolumn{5}{|l|}{ Aachen } \\
\hline age of wamen (vears) & $35.7[5.1]$ & $33.3[5.4]$ & $35.4[1.7]$ & $36.7[4.1]$ \\
\hline number of children & $2.3[0.9]$ & $27[1.0]$ & $2.1[1.0]$ & $2,3[0.8]$ \\
\hline age of children (vears) & $7.5[3.6]$ & $8.0[4.0]$ & $7.4[3.7]$ & $7.5[3.2]$ \\
\hline German nationality $(\%)$ & 92.4 & 84.8 & 95.0 & 92.2 \\
\hline working wonen $(\%)$ & 41.7 & 42.4 & $38: 6$ & 449 \\
\hline
\end{tabular}

$[x, x]$ : standerd devitation

'analysis of variance or chi-square test, statistically significant class differance: $0.01<p<0.05_{*}$, $p<0.01$

\section{Class differences in fat intake}

Daily intake of energy and the consumption of dietary fat for the three social classes in Maastricht, Liège and Aachen is shown in table 3.4. As energy intake varied berween the classes, the intake of fat was not only expressed in absolute amounts, but also adjusted for energy intake. Women in Maastricht and Liège showed similar patterns with regard to class differences: lower class women 
consumed more energy and fat than middle and higher-middle class women. In Liège these differences were even larger than in Maastricht. In Aachen energy and far intake showed no class differences. Analysis of variance of all respondents rogether demonstrated that these class differences in fat intake varied significantly between the cities. In none of the three cities a class difference in the proportion of the energy intake derived from fat was apparent.

\section{Tablle 3.4}

Mean daily energy intake and dietary fat consumption unadjusted and adjusted for energy intake by social class

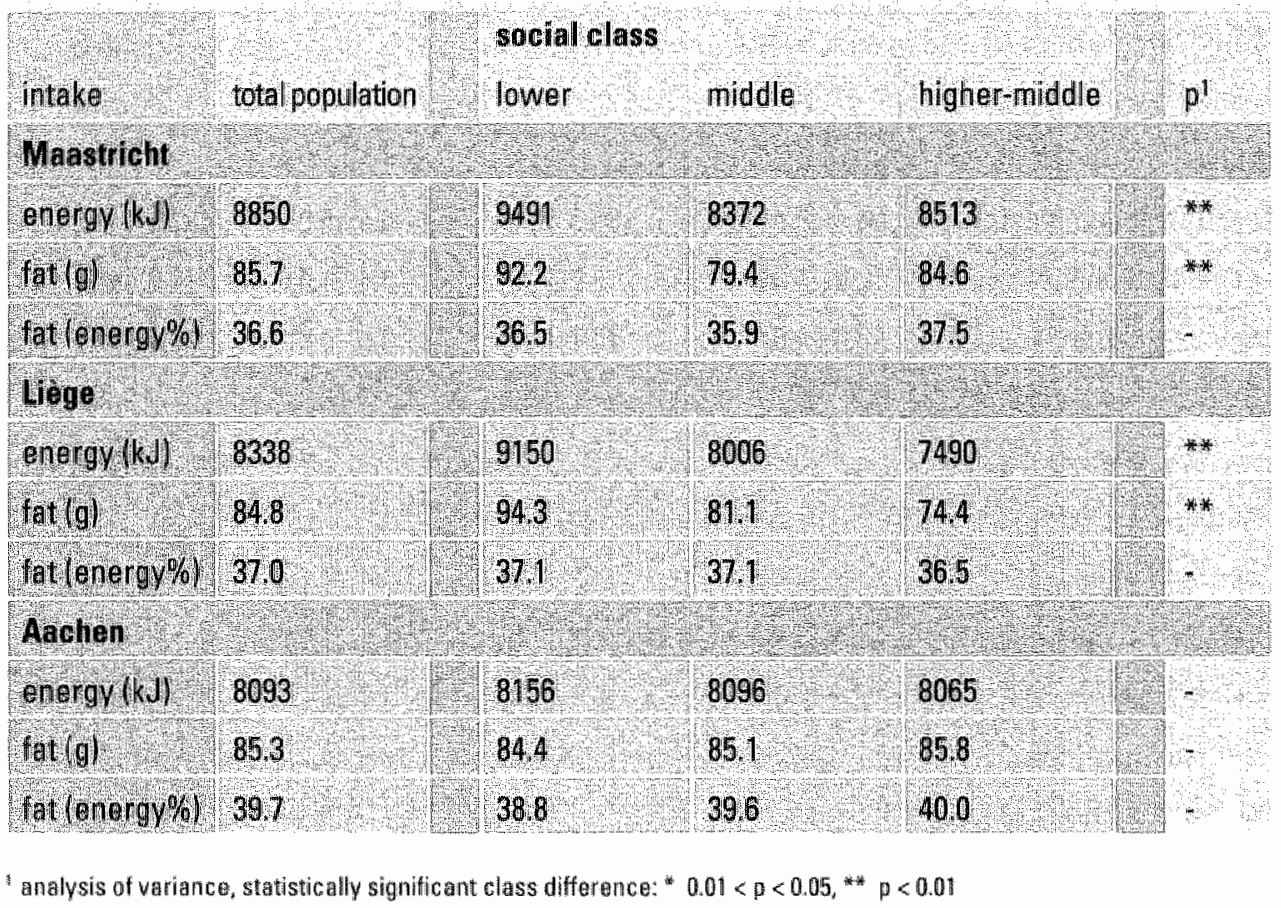

\section{Class differences in food items that contribute to fat intake}

To study the presence or absence of class differences in fat consumption in greater detail, food groups that contribute to the intake of far were analysed. For instance, the lower fat consumption by higher-middle class women in Maastricht and Liège might be explained by a lower intake of products that contain fat and/or by the selection of lean products. Also in Aachen, where no class differences in the intake of fat were found, higher-middle class women may derive this nutrient from different sources than working class women. 


\section{Table 3.5}

Mean daily consumption of food groups and the proportion of low-fat and meditim-fat food items by social class

\begin{tabular}{|c|c|c|c|c|c|}
\hline food items & total population & $\begin{array}{l}\text { social } \\
\text { lower }\end{array}$ & middle & higher-middle & $p^{1}$ \\
\hline Maastricht & & & & & \\
\hline meat products $\quad(\mathrm{g})$ & 112 & 122 & 109 & 99 & *.* \\
\hline low/nedium fat $(\%)$ & 73 & 69 & 75 & 76 & $* *$ \\
\hline milk prodicts & 295 & 298 & 281 & 311 & $\therefore$ \\
\hline low/medium-fat $(\%)$ & 67 & 62 & 72 & 66 & - \\
\hline cheese $(g)$ & 31 & 23 & 32 & 41 & **** \\
\hline low-at $(\%)$ & 10 & 14 & 10 & 5 & . \\
\hline oils and fats $\quad(g)$ & 45 & 49 & 43 & 40 & ** \\
\hline medium -tat $(\%)$ & 46 & 50 & 47 & 37 & * \\
\hline Liège & & t & man & (n) & the \\
\hline meat products (g) & 135 & 139 & 134 & 131 & - \\
\hline low/mediun-fat $1 \%$ ) & 82 & 81 & 83 & 85 & - \\
\hline milkproducts (g) & 337 & 399 & 298 & 302 & - \\
\hline low/medium-fat $(\%)$ & 48 & 39 & 53 & 58 & $* *$ \\
\hline cheese & 28 & 28 & 28 & 25 & - \\
\hline low-fat $(\%)$ & 22 & 26 & 21 & 16 & - \\
\hline oils and fats $\quad(1)$ & 40 & 47 & 39 & 30 & *** \\
\hline nediumplat $\%$ ) & 40 & 39 & 43 & 34 & $=$ \\
\hline Aachen & te & 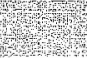 & & 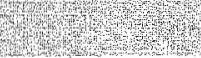 & 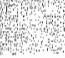 \\
\hline meat products $(g)$ & 81 & B6 & 89 & 71 & * \\
\hline low/medium-fat $(\%)$ & 72 & 68 & 74 & 71 & . \\
\hline milk products $(g)$ & 273 & 299 & 283 & 252 & - \\
\hline low/medium fat $(\%)$ & 30 & 39. & 30 & 27 & - \\
\hline cheese $\quad(g)$ & 24 & 15 & 24 & 28 & ** \\
\hline low-fat $(\%)$ & 9 & 18 & 9 & 5 & **** \\
\hline oils and tats $(\mathrm{g})$ & 41 & 43 & 42 & 39 & - \\
\hline medium - fat (\%) & 14 & 17 & 13 & 13 & - \\
\hline
\end{tabular}


The daily consumption of meat and mear products, milk and milk producrs, cheese and edible oils and fats are presented for each social class and each city in table 3.5. In addition, the contribution of products that contain less fat is reported for each food group. In general, class differences in these food groups were in line with the class difference in far intake. If class differences in food consumption were apparent, higher-middle class women consumed smaller amounts and chose more often low-fat products compared to working class women. In Maastricht and Aachen these women consumed less meat and Dutch higher-middle class women chose more often medium-and low-fat meat products. In Liège they chose more often low-and medium-fat milk products, and in Maastricht and Liège they consumed oils and fats in smaller quantities. The most obvious exception was the consumption of cheese, which was highest in the higher-middle social classes in Maastricht and Aachen. In Aachen higher-middlle class women chose less often low-fat cheese and in Mastricht they consumed less often medium-fat oils and fats. According to the analysis across cities, class differences in the proportion of low- and medium-fat milk products and in the daily consumption of cheese varied between the three cities.

\section{Class differences in fibre intake}

Table 3.6 shows the figures for fibre intake. The absolute intake of fibre in the three cities did not vary according to social class. Yet, in Maastricht and Liège a class difference in the amount of fibre for each ingested unit of energy was found: highermiddle class women consumed more fibre per megajoule compared to middle and lower class women. The women in Aachen showed a comparable tendency.

\section{Table 3.6}

Mean fibre consumption unadjusted and adjusted for energy intake by sacial class

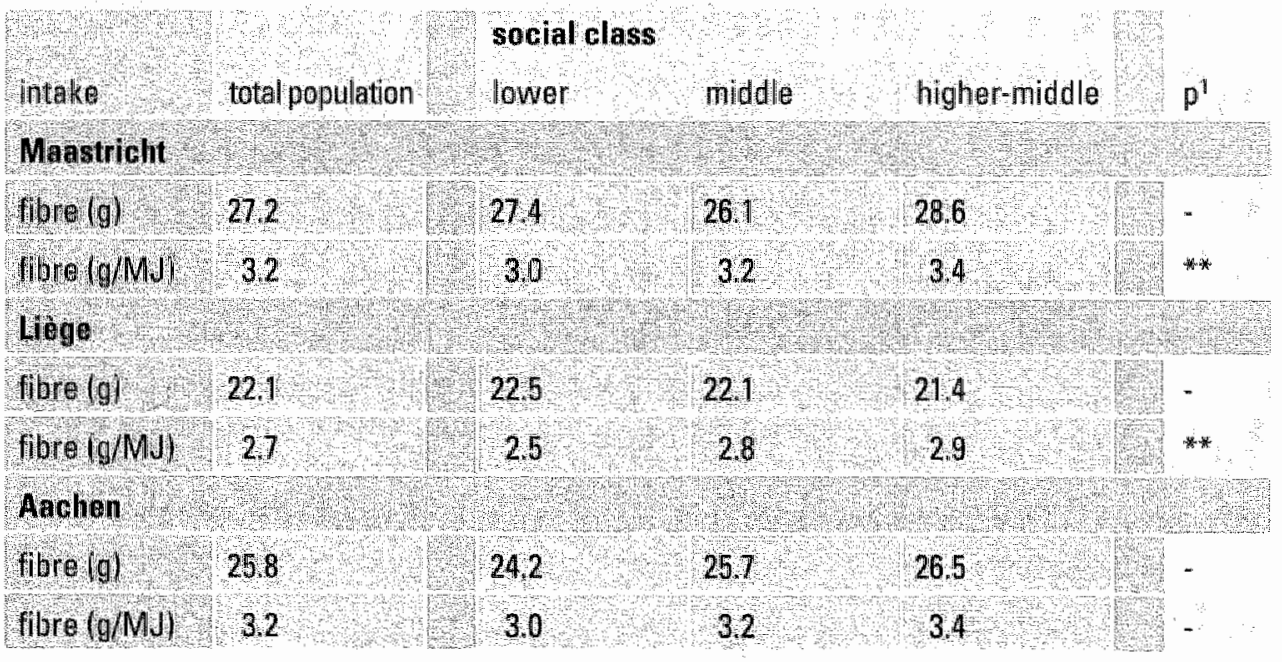

"analysis of variance, statistically significant class difference $e^{*} 0.01<p<0.05_{0}^{* *} p<0.01$ 


\section{Table 3.7}

Mean daily consumption of food groups and the proportion of high-fibre food items by social class

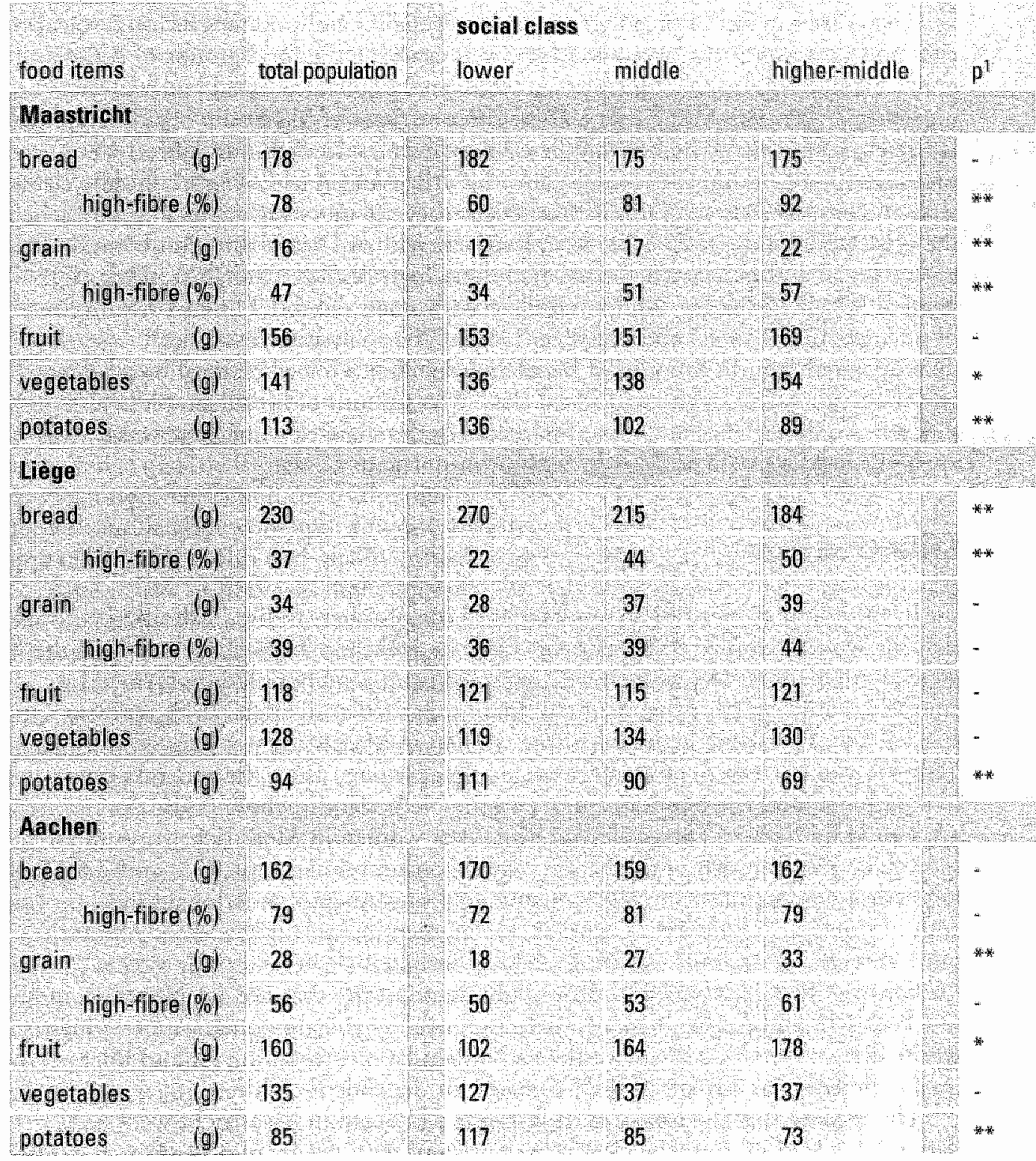

analysis of variance, statistically significiant class difference: $* 0.01<p<0.05_{1}^{* *} p<0.01$ 


\section{Class differences in food items that contribute to fibre intake}

The consumption of bread, grain, fruit, vegetables and potatoes for each social lass and each city is presenred in table 3.7. Regarding the food groups of bread and grain, women still can choose between white and wholemeal bread and berween unpolished rice and polished rice. Therefore, the share of high-fibre bread and grain is reported. In general, higher-middle class. women consumed more fibre-rich products than working class wornen. In Maastricht and Aachen higher-middle class women consumed more grain, in Mastricht they are more vegetables and in Aachen they consumed more fruit. Moreower, in Maastricht and Liege they chose more often brown bread and in Maastricht they had more high-fibre grain than working class women. On the contrary, higher-middle class women showed a lower consumption of potatoes (in all cities) and bread (in Liège). The analyses across cities

demonstrated that the amount of bread and the choice for wholemeal bread showed an interaction effect of city and social class. The amount of bread showed a class difference only in Liege and class differences in the share of wholemeal bread were appatent in Mastricht and Liège, but not in Aachen.

\section{Discussion}

In the comparison of these results with those of other studies, it should be noted that the women studied in Maastricht, Liege and Aachen formed a selection of the general population. The women were sampled from a subpopulation, formed by complete families with dependent children, in particular districts. In the present study $37 \%$ of total energy intake of the women in Mastricht was derived from fat. This was slightly lower compared to a sample of women from the general population in a national food consumption survey in the Necherlands, whose fat intake accounted for $41 \%$ of energy intake. Moreover, women in Mastricht consumed more fibre than women in the national food consumption sample $(3.2$ and $2.6 \mathrm{~g} / \mathrm{MJ}$ respectively) (Hulshof $e t a l, 1991$ ). Compared to women of a national food. consumption survey in West Germany, the women in Aachen consumed about the same amount of fat, but more fibre (median in national survey is $22 \mathrm{~g}$ versus $25 \mathrm{~g}$ in Aachen) (Heseker et al, 1992). This might demonstrate that the samples of women in Marstricht and Aachen formed a selection of the general population of women, whose diet was more in line with the recommendations regarding fat and fibre intake, probably as a result of their concern for dependent children.

The finding that the intake of milk, meat and bread in Maastricht were patterned according to social class, was consistent with results of other Dutch studies that showed a larger consumption of lean milk and meat products and a higher consumption of brown bread in the higher-middle social classes (Hulshof et al, 
1991; Kromhour, Doornbos \& Hoffmans, 1988). The quantity of meat, cheese, grain, and potatoes in Aachen showed similar class differences as those observed in the West German survey. Only the consumption of fruit did not differ between classes in the national food consumption survey, while in Aachen a class difference was apparent (Heseker et al., 1992).

With respect to class differences in far consumption, higher-middle class women in Maastricht and Liège consumed less fat compared to working class women, whereas in Aachen fat intake showed no class difference. Yet, compared to working class women, higher-middle class women did not always consume less foods, that contributed to fat, and less high-fat products. Of course, health aspects are not the only important consideration when women choose food. Other incentives include for instance food preferences, quality, convenience and costs (Furst, Connors, Bisogni, Sobal \& Winter-Falk, 1996; Steproe, Pollard \& Wardle, 1995). Possibly, in the selection of some foods like meat diminishing the intake of fat for health reasons may be an important considerarion, while in the case of other foods like cheese aspects of qualiry may be of overriding importance. Similarly, higher-middle class women may try to limit the amount of oil and fat they use in order to reduce fat intake, however, if they use it, they may prefer butrer to low-far margarine because of its better quality. If these assumptions would be true, the results mentioned above may be interpreted conform to the theory of Elias (1982) and Bourdieu (1989): higher-middle class women distinguish themselves from working class women by appraising both thealth and quality in their choice of food.

Total intake of fibre was highest among the higher-middle class women, although this tendency in Aachen was not significant. In Maastricht and Aachen most dass differences in food consumption were in line with this result. However, inspection of the class differences in food groups in Liège suggested that the larger intake of fibre among the higher-middle class women via grain and brown bread neutralised their smaller fibre intake via bread and potatoes. Probably higher-middle class women consumed more of other fibre-rich food items, that were not included in our selection of foodstuffs, like pasta. Also these class patterns in fibre intake seem to correspond with the findings of Ellias (1982) and Bourdieu (1989): higher-middle class people prefer 'modern' eating habits like wholemeal bread rather than white and more fruit and (raw) vegetables than previously, whereas lower class people favour traditional foods like potatoes and white bread. Van Otterloo and Van Ogtrop (1989) described that Dutch working class women viewed white bread and mear as luxuries, which their parents could afford only now and then when they were young. As these women presently could purchase these foods each day, they particularly preferred these foods to brown bread and pulses, which they often got to eat in their youth.

Of course, this interpretation of the data is not conclusive. Future studies might focus on trends in consumption and/or on the different considerations that may underlie the selection of food, like preferences, costs and quality besides health, in order to test the hypotheses regarding class differences based on the theories of Elias 
and Bourdieu.

With respect to cultural variation of class differences in fat and fibre intake, tables 4 to 7 indicate that class differences were rather uniform across the cities. The overall analysis of variance confirmed this impression. Of the 15 food groups studied only 4 food groups showed a significant interaction effect of social class and city, namely cheese, bread, and the preference for brown bread and lean milk products, of which only the choice for lean milk products showed contrasting class differences across the cities. These findings support the view that new food habits generally are uniform across the cities.

With regard to cultural differences in the intake of fat and fibre, the same analysis showed that the three cities did not vary in fat intake, but that they differed in fibre intake. In general, the women in Maastricht consumed more fibre, both in absolute amounts and relative to energy intake, than the women in Aachen and Liège. Moreover, the intake of all food groups (except milk products) differed significantly between the cities. Thus, cultural context was obvious, when the absolute daily intake of products was taken into account. For instance, class differences in meat consumption were uniform across the towns: higher-middle class women consumed less meat than working class women. Yet, as the three cities showed large differences in toral meat consumption, higher-middle class women in Liège reported a higher daily intake of meat than lower class women in Maastricht, and higher-middle class women in Maastricht consumed more meat than working class women in Aachen.

Finally, class differences in eating habits were less pronounced in Aachen than in the other cities. This might be caused by the selection of districts in Aachen, that appeared to be less homogeneous according to social class. It could be that people in these heterogeneous districts had more contacts with people of different socioeconomical backgrounds, and shops in these districts may have adapted their assortment to a wider public. As a consequence, class differences in dietary habits may be smaller than in homogeneous areas.

In general, the suggestion that the diet of higher-middle class women is more in accordance with the dietary recommendations than the diet of working class women wats confirmed for the intake of fat and fibre in Maastricht and Liège. The fact that no class differences were found for the intake of dietary fat in Aachen, while contrasting class differences were apparent in the consumption of food groups like mear and cheese, illustrates that studies of food consumption patterns on the nutrient level may reveal interesting patterns. Moreover, also in Maastricht and Liège some food groups showed contrasting results with the overall intake of fat and fibre. This implies that health promotion campaigns, aimed at a decrease or increase in the consumption of specific nutrients, should translate their tecommendations to the level of food items. Consequently these recommendations may vary for different subpopulations. 


\section{References}

Bausch-Goldbohm, R.A., Van Den Brandt, P.A., Van 't Veer, P., Sturmans, F. \& Hermus, R.J.J.

(1988). Results of the methodological study for the design of a simplified, selfadministered questionnaire. In; E. Riboli \& R. Saracci (Eds.), Diet, hormones and cancer" methodological isues for prospectite studies. IARC Technical Report No. 4 (pp. 79-89). Lyon: International Agency for Research on Cancer.

Block, G.

(1982). A review of walidations of dietary assessment merhods. American Jowmal of Epidemiology 115, 492-505.

Bourdieu, P.

(1989). Distinction. A social critique of the judgement of taste. London. Routledge \&

Kegan Paul. [Originally published in French: Bourdiew, P. (1979). La distinction.

Critique sociale du jugement. Paris: Les Editions de Minuit.]

Calnan, $M$.

(1990). Food and health: a comparison of beliefs and practices in middle-class and working-class households. In: S. Cunningham-Burley \& N.P. McKeganey (Eds.), Readings in medical sociology (pp. 9-36). London: Routledge.

Cameron, M.E. \& Van Staweren, W.A.

(1988). Manual on methodology for food consumption studies. Oxford: University Press. Charles, N. \& Kerr, M:

(1986). Issues of responsibility and control in the feeding of families. In: $S$. Rodmell \& A. Watt (Eds.), The politios of health education: raising the issues (pp. 57-75). London: Routledge.

Charles, N. \& Kerr, M.

(1987). Just the way it is: gender and age differences in family food cousumption. In:

J. Brannen \& G. Wilson (Eds.), Give and take in families. Studies in resource distribution (pp. 154-175). London: Allen \& Unwin.

Charles, N. \& Kerr, M.

(1988). Women, food and families. Manchester: University Press.

Davey Smith, G., Bartley, M. \& Blane, D.

(1990). The Black report on socioeconomic inequalities in health 10 years on. British Medical Joumal, 301, 373-377.

De Craene, I., De Backer, G., Komitzer, M., De Henauw, S., Bara, L., Rosseneu, M. \& Vercaemst, $R$.

(1990). Determinants of far consumption in a general population. Rewte d'Epidémiologie et de Santé Publique, 38, 539-543. 
Elias, N.

(1982). Het civilisatieproces. Soctogenetische en psychogenetische onderzoekingen. Utrechn: Spectrum. (Originaly published in German: Elias, N. (1939). Uber den Prozess der Zivilisation. Soziogenetische und Psychogenerische Untersuchungen. Bazel: Haus: zum Falken.]

Eurostat Statistical Office of the European Communities

(1994). Basistatistieken van de Gemeenshap [Basic statistics of the European Communities. Luxembourg: Office for Official Publications of the European Communities.

Eurostat Statistical Office of the European Communities

(1995). Demograpbic statistics 1995. Luxembourg: Office for Official Publications of the European Commanities.

Furst, T., Connors, M., Bisogni, C.A., Sobal J. \& Winter-Falk, L.

(1996). Food choice: a conceptual model of the process. Appetite, 26, 247-266.

Goldbohm, R.A., Van "t Veer, P., Van Den Brandt, P.A., Van 't Hof, M.A., Brants, H.A.M., Sturmans, E. \& Hermus, R.J.J.

(1993). Reproducibility of a food frequency questionnaire and stability of dietary habits determined from five annually repeated measurements. In: P.A. Van Den Brandt \& R.A. Bausch-Goldbohm, A prospective cohont stidy on diet and cancer in the Netherlands. Design, conduct, analysis and first results after 3.3 years of follow up (thesis, pp. 47-58). Maastricht: University Press.

Goldbohm, R.A., Van Den Brandt, P.A., Brants, H.A.M., Van "t Veer, P., Al, M., Sturmans, F. 8 Hermus, R.J.J.

(1994). Validarion of a dietary questionnaire used in a large-scale prospective cohort study on diet and cancer. Exropean Journal of Clinical Nutrition, 48, 253-265.

Hautrast, J.G.A.J.

(1993). The future of nutrition in Europe. European Joumal of Clinical Nutrition, 47, Suppl. 1, S96-\$100.

Helmert, U., Shea, S., Hernat, B. \& Greiser, E.

(1990). Relationship of social class characteristics and risk factors for coronary heart disease in West Germany, Public Healb, 104,399-416.

Helmert, U., Mielck, A. \& Classen, E.

(1992). Social inequities in cardiovascular disease risk factors in East and West Germany. Social Science and Medicine, 35, 1283-1292.

Heselker, H., Adoll, T., Eberhardt, W., Hartmann, S., Herwig, A., Kübler, W., Matiaske, B., Moch, K.J., Schneider, R. \& Zipp, A.

(1992). Lebensmittel- und Nabrstoffaufname Eruachsener in der Bundesrepublik

Dentrobland fFood and nutrient intake of adults in the Federal Republic of

Germany]. Niederkleen: Wissenschafilicher Fachverlag Dr. Fleck.

Heseker, B. \& Heseker, H.

(1993). Näbrstoffe in Lebewmituln. Die Große Energie- und Nabrwertabelle [Nutrients in foodstuffs. The large energy and nutritional value table]. Frankfurt am Main: Umschau. 
Hulshof, K.FA.M, Löwik, M.R.H., Kok, F.J., Wedel, M., Brants, H.A.M., Hermus, R.J.J. \& Ten Hoor, $\mathrm{F}$.

(1991). Diet and other life-style factors in high and low socio-economic groups

(Dutch Nutrition Surveillance System). Eutropean fournal of Clinical Nutriton, 45 , $441-450$.

Hunter, D.J., Rimm, E.B., Sacks, F.M., Stampfer, M.J., Colditz, G.A., Litin, L.B. \&. Willent, W.C.

(1992). Comparison of measures of fatty acid intake by subcutaneous fat aspirate, food frequency questionnaire, and diet records in a free-living population of US men. American Journal of Epidemiology, 135, 418-427.

James, W.P.T., Ferro-Luzzi, A., Isaksson, B. \& Szostak, W.B.

(1988). Healthy nutrition. Preventing nutriton-related diseases in Europe. Copenhagen: Joosten, J.

WHO Regional Publications, European Series No. 24.

(1995). De inuloed van klasse, status en burgerschap op subjectieve gezondhetd [The influence of class, status and citizenship on subjective health] (thesis). Maastricht: University Press.

Kirchgässler, K.U.

(1990). Health and social inequities in the Federal Republic of Germany. Sacial

Science and Medicine, 31, 249-256.

Kromhout, D., Doornbos, G. \& Hoffmans, M.D.A.E.

(1988). Voedsellkeuze, leefwijze en sterfte in relatie tot opleiding [Food choice,

lifestyle and mortality in relation to education]. Trjdschrift Sociale Gezondherdszorg 66, 345-348.

Kromhout, D., Keys, A., Aravanis, C., Buzina, R., Fidanza, F, Simona, G., Jansen, A., Menotti, A., Nedeljkovic, S., Pekkarinen, M., Simic, B.S. \& Toshima, H.

(1989). Food consumption patterns in the 1960s in seven countries. American Joumal of Clinical Nutrition, 49,889-894.

Kunst, A.E. \& Mackenbach, J.P.

(1994). The size of mortality differences associated with educational level in mine industrialized countries. American Journal of Public Health, 84, 932-937.

Lagasse, R. Humblet, P.C., Lenaerts, A., Godin, I. \& Moens, G.F.G.

(1990). Health and social inequities in Belgium. Social Science and Medicine, 31 . $237-248$.

Lahelma, E. \& Valkonen, T.

(1990). Heath and social inequities in Finland and elsewhere. Social Science and Medicine, 31, 257-265.

Lepage, $\mathrm{Y}$.

(1985). Recent dietary trends in Belgium: socio-economic aspects. In: J.M. Diehl \& C. Leitzmann (Eds.), Measurement and determinants of food babits and food preferwees: report of an EC workshop, Giessen, West-Germany. Euro-Nut neport 7. (pp. 109-116). Wageningen: Stichting Nederlands Instituut voor de Voeding. 
Luschen, G. \& Cockerham, W.C.

1995. Health and Social Stratifcation. In: G. Luschen, Wockeman, J. Van Der Zee, F. Sewths, J. Diederiks, M.G. Ferrando, A dWoutaud, R. Peeters, T. Abel \& S.

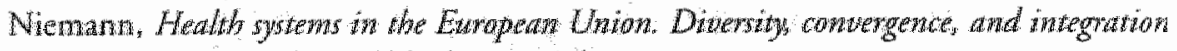
(pp. 89- 100). Munchen: Oldenbourg Verlag.

Mackenbach, ].

(1992). Socio-conomic health differences in the Necherlands: a review of recent empiricat findings. Socual Scince and Medicine, 34, 213-226.

Menmell, S. Murcort, A \& Van Orerloo, A.H.

(1992). The sociology of food: enting diet and cultwe. London: Sage Publicatrons. Murcotr, $A$.

(1983). Cooking and the cooked: a note on the domestic preparation of meals. In: A. Murcotr (Ed), The sociology of food and exing. Essays on the social signifiance of food (pp. 178-185). Aldershot: Gower.

Murcont, A.

(1985). The sudy of food habits: objectives, methods and conseguences. In: J.M.

Died \& C. Leitamann (Eds.), Medsument and determinants of food habits and food preferences report of an EC workshop, Giesen, West-Germany. Euro-Mut report 7 (pp. 13-27). Wageningen: Stichting Nederlands Institut voor de Voeding.

Murcott, A.

(1993). Talking of good food: an empirical study of women's conceptualizations.

Food and Foodways, 5, 305-318.

Nevo Tabel

(1993). Nederlandse zoedingsmiddelentabel [Dutch food composition table]. Den

Nubel

Haag: Voorlichringsbureau voor de Voeding.

(1992). Belgische voedingsmiddelentabel [Belgian food composition table]. Brussels: Nubel.

PH. R. Peters, T.J. \& Robling, M.R.

(1995). Social class and prevencive health behaviour: a Brinish example. Jowmal of Epidemiology and Commowity Halth. 49, 28-32.

Prătctalı, R. $R$.

(1995). Social class and food in the Nordic countries. Emahmungs-Umschan, 42 , Beiher, $16-20$.

Pràttailia, R, Berg, M.A. \& Puska, P.

(1992). Diminishing or increasing contrasts? Social class variation in Finnish food consumption patterns, 1979-1990. European Jowmal of Clinical Nutrition, 46, 279 287.

Steptoc, A. Pollard, T.M. \& Wardle, J.

(1995). Developmen of a measure of the motives underlying the selection of food:

the food choice questionnaire. Appetite, 25, 267-284.

Townsend, P., Davidson, N. \& Whitehead, M.

(1988). Inequalities in Healh. London: Penguin. 
Van Berkel-Van Schaik, A.B. \& Tax, B.

(1990). Natr en standardoperationalisatie wan sociad econowische statas woor epidemiologisch en sociad-medisch onderzoel [Towards a standardised. operationalisation of socio-economic status for epidemiologicall and social-medical research]. Rijswijk: Ministerie van Welzijn, Volksgezondheid en Cultuur.

Van Otterloo, A.H.

(1990). Eten en eetlast in Nederland (1840-1990). Een historish-sociologiche studue [Food and appetite in the Netherlands (1840-1990). A historic-sociological study"]. Amsterdam: Bert Bakker.

Van Otterloo, A.H. \& Van Ogtrop, J.

(1989). Het regime van veel, vet en zoet: praten met moeders over voeding en guzondheid [The regime of plenty, fat and sweet: talking with mothers on food and health]. Amsterdam: VU Uitgeverij.

Willett, W.C.

(1994). Diet and health: what should we eat? Science, 264, 532-537.

Willetr, W.C., Sampson, L., Stampfer, M.J., Rosner, B., Bain, C., Witschi, J., Hennekens, C.H. \& Speizer, F.E.

(1985). Reproducibility and validity of a semiquantitative food frequency questionnaire. American Joumal of Epidemiology, 122, 51-65.

Winkleby, M.A. Jatulis, D.E., Frank, E. \& Fortmann, S.P.

(1992). Socioeconomic status and health: how education, income, and occupation contribute to risk factors for cardiovascular disease. American Jownal of Public Heath. $82,816-820$. 


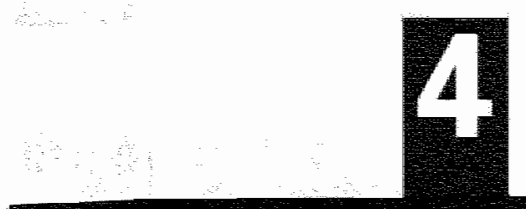

Christianne L. H. Hupkens, Ronald A. Knibbe and Maria J. Drop

Social class differences in food consumption:

the explanatory value of

\section{permissiveness and \\ health and cost considerations}
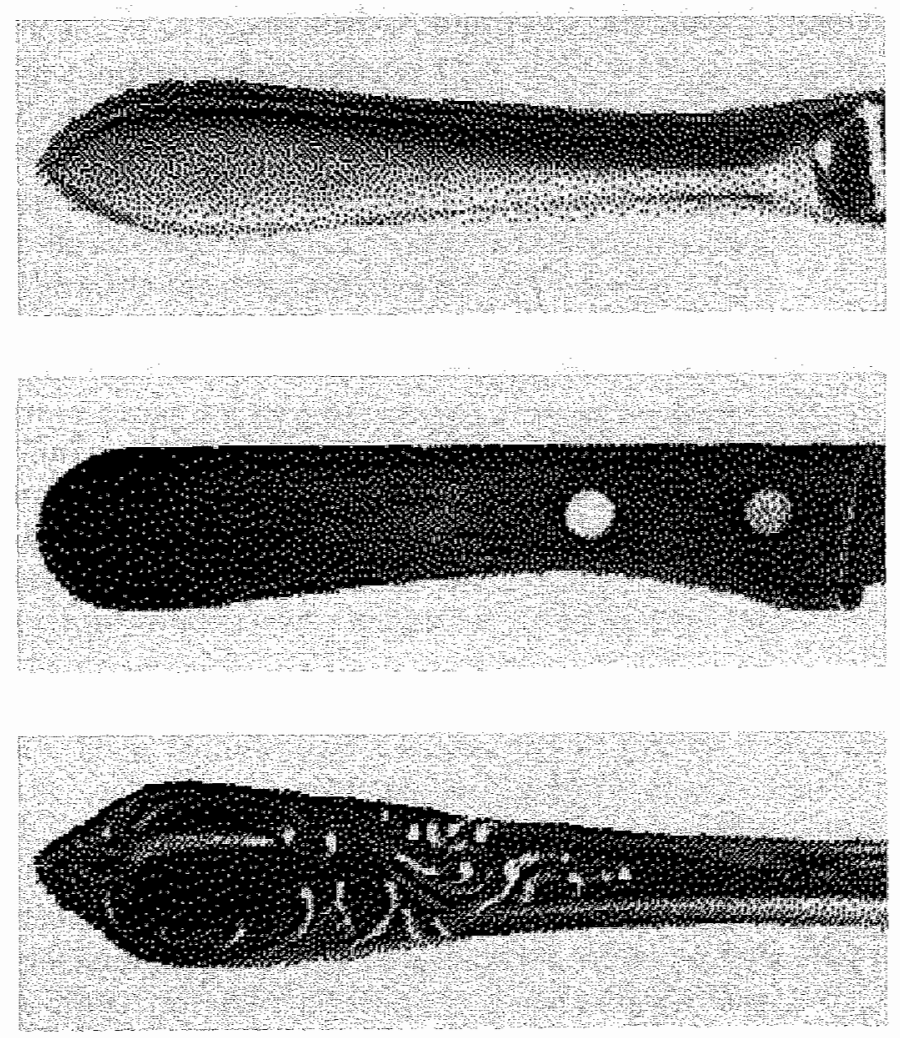


\section{Abstract}

In general higher-middle class people appear to have healthier diets than working class people. Considerations that underlie the choice of foodstuffs may explain this class difference in eating habits. Qualitative studies on food beliefs show that working class mothers consider health less frequently in their choice of food, while they take the preferences of family members and expenses more often into account than their higher-middle class counterparts. In this paper quantitative survey dara are used to explore the explanatory power of these factors. Data were analysed of 849 women, living with a partner and at least one child, in three European cities: Maastricht (the Netherlands), Liège (Belgium) and Aachen (Germany).

Regarding food consumption, most but not all class differences were in line with the expectations. Class differences in the food choice considerations corresponded with the findings of other studies. Higher-middle class mothers were less permissive and they considered health more often and costs less often than working class mothers. However, regression analyses indicated that these considerations scarcely explained class patterns in food consumption. As the results in the three cities were consistent, these conclusions seem to be valid for the large majority of the families living in Maastricht, Liège and Aachen. 


\section{Introduction}

Many studies in western countries have reported social inequalities in food consumption. Social epidemiological and qualitative studies on food consumption patterns showed that diets in the higher social classes are more often in line with dietary recommendations than those in the working classes (Lepage, 1985; Charles \& Kerr, 1988; Kromhout, Doornbos \& Hoffmans, 1988; Calnan, 1990; De Craene, De Backer, Kornitzer et al., 1990; Hulshof, Löwik, Kok et al, 1991; Mennell, Murcott \& Van Otterloo, 1992; Prättälä, Berg \& Puska, 1992; Heseker, Adolf, Eberhardt et al, 1992; Prättälä, 1995; Ministry of Agriculture, Fisheries and Food, 1995). A study on dietary trends between 1965 and $199 \mathrm{l}$ in the United States showed that especially higher class people improved their diet according to the dietary guidelines (Popkin, Siega-Riz \& Haines, 1996). The study reported here explores class differences in food consumption of women and aims to explain these class differences. The sample consists of women, living with a partner and taking care of schoolgoing children in three European cities: Maastricht (the Nerherlands), Liège (Walloon part of Belgium) and Aachen (Germany).

The study focuses on mothers, as they usually provide food for their family, even when they are in paid employment (Murcott, 1986; Blaxter \& Paterson, 1983). Generally mothers deal with contrasting intentions in their choice of food for their family. On the one hand, to show their lowing care and to provide peaceful dinners, they want to provide dishes that their partner and children appreciate. On the other hand, they shoulder the responsibility for a healthy diet. In the industrialised countries especially during the last few decades a healthy dier and a tasty dier have seemed to diverge. Before the economic expansion of the 1960 s a healthy diet consisted of a substantial meal preferably with a large piece of meat to provide enough energy to perform the daily tasks. For large caregories of the population such a diet was a luxury, which they could not afford each day. Since the 1960s more families could afford these former luxuries and the supply of food items increased enormously (Mennell, Murcott \& Van Otterloo, 1992). Consequently, worries about too little food have been replaced by anxiety for the consequences of an abundant diet. Accordingly, health recommendations regarding food not only became more complex, but they also came into conflict with the general preference for sweet and fat food.

Most studies on class differences in food choice considerations (or food beliefs) have been qualitarive studies. These studies confirmed that there is a class difference in the extent to which mothers take health, costs and the taste preferences of their family into account when buying and preparing food. Van Otterloo and Van Ogtrop (1989), DeVault (1991), Charles and Kerr (1988) and Calnan (1990) showed that higher-middle class mothers mentioned the 'goodness' or health value of foods more often as their primary consideration, while lower class mothers mentioned the cost of food and the preferences of partner and children more often as important 
considerations in their choice of food. Of course, this does not mean that working class mothers were not interested in healthy food. However, especially the studies of Calnan (1990) and DeVault (1991) showed that because of their more limited budger, lower cllass mothers were more often forced to take costs into account. Moreover, compared to mothers who were better off, mothers on a tight budget were less able to neglect the taste preferences of their family members, because they could not afford to buy food that might be rejected by their family.

A study of food systems within nuclear families living in London showed that women often looked after their own preferences as well as those of the rest of the family if they had enough money to spend on food, while in the poorest households women met the preferences of their family, but not their own (Wilson, 1989). This corresponds with the conclusions of the other qualitative studies (Charles \& Kerr, 1988; Calnan, 1990; Van Otterloo \& Van Ogrrop, 1989; DeVault, 1991) that lower class mothers rook the food preferences of their husband and children more often into consideration than mothers of the higher social strata.

Yet, despite the qualities of these studies, there are rwo important limitations with regard to the conclusions these studies allow: (1) the statistical generalisation and (2) the explanatory value of food beliefs for class differences in food consumption. Concerning the statistical generalisation, all studies (except that of Charles and Kerr (1988)) used small samples. Moreover, most samples were selected on the basis of theoretical interests and often convenience samples were used, like women attending a health care centre or participating in another survey. This does not diminish the theoretical relevance; however, it remains unclear to what extent the class differences reported in these studies can be statistically generalised to the population at large. In a strong plea for the active development of a multidisciplinary approach to the study of food habits, Murcott (1985) stressed that the ethnographic and the survey method should complement each other to increase our understanding of food habits and preferences. The present study allows an assessment to be made of the extent to which these class differences in food choice considerations are replicated in a larger and randomly selected sample, using the survey method. An additional point is that, whereas studies on food beliefs are predominantly British, the present study has been conducted in three countries on the European continent.

The other limitation of most studies on food beliefs is that the influence of these beliefs on the selection of food is exemplified, but not systematically studied, for a range of foods. Only two studies described food consumption patterns. Charles and Kerr (1988) reported that higher-middle class families consumed more foods that were highly regarded as being good for health like fresh fruit, milk, cereals and wholemeal bread, while working class families ate more white bread. Calnan (1990) reported similar results based on his study on food purchases in working class and middle class households. These two studies analysed both class patterns in food beliefs and in food consumption, but unfortunately these topics were analysed separately and the relation between food beliefs and food choice was not examined. 
Therefore, the extent to which these considerations explain class differences in food consumption is still not clear. In the present study the explanatory value of food considerations is systematically examined for the consumption of a wide range of food items and snacks.

Hence, the present study aims to bridge the gap between the large scale population studies, referred to in the first paragraph, showing class differences in food consumption, and the mainly qualitative sociological studies on class differences in food beliefs. To this end the present study focuses on three topics: class differences in food consumption, class differences in food considerations, and the extent to which food considerations explain class differences in consumption.

For the analysis of class differences in food consumption, food items and snacks were selected that contribute largely to the intake of fat and fibre. These nutrients are most likely associated with healthy eating, as health promotion campaigns in the three countries have recommended people to consume less fat and more fibre for several years. We hypothesise that women of the higher-middle social classes consume less snacks and foods that contribute primarily to the intake of fat, and more foods that contain fibre than working class women. With respect to the food considerations, we expect that, in line with the outcomes of the studies mentioned before, higher-middle class mothers consider health more often in their choice of food, while lower class mothers take costs and the food preferences of their family more often into account. We subsequently analyse whether class differences in these considerations explain class differences in food consumption. Finally, we examine whether the associations between social class, considerations and food consumption are similar or different in the three cities.

\section{Data and Methods}

\section{Survey}

Data on dietary and eating habits were collected from 849 women in Maastricht $(\mathrm{N}=304)$, Liège $(\mathrm{N}=316)$ and Aachen $(\mathrm{N}=229)$ between November 1993 and February 1994, except for the Christmas period between 23 December and 9 January. The inclusion criteria were: (i) having a family with at least one child aged 4-14 years who lives at home, and (ii) living together with a male partner, as we were interested in complete families.

In each ciry working class and higher-middle class districts, populated by families with school-going children, were selected in order to reach enough mothers of working class and middle class backgrounds. The selection of these districts was based on demographic data (if available), and on the advice of a municipal official. In randomly selected streets in these districts trained female interviewers, students and graduates of the Universities of Maastricht, Liège and Aachen, approached each address. If families met the inclusion criteria, the interviewers explained how to 
complere the questionnaire. In addition, they made an appointment with the woman to collect the questionnaire about one week later at her home.

To obtain dara about the sampling procedure and the non-response, the interviewers kept accounts of all addresses they contacted during the distribution and collection of the questionnaires. The response rate was highest in Maastricht $(79 \%)$ and Liege $(78 \%)$ and lowest in Aachen $(67 \%)$. In all three cities the highermiddle class districts showed the highest response (Maastricht: $82 \%$ versus $76 \%$ in working class districts; Liège: $83 \%$ versus $73 \%$; Aachen: $73 \%$ versus $62 \%$ ). Nonresponse might possibly have been selective. For example, people with a low educational level may have problems with reading or writing and may refuse to collaborare for this reason. Consequently, results on class differences in the present study may be underestimared.

On average, the women were about 36 years old, the majority had 2 or 3 children living at home, their children were about 8 years old, only a few women belonged to ethnic minorities, and nearly half of the women had a paid or unpaid job. More detailed information on the composition of the samples in the three cities has been described elsewhere (Hupkens, Knibbe \& Drop, 1997).

\section{Questionnaire}

The questionnaire involved two parts: a food frequency questionnaire and a questionnaire on food pracrices. The semi-quantitative food frequency questionnaire was validated on the ability to rank subjects. This questionnaire was developed by Bausch-Goldbohm and Van Den Brandt for a large cohort study on diet and cancer in the Netherlands (Bausch-Goldbohm, Van Den Brandt, Van 'c Veer, Sturmans \& Hermus, 1988). Both the validity and the reproducibility were tested and appeared to be satisfactory (Goldbohm, Van Den Brandt, Brants et al., 1994; Goldbohm, Van 't Veer, Van Den Brandt et al., 1993). The original quesrionnaire was shortened in consultation with Bausch-Goldbohm, as some items were too extensive for the present study. The questionnaire on food practices was based on the results of a qualitative study of Van Otterloo and Van Ogtrop (1989). In collaboration with Van Otterloo, questions were formulated on, for example, meal patterns, the preparation of meals, food regimes, health considerations and preferences.

The translated food frequency questionnaire was checked by Belgian and German dietitians and researchers for three reasons: (i) to include common Belgian or German food items, (ii) to exclude typical Dutch foods, and (iii) to improve the description of the food items, for instance by using local wordings or local brands as examples. Morcover, in collaboration with Belgian and German social scientists questions about religion, educarion, occupation and working situation were formulated. Next, the translation of the questionnaire as a whole was checked by interviewers who lived in Liège or Aachen. Finally, in each city the questionnaire was tested in a pilot-study to check wherher the questions were comprehensible. As a result, the wording of a few questions was improved. 


\section{Data}

\section{Social class}

In general, social class is based on education, occupation and/or income. Studies that compared these three measures for their power to predict health behaviour reported that educational level is usually the most consistent and reliable measure (Pill, Peters \& Robling, 1995; Winkleby, Jatulis, Frank \& Fortmann, 1992). An expert committee in the Netherlands also recommended using educational level as a measure for social class in epidemiological and social medical studies (Van BerkelVan Schaik \& Tax, 1990). Compared to occupational status and income, educational level has the advantage that it can be applied to everybody, and that it is less susceptible to economic constraints.

Similarly, in the present study regression analyses of five possible indicators of social class on food consumption showed that the women's educational level was more consistently and strongly related to food consumption than educational level of their partners, occupational status of women and partners, and income source (a dichoromous variable: either salary or state benefit). Therefore the highest completed education of the women was used as an indicator of social class. According to the educational structure in each country, 7 educational levels were used in the Durch and German questionnaires and 6 levels in the Belgian version. Next, women were classified into 3 social classes: lower social class (i.e. elementary and lower vocational training for 12-16 years old), middle class, and higher-middle class (i.e. higher vocational training for $18+$ years old and university).

\section{Food consumption}

The average daily consumption of food items that are part of meals and snacks was analysed. Foods were selected that contributed considerably to the intake of fat and fibre. In the three cities on average more than $70 \%$ of the fat intake was derived from meat products, milk products, cheese and oil and fats and more than $75 \%$ of dietary fibre intake originated from bread, grain, fruir, vegetables and potatoes. As brown bread contains more fibre than white bread, the consumption of brown bread (including wholemeal bread) rather than total bread consumption was analysed. Three categories of snacks were chosen, namely chips, savoury snacks (like nuts and crisps) and sweets (including cakes and biscuits). The consumption of these foods was expressed in the average number of grams the women consumed per day.

\section{Considerations}

The morhers were asked how often they took health into account when they bought or prepared food. Answer possibilities ranged from never (1), sometimes (2), regularly (3), often (4) to always (5). Three questions were formulated to measure the extent to which the mothers considered expense when they bought bread, meat, and vegetables, with similat answer categories as indicated above. The reliability of the answers to these three questions was satisfying (Maastricht: Cronbach's alpha = 
0.85; Liège: alpha $=0.70$; Aachen: allpha $=0.81$ ), and thus these answers were combined to one five-point scale.

Permissivencss concerning food preferences was assessed by how strict the mothers controlled their children's consumption with respect to foods children prefer, but which their parents generally consider less healthy, namely white bread, sweet fillings, chips, dessert, sweets, sweet yoghurt drinks, and soft drinks. For each of these seven food groups mothers noted whether they restricted their children eating it or whether their children were allowed to eat it whenever they wanted. Th number of foods that the mothers restricted their children eating was used as a pros for permissiveness: the more foods the mothers restrict, the less they are inclined to indulge their children's preferences, and thus the less permissive they are.

\section{Analysis}

Analysis of variance was used to measure class differences in food consumption. In order to examine whether the three food choice considerations differed between social classes, correlation coefficients berween social class, permissiveness and considerations regarding health and expenses were examined. Finally, each food consumption variable was regressed on social class, permissiveness, and health and cost considerations. Two different methods of regression analyses were applied.

First, the food variables were regressed on social class. If social class showed a significant effect on food consumption, the three considerations were added to the regression equation in order to cxamine whether class differences in food consumption could be explained by these considerations. Secondly, we analysed whether the influence of the considerations on food consumption differed between the classes. To give an example (based on the study of DeVault (1991)), working class women who compare prices may buy less fruit compared to working class women who do not consider costs. On the other hand, higher-middle class women who economize may buy more fruit, particularly if it is on special offer than women of the same social class who do not consider expenses. A class difference in how cost considerations influence fruit consumption might be indicated by a significant interaction between social class and cost considerations. Therefore first-order interaction terms between the three considerations and social class were included in a stepwise regression analysis.

These analyses have been performed for all respondents together and for each ciry separately. The results for all respondents are presented in tables and interesting exceptions in the different cities are described in the text. 


\section{Results}

\section{Class differences in food consumption}

Table 4.1 shows that in almost all cases the expected class differences in food consumption were found. Regarding the consumption of foodstuffs that contribute to far, it appeared that higher-middle class women consumed less meat and mear products, less milk and milk products, and less edible oil and fats, but more cheese. With regard to the consumption of fibre-rich foods, higher-middle class women consumed less potatoes, but more brown bread, grain and slighrly more fruit and vegetables than lower class women. The consumption of snacks conformed to the expectation: higher-middle class women consumed less chips, savouries and sweets. The class patterns in food choice were similar in the three cities, but nor of the same magnitude. Generally, class differences were largest in Maastricht and smallest in Aachen.

\section{Table 4.1}

Mean daily consumption of food items that contribute to fat and fibre intake and snacks by social class

\begin{tabular}{|c|c|c|c|c|c|c|c|c|c|}
\hline & $\begin{array}{l}\text { total } \\
\text { popul }\end{array}$ & tion & $\begin{array}{l}\text { social } \\
\text { lower }\end{array}$ & class & middle & & higher & middle & \\
\hline od items (g/day) & mean & s.d. & mean & s.d & mean & s.d. & mean & s.d. & $p^{1}$ \\
\hline meat products & 113 & 58 & 126 & 64 & 113 & 54 & 97 & 53 & $* *$ \\
\hline milk products & 307 & 305 & 352 & 391 & 289 & 271 & 279 & 216 & *** \\
\hline eese & 28 & 25 & 25 & 28 & 28 & 23 & 32 & 22 & the \\
\hline oil and fats & 42 & 22 & 48 & 23 & 41 & 21 & 37 & 20 & **** \\
\hline brown bread & 107 & 83 & 86 & 83 & 112 & 85 & 124 & 72 & $*$ \\
\hline grain & 26 & 30 & 20 & 32 & 28 & 30 & 31 & 27 & ** \\
\hline potatoes. & 99 & 69 & 125 & 86 & 92 & 58 & 77 & 47 & ** \\
\hline ruit and vegetables & 279 & 155 & 264 & 161 & 276 & 147 & 300 & 159 & $*$ \\
\hline chips & 3 & 9 & 7 & 12 & 2 & 6 & 1 & 4 & 4 \\
\hline savouries & 12 & 19 & 16 & 25 & 9 & 13 & 10 & 17 & * \\
\hline eets & 20 & 25 & 27 & 33 & 16 & 21 & 16 & 18 & $*$ \\
\hline
\end{tabular}

'analysis of variance, linearity of cllass differences: *0.01<p<0.05, *** $p<0.01$ 


\section{Class differences in food choice considerations}

Table 4.2 shows the proportion of mothers who considered health and costs often or wery often in their choice of food. Also the average number of foods that mothers of different social classes restricted their children eating is reported. The class differences were as expected: higher-middle class mothers considered health more ofter and costs less frequently than working class mothers, while the latter restricted fewer foods, indicating that they were more permissive.

Before including these variables in the regression analyses, the three correlation coefficients between the considerations were inspected. Only the correlation between health considerations and permissiveness was found to be significant $(r=0.17 ; p<$ 0.01 ): mothers who considered health more often also controlled their children's consumption more often.

\section{Table 4.2}

Proportion of women who consider health and costs often or very often and average number of foods women restrict their children eating by social class (including the number of respondents N)

\begin{tabular}{|c|c|c|c|c|c|c|c|}
\hline \multirow[b]{2}{*}{ social class } & \multicolumn{2}{|c|}{ health } & \multicolumn{2}{|l|}{ costs } & \multicolumn{3}{|c|}{ restricted foods } \\
\hline & $\%$ & $\mathrm{~N}$ & $\%$ & $\mathbb{N}$ & mean & s.d. & N \\
\hline lower & 50 & 268 & 53 & 263 & 27 & 18 & 270 \\
\hline midale & 61 & 348 & 39 & 339 & 3.6 & 17 & 349 \\
\hline higher middle & 69 & 221 & 28 & 211 & 3.9 & 16 & 222 \\
\hline$[1]$ & 59 & 837 & $41 \times x$ & 813 & $346 *$ & 18 & 841 \\
\hline
\end{tabular}

' chi square test, statistically significant class differences: * $0.01<p<0.05, * * * 0.01$

"analysis of wariance, statistically significant class differences: $0.01<p<0.05$, *** $p<0.01$

\section{Explanation of social class differences in food consumption}

In order to examine whether social class differences in food consumption could be explained by the three considerations, all food consumption variables of table 4.1 were included in the analysis, except in case the class differences in consumption were small (fruit and vegetables), or when consumption was not related to any of the three considerations (sweets). Nine regression analyses were performed: one for each of the remaining consumption variables. The consumption variables were first regressed on social class and subsequently the considerations were added. Table 4.3 shows the regression coefficients of social class both before and after addition of the considerations (regression model 1 and 2 respectively). 


\section{Table 4.3}

Mutiple regression analysis of social class before (model 11 and after additon of considerations regarding health, number of restricted foods and costs (model 2 ) on food consumption (standardised regression coefficients)

\begin{tabular}{|c|c|c|c|c|c|c|c|c|c|}
\hline 9 & meat & milk & cheese & $\begin{array}{l}\text { olland } \\
\text { fats }\end{array}$ & $\begin{array}{l}\text { brown } \\
\text { bread }\end{array}$ & gram & $\begin{array}{l}\text { pota- } \\
\text { toes }\end{array}$ & Whos & $\begin{array}{l}\text { savol } \\
\text { ries }\end{array}$ \\
\hline a & $-19^{*}$ & $-10 *$ & $09 * *$ & $-20 *$ & $17 \%$ & $12 *$ & $427 *$ & 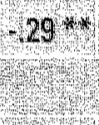 & $-12+4$ \\
\hline socta & $16^{* *}$ & $10 *$ & $108 \%$ & $16 \%$ & $10 x$ & 094 & $22 *$ & $25 \times$ & $08 x^{2}$ \\
\hline Meath & 03 & 144 & $17 * 7$ & $-11 * x$ & $11 \times x$ & $15 *$ & -12 : & $109^{*}$ & -102 \\
\hline restricted food & $10 *$ & $-08^{*}$ & 02 & 05 & $20 *$ & 05 & 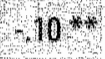 & lo & -10 \\
\hline ces & O. & 02 & 06 & 1 & & & $10^{*}$ & & 06 \\
\hline
\end{tabular}

$0.01<p<0.05, * 0<0.01$

In most cases the regression coefficient of social class decreased only slighty when the three considerations were taken into account. The influence of social class on all food consumption variables remained significant. This means that social class differences in food choice were scarcely explained by these considerations.

Apart from the class differences in food consumption, women who took health into consideration consumed less snacks, less dietary oil and fats, and more foods that contribute to fibre compared to women who considered health less often. Also women who restricted their children more often seemed to choose a healthier diet with less meat, milk, potatoes and savouries, and more brown bread. Compared to women who did not consider costs, women who did so more often consumed more oil and fats and more potatoes.

Finally, to analyse whether the infuence of the considerations on food consumprion differed between the classes, first-order interaction terms between. social class and the three considerations were added to the regression equation (these results are not reported, but can be obtained from the first author). Of the nine food groups only one food group showed a significant interaction term $(\mathrm{p}<0.01)$. The interaction term of social class and the number of restricted foods significantly influenced meat consumption. Cross-tables revealed that middle and higher-middle class women who were stricter consumed less meat than the more permissive women, while there was no clear association between stricmess and the consumption of meat among working class women.

The associations of these considerations with actual food consumption appeared to explain only a small part of the variance (4-11\%). Regression analyses of the cities separately showed that the associations between social class and food choice 
considerations did not vary considerably between the ciries. Generally, in Maastricht and Aachen social class and the three considerations predicted food consumption somewhat better than in Liège.

\section{Discussion}

Most class patterns in food consumption, found in the present study, corresponded with the results of social epidemiological studies and more qualitative studies (Lepage, 1985; Charles \& Kerr, 1988; Kromhout, Doornbos \& Hoffmans, 1988; Calnan, 1990; De Craene et al, 1990; Hulshof et al., 1991; Mennell, Murcott \& Van Otterloo, 1992; Prättälä, Berg \& Puska, 1992; Heseker et all, 1992; Prärtälä, 1995; Ministry of Agriculture, Fisheries and Food, 1995). Higher-middle class women appeared to consume less snacks and fewer foods that contribure to the intake of dietary fat, and more foods that contribute to the intake of fibre. Yet, there were two exceptions: they are more cheese and less potaroes than working class women. Probably, they ate more cheese instead of meat and more grain (like rice) instead of potatoes.

Also the results on class differences in permissiveness and health and cosr considerations were in line with the results of the studies on food beliefs (Charles \& Kerr, 1988; Calnan, 1990; Van Otterloo \& Van Ogtrop, 1989; DeVault, 1991). Higher-middle class mothers considered health more frequently and costs less often and they applied more food restrictions, indicating that they were less permissive than working class mothers.

In contrast to the results on class differences in food consumption and considerations, the results regarding the explanatory value of these considerations for class differences in consumption were not in line with the expectations. Class differences in the considerations hardly explained class patterns in food consumption. The finding that social class was more often related to eating habits than these considerations corresponded with the conclusion of a study on determinants of health behaviour among lower class mothers in Great Britain (Pill, Peters \& Robling, 1993) that socio-demographic variables like tenure were dominant factors rather than attitudes and beliefs. Finally, the associations between social class and food choice considerations did not vary considerably between the cities.

The main point of discussion is why class differences in food consumption were not explained by class differences in these considerations, as suggested by almost all studies on food beliefs. Four possible reasons are considered here: class differences in the impacr of these considerations on food choice, an inappropriate selection of food consumption variables, the impacr of social desirability, and the exrent to which the present sample allows generalisarion.

With regard to the first point, it might be that considerations lead to different food choices among working class mothers than among higher-middle class mothers. For instance, in the higher social stratum mothers who consider health often may 
buy less meat than mothers who consider health less often. Thus, health considerations and meat consumption would be negatively correlated in this social class. In contrast, in the working class health considerations and meat consumption may be positively correlated, if mothers who are health-conscious purchase more meat than mothers who are less so. As a result of this contradiction, the main effect of health considerations on meat consumption in a regression analysis would be small. However, this discrepancy would be indicated by a significant interaction term between social class and health considerations. In the present study interaction effects were, with one exception, not found. This means that the discrepancy between classes in the effect of considerations does not explain the results.

Secondly, concerning the selection of the food consumption variables, it might be that food choices other than those included in the present study would be more strongly related to health, taste and cost considerations. The extent to which women consider health, costs and/or preferences may affect, for instance, whether they decide to buy lean or fat types of meat rather than how much meat chey buy. Consequently, in contrast to class differences in the total amount of meat, class differences in the choice between lean and fat meat might be explained by these deliberations. To explore this, the choice between low-fat and high-fat meat products, milk products, cheese, and oil and fats were regressed on social class, and subsequently the three considerations were included. The results of these analyses led to the same conclusion, as class differences in these food consumption variables were not explained by the three considerations either.

Thirdly, mothers might have given socially desirable answers to the questions how often they considered health and costs in their selection of food and the food restrictions they imposed on their children. If this were the case in the present study, the variation in these answers would be small. The results in table 4.2 , however, show considerable variation. Therefore it is doubtful whether more sophisticated and validated operationalisations of these considerations, which are less susceptible to social desirability, would explain more of the class differences in food consumption.

Finally, concerning the generalisation of the main outcomes of the present study, two points will be discussed. First, the majority of the cited studies have been conducted in the United Kingdom (UK). In this country the stronger hierarchy of social classes may have a larger impact on lifestyle than on the continent. As income inequalities and the number of households living in poverty are larger in the UK than in the Netherlands, Belgium and Germany, it seems that class differences in terms of material resources are larger in the UK (Kooiker \& Christiansen, 1995). Only further empirical research can show to what extent the outcomes of the present study can be replicated in socieries differing in class structure and/or cultural variations between social classes.

The second point is illustrated in a more detailed comparison of the present sample with the sample in the Dutch study on class differences in food regimes (Van Otterloo \& Van Ogtrop, 1989). In that study the category of lower class mothers was divided in two groups according to their source of income: social security 
benefits and wages. In the first category unemployed families, incapacitated and unskilled manual workers, and divorced morhers with a low educational level were included, while the second category consisted of skilled and semi-skilled labourers. The most striking differences in food choices and food preferences were found between the low educated mothers who depended on social security benefits and the high educated mothers who were married to professionals. However, the two groups of working class mothers too differed in their attitudes and practices on food. Mothers who themselves or their parner were skilled or semi-skilled labourers had more in common with higher-middle class mothers than mothers from a socially more deprived background. The lower class families in the present study were comparable to the category of semi-skilled and skilled workers in the study of Van Otterloo and Van Ogtrop, as lone mothers were not included in the survey and more than $80 \%$ of the lower class families in the samples earned an income.

As a consequence of the selection of districts and the sampling method, people from the more extreme low and upper classes were not represented in the study. Thus, our conclusions cannot be generalised to include the most deprived and the most well off people. However, generally the samples in Maastricht, Liège and Aachen represented the majority of lower, middle and higher-middle social class families in these cities. Moreover, as the results in the three cities were consistent, it can be concluded that although the large majority of working and higher-middle class families differ in their food choice considerations, these considerations hardly explain class parterns in food choice as measured by the food items represented in this study.

\section{References}

Bausch-Goldbohm, R.A., Van Den Brandt, P.A., Van 't Veer, P., Sturmans, F. \& Hermus, R.J.J.

(1988). Results of the methodological study for the design of a simplified, selfadministered questionnaire. In: E. Riboli \& R. Saracci (Eds.), Diet, bormones and cancer: methodological isstes for prospective studies. JARC Technical Report No. 4 (pp. 79-89). Lyon: International Agency for Research on Cancer.

Blaxrer, M. \& Paterson, E.

(1983). The goodness is out of it: the meaning of food to two generations. In: A. Murcott (Ed.), The sociology of food and eating. Essays on the social significance of food (pp, 95-105). Aldershot: Gower.

Calnan, $M$.

(1990). Food and health: a comparison of beliefs and practices in middle-class and working-class households. In: S. Cunningham-Burley \& N.P. McKeganey (Eds.), Readings in medical sociology (pp. 9-36). London: Routledge.

Charles, N. \& Kerr, M.

(1988). Women, food and families. Manchester: University Press. 
De Craene, I., De Backer, G., Kornitzer, M., De Henaw, S., Bara, L, Rosseneu, M. 8 . Vercaemst, $R$.

(1990). Determinants of fat consumprion in a general population. Retue d'Epidémiologie et de Santé Publique, 38, 539-543.

DeVault, M.L.

(1991). Feeding the family: the social onganization of caring as gendered work. Chicago: The University of Chicago Press.

Goldbohm, R.A., Van 't Veer, P., Van Den Brandt, P.A., Van 't Hof M.A., Brants, H.A.M., Sturmans, F. \& Hermus, R.J.J.

(1993). Reproducibility of a food frequency questionnaire and stability of dietary habits determined from five annually repeated measurements. In: PA. Van Den Brandt $\&$ R.A. Bausch-Goldbohm, A prospective cobort study on diet on cancer in the Netherlands. Design, conduct, analyri and frot results after 3.3 years of follow-tap (thesis, pp. 47-58). Maastricht: University Press.

Goldbohm R.A., Van Den Brandt, P.A., Brants, H.A.M., Van 't Veer, P., Al, M., Sturmans, F. \& Hermus, R.J.J.

(1994). Validation of a dietary questionnaire used in a large-scale prospective cohort study on diet and cancer. European Joumal of Clivical Nutrition, 48. 253-265.

Heseker, H., Aclolf, T., Eberhardt, W., Hartmann, S., Herwig, A., Kübler, W., Matiaske, B., Moch, K.J., Schneider, R. \& Zipp, A.

(1992). Lebensmittel-wnd Nabrstoffaufrabme Erwadsener in der Bundesnepublik

Deutschland [Food and nutrient intake of adults in the Federal Republic of Germany]. Niederkleen: Wissenschafticher Fachverlag Dr. Fleck.

Hulshof, K.F.A.M., Löwik, M.R.H., Kok, F.I., Wedel, M., Brants, H.A.M., Hermus, R.J.J. \& Ten Hoor, F.

(1991). Diet and other life-style faccors in high and low socio-economic groups

(Dutch Nutrition Surveillance System). European Journal of Clinical Nutrition, 45. $441-450$.

Hupkens, C.L.H., Knibbe, R.A. \& Drop, M.J.

(1997). Social class differences in women's fat and fibre consumption: a crossnationall study. Appetite, 28, $131-149$.

Kooiker, S. \& Christiansen, "T.

(1995). Inequalities in health: the interaction of circumstances and health related behaviour. Sociology of Health and Illness, 17, 495-524.

Kromhout, D., Doornbos, G. \& Hoffmans, M.D.A.F.

(1988). Voedselkeuze, leefwijze en sterfte in relatie tot opleiding [Food choice, lifestyle and mortalicy in relation to education. Tijdschrift Soctale Gezondheidsworg, $66,345-348$.

Lepage, $\mathrm{Y}$.

(1985). Recent dietary trends in Belgium: socio-economic aspects. In: J.M. Diehl \&

C. Leitzmann (Eds.), Measurement and deterninants of food habits and food preferences. Report of an EC worksbop, Giessen. Euro-Nut Report 7 (pp. 109-116). Wageningen: Stichting Nederlands Instituut voor de Voeding. 
Mennell, S., Murcote, A. Q Van Otterloo, A.H.

(1992). The sociology of food: waing, det and culture. London: Sage Publications.

Ministry of Agriculture, Fisheries and Food

(1995). National Food Survey 1994. Atwual report on bousehold food consumption and expenditure, London: HMSO.

Murcott, A.

(1985). The study of food habits: objectives, methods and consequences. In: J.M.

Dich $\&$ C. Jeitzmann (Eds), Measupement and determinants of food babits and food preferences. Report of an EC workshop, Giessen. Euro-Nut Report 7 (pp. 13-27).

Wageningen: Stichting Nederlands Institut voor de Voeding.

Murcotr, $A$.

(1986). You are what you eat anthropological factors influencing food choice. In: $\mathrm{C}$.

Ritson, L. Gofron \& J. Mckenzie (Eds.), The food consumer (pp. 107-125).

Chichester: John Wiley and Sons.

Pill, R, Peters, T.J. \& Roblling, M.R.

(1993). Factors associated with health behaviour among morhers of lower socioeconomic status: a British example. Social Sctence and Medicine, 36, 1137-1144.

Pill, R., Peters, "T.J. \& Robling, M.R.

(1995). Social class and preventive health behaviour: a British example. Joumal of Epidemiology and Community Healh, 49, 28-32.

Popkin, B.M., Siega-Riz, A.M. \& Haines, P.S.

(1996). A comparison of dietary trends among racial and socioeconomic groups in the United Stares. New England Journal of Medictne, 335, 716-720.

Puättälà̃, R.

(1995). Social class and food in the Nordic countries. Emäbrungs-Umschau, 42, Beiheft, 16-20.

Prärträlä, R., Berg, M.A. \& Puska, P.

(1992). Diminishing or increasing contrasts? Social dass variation in Finnish food consumption patterns, 1979-1990. European Joumal of Clinical Notrition, 46,279287.

Van Berkel-Van Schaik, A.B. \&x Tax, B.

(1990). Natren standachdoperationalisatie wan social- economische status wor epidewiologisty en saciantmedisch onderzoek [Towards a standardised operationalisation of socio-economic status for epidemiological and social-medical research]. Rijswijk: Münisterie van Welzijn, Volksgezondheid en Cultuur.

Vat. Otterloo, A.H. \& Van Ogtrop, I.

(1989). Het regine wan veel, vet en zoet: praten met moeders over woeding en gezondhe id [The regime of plenty, fat and sweet: talking with mothers on food and health]. Amsterdam: VU Uitgeverij.

Wilson, G.

(1989). Family food systems, preventive health and dietary change: a policy to increase the health divide. Jownal of Social Policy, 18, 167-185. 
Winkleby, M.A. Jatulis, D.E., Frank, E. \& Formann, S.P.

(1992). Socioeconomic status and health, how education, ncome, and accupation contribute to risk factors for cardiovascular disease. American foumal of Public Herth, $82,816-820$. 


\section{Christianne L. H. Hupkens, Ronald A. Knibbe,}

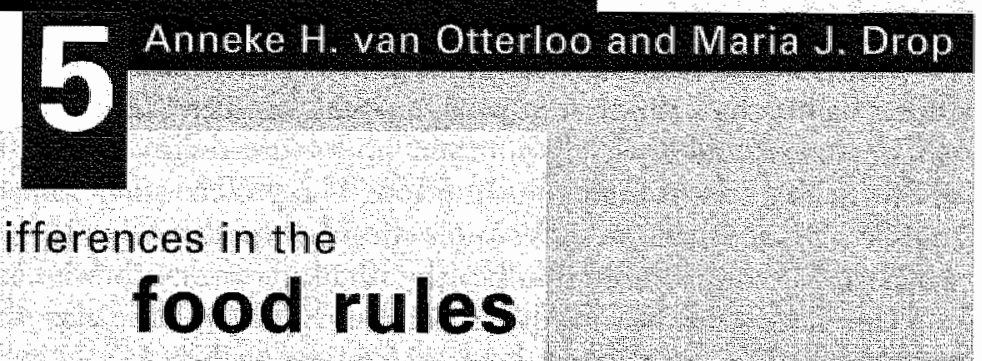

mothers impose on their children

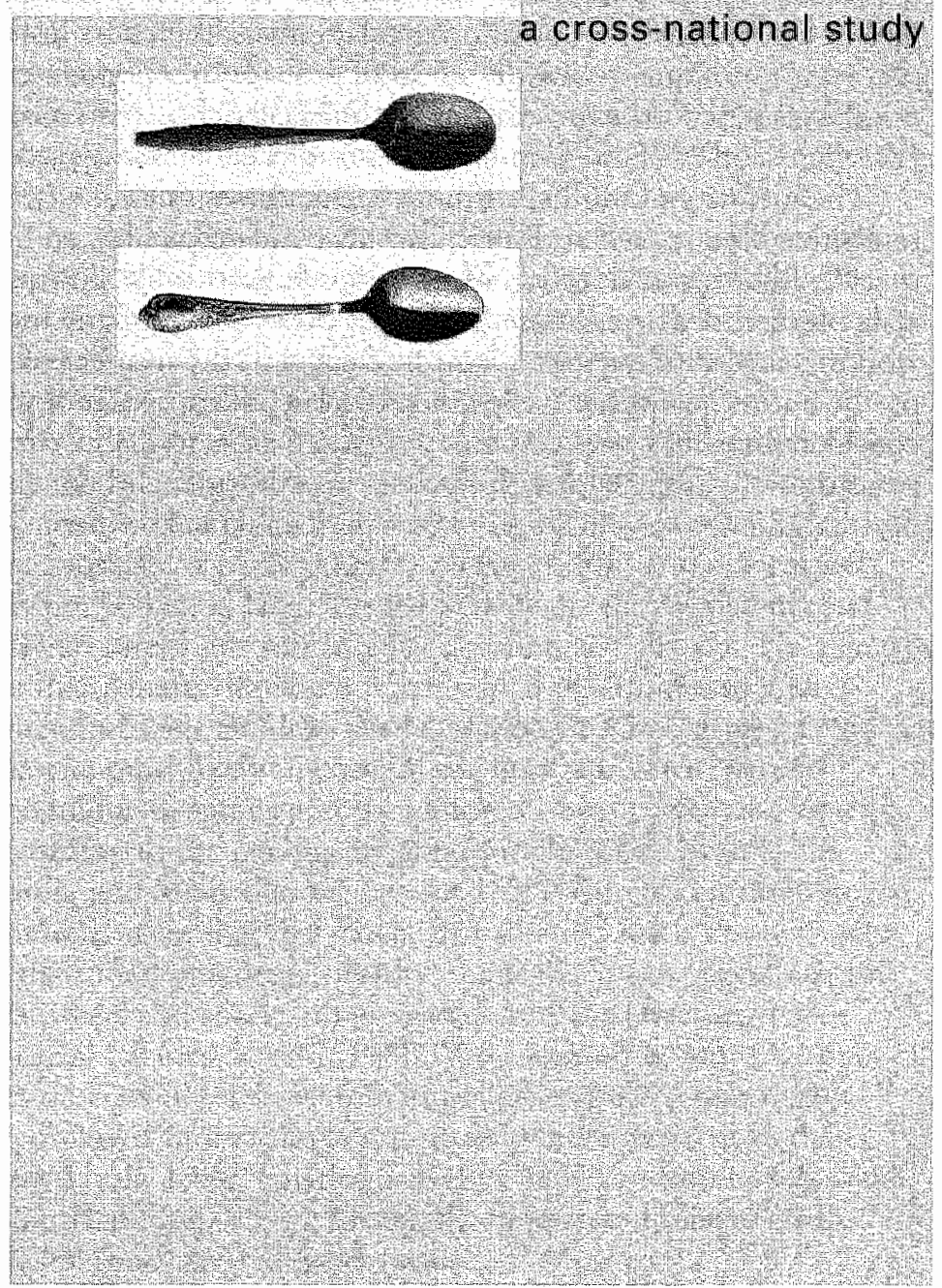




\section{Abstract}

Many studies indicate that children in higher-middle class families have healthier earing habits than children in working class families. Class differences in food rules, which parents and especially mothers impose on their children, may underlie these social inequalities in food consumption. The present study analyses whether highermiddle class mothers prescribe more "healthy" foodstuffs to their children and whether they restrict more 'unhealthy' food items than lower class mothers.

Moreover, the study examines whether higher-middle class mothers consider health aspects more often and the preferences of their family members less often in their choice of food compared to working class mothers, and whether class differences in these considerations explain class differences in food rules. To answer these questions, questionnaires on food practices of 849 women living in highermiddle class or working class districts in Maastricht (the Netherlands), Liège (Belgium) and Aachen (Germany) were collected and analysed.

The majority of mothers of both social classes in each city prescribed primarily foods that were served at dinner like meat and vegetables, and most mothers limited their children's consumption of sweet foods, soft drinks and snacks. Higher-middle class mothers restricted more foods, but prescribed as many food items as their working class counterparts. Class differences in the number of restricted foods were partly, but not completely explained by class differences in health and taste considerations. Despite national variations in dietary habits and possibly in the education of children, class differences in food rules and the explanatory power of health and raste considerations were comparable in the three cities. 


\section{Introduction}

Many studies in western countries have reported social inequalities in food consumption. In general diets in the higher social classes are more often in line with dietary recommendations than in the working classes (e.g. Mennell, Murcott \& Van Otterloo, 1992; Prättälä, Berg \& Puska, 1992; Hulshof, Löwik, Kok et al, 1991; Calnan, 1990; Kromhout, Doornbos \& Hoffmans, 1988; Charles \& Kerr, 1988). Studies that examine food consumption patterns of children indicate that this class disparity starts in young childhood and continues to exist in adolescence (Klocke, 1995; Van Der Lucht \& Groothoff, 1995; Kennedy \& Goldberg, 1995; Laitinen, Räsänen, Viikari \& Åkerblom, 1995; Oakley \& Rajan, 1993; Donkin, Neale \& Tilston, 1993; De Vries, Lucker, Cremers \& Katan, 1990; Van Poppel, Schneijder, Maas, Schrijver, Sluiter-Van Nies \& Kok, 1989; Mayall, 1986; Golding, Haslum \& Morris, 1984). Like other healch habits, eating habits that are acquired during childhood influence eating behaviour in adulthood too (Klocke, 1995; Contento, Basch, Shea et al., 1993; Cohen, Brownell \& Felix, 1990; Van Der Lucht \& Groothoff, 1990; Lupton, 1996). Despite the fact that these studies indicate the importance of children's diets for both their present and their future health, the origins of class patterns in earing habits have only been occasionally investigated.

The present paper explores a possible explanation for class differences in children's diet, namely the food rules parents employ. More specifically, we investigate the extent to which mothers of different social classes oblige their children to eat healthy foods and limit the consumption of unhealthy foods. Furthermore, we examine whether class differences in food rules can be explained by class differences in the mothers' considerations regarding health and taste aspects.

Since eating behaviour is by and large learned behaviour, clearly, parents and especially mothers play an important role in what children actually eat. The concept of food rules assumes that parents develop a praxis which determines to a large extent the everyday menu of their children (Van Otterloo \& Van Ogtrop, 1989). Of course these food rules are most likely to concentrate on foods where parents' preferences about the children's menus and the children's own preferences diverge: namely foods that according to the parents are good for children's health, but unpopular with children, and foods that are favoured by children, bur disapproved of by their parents. Indeed, according to French, British and Dutch mothers who were interviewed on their food practices, 'healthy' foods like green vegetables and 'unhealthy' foods like sweets and snacks often caused conflicts (Fischler, 1986; Blaxter \& Paterson, 1982; Charles \& Kerr, 1988; Van Otterloo \& Van Ogtrop, 1989). Several studies on class differences in food practices showed that highermiddle class parents employed more rules and especially more restrictions than working class parents (Mayall, 1986; Charles \& Kerr, 1988; Van Otterloo \& Van Ogtrop, 1989; De Bourdeaudhuij, 1997). Generally, food rules in lower class families were more flexible and covered fewer foods. 
Bourdieu's theory (1989) on class differences in taste offers the most general theoretical framework for class differences in consumption. This theory holds that lower class people tend to value more strongly recently acquired luxuries, like white bread, meat, sweets and snacks, while middle class people seek distinction by. stressing the health aspects of food. With respect to food rules this class difference implies that, compared with working class mothers, mothers in the higher social classes prescribe more healthy foods and limit more strongly the consumption of unhealthy foods (Van Otterloo \& Van Ogtrop, 1989).

Based on lengthy interviews with Dutch mothers from working class and professional middle class backgrounds who had young children, the study of Van Otrerloo and Van Ogtrop (1989) offered hypotheses abour how social class influences food rules. Although all mothers agreed that both health and taste considerations were important criteria in their choice of food, there appeared to be : class difference in these considerations. In lower class families taste considerations appeared to be a more important criterion, whereas health considerations were more influential in higher-middle class families. Other studies too showed that highermiddle class mothers stressed health aspects more often and taste preferences less often in their choice of food and in their food rules (DeVault, 1991; Calnan, 1990; Charles \& Kerr, 1988; Mayall, 1986). These studies thus indicate that health and taste considerations may explain class differences in food regulations.

Due to the small scale of these studies it is difficult to assess to what extent these findings can be generalised and thereby explain the class differences in children"s diets observed in the epidemiological studies mentioned in the first paragraph. In this study, therefore, we first of all assess to what extent the differences in food rules found in qualitative studies can be generalised to the general population. Secondly, if there are class differences in the food rules morhers apply, we will assess to what extent health and taste considerations explain these class differences.

The sample consists of higher-middle and working class mothers who care for at least one child aged between 4 and 14 years. We focus on mothers, as they usually provide food for their family. In families with young children, generally men still are the breadwinners and women the homemakers, even when women are in paid employment (Lupton, 1996; Richardson, 1993; Murcott, 1986; Blaxter \& Paterson, 1986). As most morhers take the preferences and wishes of their husbands into account in their selection of food, food choices appear to differ between complete families and lone parent families (Murcott, 1993; Van Otterloo \& Van Ogtrop, 1989; Charles \& Kerr, 1986). Similarly, food rules may also differ between these types of families. Despite the increase of alternative ways of living, couples with children are still the most frequent mode of cohabitation of all households with children (Eurostat, 1995). As the number of lone parent families in the sample might be too small to justify conclusions, only complete families were included in the present study.

Socialization of children, including teaching children what, when and how to eat, is influenced by cultural norms and values about how to raise children. In order to 
study whether food rules and class differences in these rules are comparable in different cultures, we questioned women who lived in Maastricht (the Netherlands), Liège (Bellgium) and Aachen (Germany). These cities are located in three linguistic areas, but less than 50 kilometres apart within the Euregion Rhine-Maas; which consists of the Belgian provinces Limburg and Liège; the southern part of Dutch Limburg, and the region around Aachen in Germany. Besides cultural differences in how parents educate their children, food habits in these towns differ too, just as for instance national dishes and the supply of food differ between countries. We hypothesised that, despite these national differences, higher-middle class parents in each town impose stricter rules compared to working class parents. In sum, the present paper focuses on an explanation of social class differences in food rules by examining health and taste considerations, based on quantitative data that allow for cross-cultural comparison.

\section{Data and Methods}

\section{Survey}

Data on dietary and eating habits were collected from 849 women in Maastricht, Liège and Aachen between November 1993 and February 1994, except for the Christmas period between 23 December and 9 January. The inclusion criteria were:

(i) having a family with at least one child aged 4-14 years who lived at home, and

(ii) living togerher with a male partner, as we were interested in complete families.

In each city working class and higher-middle class districts, populated by families with school-going children, were selected in order to reach enough mothers of working and middle class backgrounds. The selection of these districts was based on demographic data (if available), and on the advice of a municipal official. In randomly selected streets in these districts, trained female interviewers, students and graduates of the Universities of Maastricht, Liège and Aachen, approached each address. If families met the inclusion criteria, the interviewers explained how to complete the questionnaire. In addition, they made an appointment with the woman to collect the questionnaire about one week later at her home.

To obtain data about the sampling procedure and the non-response, the interviewers kept accounts of all addresses they contacted during the distribution and collection of the questionnaires. The response rate was highest in Maastricht (79\%) and Liège (78\%) and lowest in Aachen (67\%). In all three cities the highermiddle class quarters showed the highest response (Maastricht: $82 \%$ compared with $76 \%$ in working class quarters; Liège: $83 \%$ and $73 \%$ respectively; Aachen: $73 \%$ and $62 \%)$.

Characteristics of the three samples are presented in table 5.1. In general the women were about 36 years old, the majority had 2 or 3 children living at home, and on average their children were about 8 years old. In Liège a relatively large 
number of the women were foreign (14\%). The majority of these women were from: Iraly $(7 \%)$ and other European countries (3\%), while only $3.5 \%$ of the women cam from another continent. About half of the women had a paid or unpaid job. More detailed information on the composition of the samples in the three cities has been described in anorher paper (Hupkens, Knibbe \& Drop, 1997).

\section{Table 5.1}

Population characteristics of the samples in Aachen, Liege and Maastricht

\begin{tabular}{|c|c|c|c|}
\hline & Aachen & Liège & Maastricht \\
\hline rumber of women & 229 & 316 & 304 \\
\hline age of women (Vears) & $357[5.1]$ & $36.4[5.4]$ & $36.6[5.4)$ \\
\hline number of chilleren & $23[0,9]$ & $24 \llbracket 101$ & 2110.81 \\
\hline age of chilirentycars & $75(3.6)$ & $94(40)$ & $80(3.6)$ \\
\hline local nationaliv $(10)$ & 92,4 & 86.2 & 99.0 \\
\hline working womer (o\%) & 417 & 49.5 & 477 \\
\hline
\end{tabular}

$[x . K]=$ standard doviatiam

\section{Questionnaire}

The questionnaire included questions on meal patterns, the preparation of meals, food rules, health considerations and preferences. These questions on food practices were formulated in collaboration with Van Otterloo and were based on the results of the qualitative study of Van Otterloo and Van Ogtrop (1989). In addition, questions about age, marital state, family composition, religion, education, occupation and working situation were included.

The Dutch questionnaire was translated into French and German. In collaboration with Belgian and German social scientists questions about religion, education, occupation and working situation were formulated. Next, the translation of the quesrionnaire as a whole was checked by interviewers, who lived in Liège or Aachen. Finally, in each city the questionnaire was tested in a pilot-study to check whether the questions were comprehensible. As a result, the wording of a few questions was improved. 


\section{Data}

\section{Food rules}

The questionnaire included a list of 20 common foods and drinks that children often consume, namely:

- brown bread, white bread, meat products, cheese, sweer fillings and milk (or buttermilk) with bread-and-milk meals,

- meat, potatoes, pasta, chips, cooked vegetables, raw vegetables, soup and dessert with dinner, and

- sweets, fruit, milk (or buttermillk), yoghurt drinks, soft drinks and fruit juice between meals.

The mothers were asked to note for each food item whether they prescribed it, whether they restricted their children eating it, or whether their children were allowed to eat it whenever they wanted. Next, of these 20 foods the number of food items mothers prescribed and the number of foods mothers restricted were computed.

\section{Social class}

In general, social class is based on education, occupation and/or income. Studies that compared these three measures for their power to predict health behaviour reported that educational level is usually the most consistent and reliable measure (Pill, Peters \& Robling, 1995; Winkleby, Jatulis, Frank \& Fortmann, 1992). An expert committee in the Netherlands (Van Berkel-Van Schaik \& Tax, 1990) also recommended using educational level as a measure for social class in epidemiological and social medical studies. Compared to occupational status and income, educational level has the advantage that it can be applied to everybody, and that it is less influenced by economic constraints.

As expected, the mothers' educational level was posirively correlated with their occupational status (Maastricht: 0.72, Liege: 0.73, and Aachen: 0.52) and with their parmers' educational level (Maastricht: 0.67, Liège: 0.68, and Aachen: 0.60). Yet, in the present study maternal educational level appeared to be the best predictor of food rules. Stepwise regression analyses of four proxies of social class (the mothers' and fathers' educational level, and their occupational status) on the number of prescribed and on the number of restricted foods showed that the mothers' educationall level was included in both regression equations, whereas the other proxies were included once or not at all. Based on these arguments, social class was indicated by the highest completed education of the mother.

According to the educational structure in each country, 7 educational levels were used in the Dutch and German questionnaires and 6 levels in the Belgian version. Next, women were classified into 3 social classes: lower social class (i.e. elementary and lower vocational training for 12-16 years old), middle class, and higher-middle class (i.e. higher vocational training for $18+$ years old and university). 


\section{Health and taste considerations}

Based on the results of the qualitative study of Van Otterloo and Van Ogtrop (1989), statements were formulated that probably reflect the considerations between the importance of health on the one hand and the relevance of taste on the other. The mothers were asked how often they took health into account when they bought or prepared food. Five answer categories were provided: (1) never, (2) sometimes, (3) regularly, (4) often, and (5) always. In addition, morhers were questioned to what extent they agreed with the following statements:

1. I think that my partner and children have to eat whar I prepare.

2 If children eat 3 meals each day, they are allowed to eat what they want in between.

3 Children"s taste can be developed.

$4 \quad$ Serving tasty food is important to please partner and children.

Answer categories of these statements also ranged on a five-point scale, from stronglydisagree (1) to strongly agree (5).

\section{Analysis}

First, foodstuffs that the majority of lower and higher-middle class mothers in the three cities prescribed or restricted are reported. Secondly, associations between social class, health and taste considerations and number of prescribed and restricted foods were analysed for all respondents together and for each ciry separately. Therefore correlation coefficients between these ordinal variables were computed.

Subsequently, if class differences in the number of prescribed and restricted foods were apparent, multivariate regression analyses were used to analyse whether these class differences could be explained by the considerations. In that case, first, the number of prescribed and restricted foods were regressed on city and social class, and secondly, the considerations were added. On the other hand, if the number of prescribed and restricted foods did not differ between social classes, only one regression model was analysed, in which the dependent variable was regressed on city, social class and considerations.

It should be noted that the present paper focuses on class differences in food rules and considerations rather than on differences between the cities. Therefore, the overall results are presented if the results in the three cities are mutually comparable. Only if there appear to be remarkable differences between the ciries, are the results presented for the cities separately. 


\section{Results}

\section{Class differences in prescribed and restricted foods}

Food items which at least one-third of the morhers prescribed their children to eat are presented in table 5.2. Those most frequently prescribed were foods that were part of dinner, like cooked and raw vegetables, meat and potatoes. In addition, more than half of the Belgian mothers prescribed soup. Many mothers also specified the consumption of milk with bread-and-milk meals and fruit, and the majority of mothers in Maastricht prescribed brown bread.

Table 5.2

Class differences in the extent mothers prescribe foods for their children (proportions)

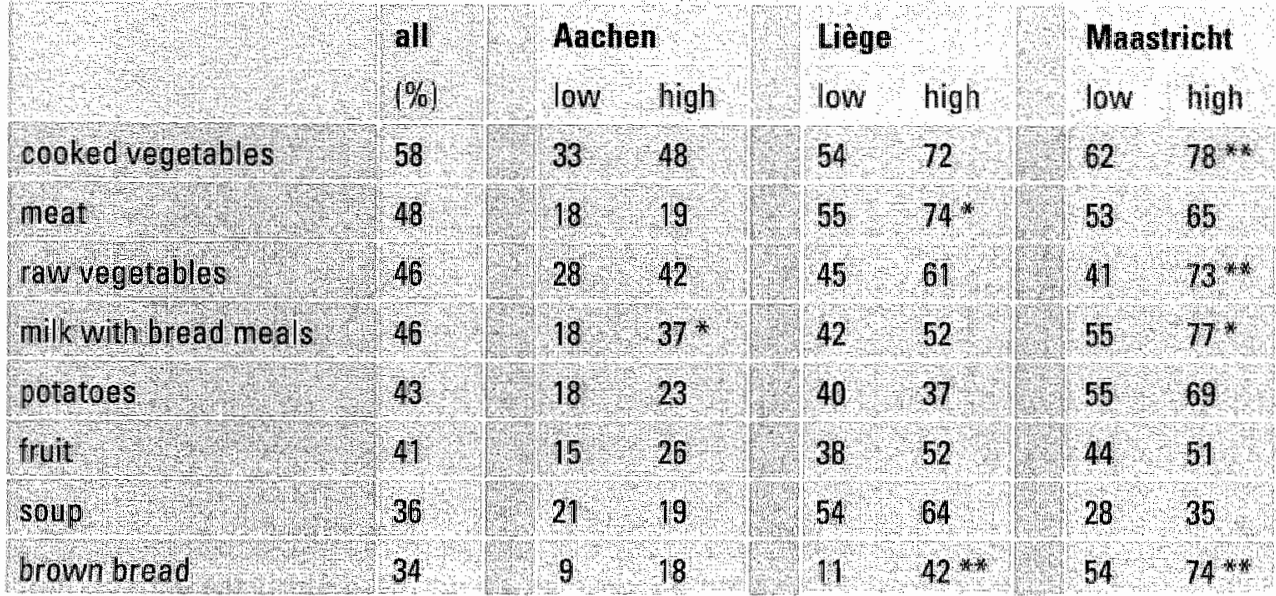

class difference chi-square test ${ }^{*} 0.01<p<0.05,0<0.01$

Although in most cases a slightly higher proportion of the higher-middle cllass mothers prescribed the foods mentioned in the table, the differences were mostly too small to be significant. Exceptions were milk (Aachen and Maastricht), meat (Liège), brown bread (Liège and Maastricht), and cooked and raw vegetables (Maastricht), which were prescribed by a significantly higher proportion of the higher-middle class mothers. The table shows also that, irrespective of social class, the proportion of mothers prescribing foods is consistently lower in Aachen.

The differences between cities are also illustrated in figure 5.1. Of the total of 20 food items that were included in the questionnaire, mothers in Maastricht and Liegge prescribed on average about 6 foods, and mothers in Aachen prescribed 2.4 foods. The figure also shows the differences between social classes. It appeared that in each ciry the number of prescribed foods did not differ significantly between the social 
classes. Thus, higher-middle class mothers did not dictate more foods than their working class counterparts.

\section{Figure 5.1}

Class differences in the number of foods mothers prescribe their children

\section{8 number of prescribed toods}

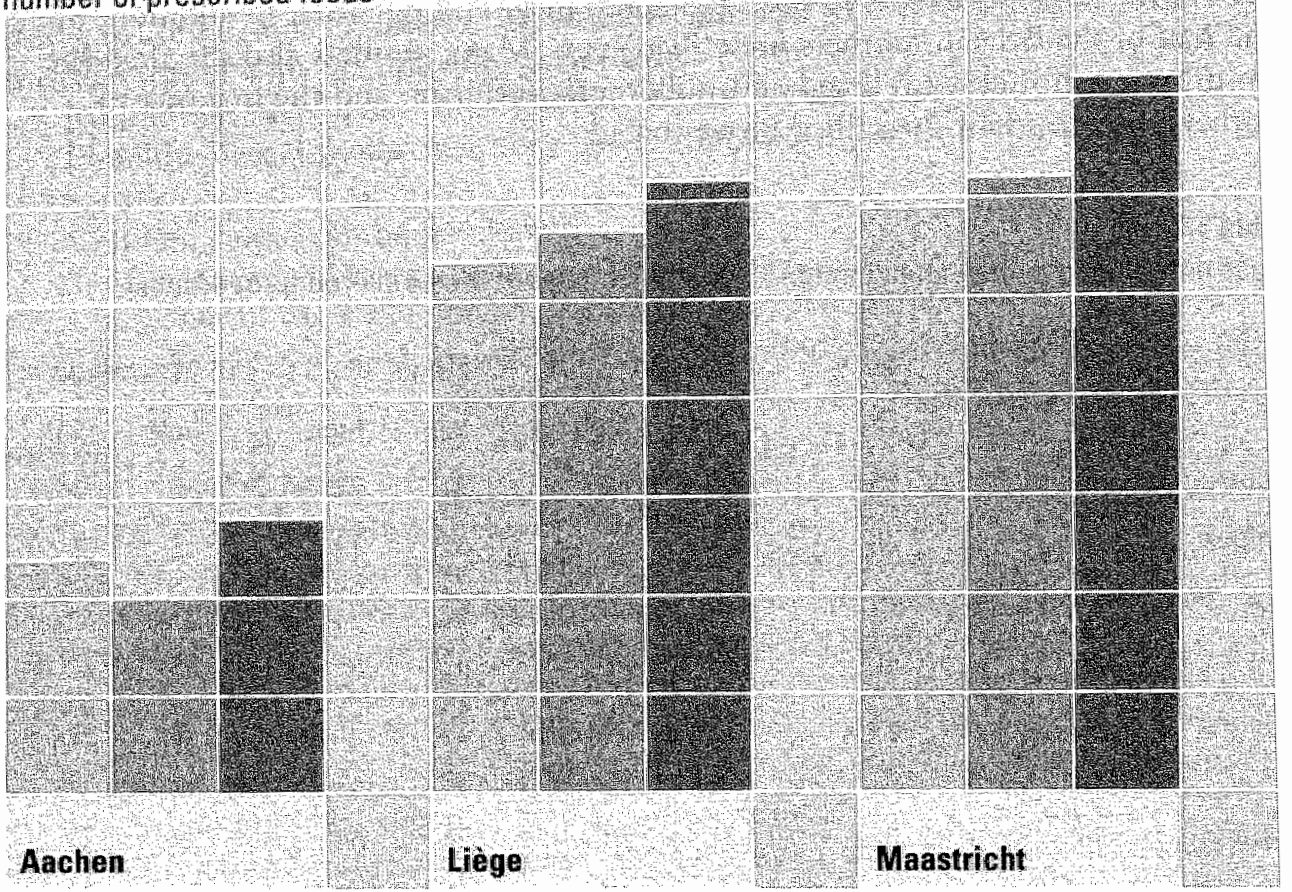

saciall chass:

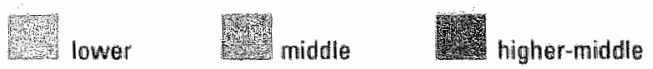

To reduce the number of figures, the class differences in food restricrions are limited to those foods which were restricted by more than one-third of the mothers in Aachen, Liège and Maastricht (table 5.3). More than two-thirds of the mothers restricted their children's consumption of sweets, soft drinks and chips. Addirionally, half of them limited the consumption of sweet fillings and $40 \%$ restricted their children's consumption of white bread. Whereas most mothers limited the consumption of these foods, hardly anybody mentioned that they proscribed these foods. Apart from sweet fillings, class differences in food restrictions appeared to be considerable: higher-middle class mothers limired more often than working class mothers their children's intakes of sweers, soft drinks, chips and white bread. The number of mothers who restricted these foods differed slightly between the ciries. In Aachen most mothers and in Liège fewest mothers limited these foods. 


\section{Table 5.3}

Class differences in the extent mothers testrict their children to eat foods (proportions)

\begin{tabular}{|c|c|c|c|c|c|c|c|}
\hline & all & Aac & & Leg & & Maa & richt \\
\hline & $(\%)$ & low & high & Low & high & low & high \\
\hline sweets & 85 & 97 & 94 & 65 & 86 W & 81 & 954 \\
\hline soft ding & 71 & 11 & 89 & 5 & 76 & 50 & $967 x$ \\
\hline CApS & 64 & 64 & $91 *$ & 32 & $500 \%$ & 60 & $82+x$ \\
\hline sweet tillings & 50 & 36 & 56 & 56 & 49 & 37 & 42 \\
\hline White bread & 42 & 39 & $74 * 6$ & 11) & 18 & 31 & $78 *$ \\
\hline
\end{tabular}

class difference, chi-square test: * $0.01<p<0.05,{ }^{* *} p<0.01$

The class differences are also apparent in figure 5.2. Analysis of variance showed that in each of the three cities higher-middle class mothers restricted significantly more foods than lower class mothers.

\section{Associations between social class and health and taste considerations}

The proportions of mothers of different social classes who agree with the health and taste statements are reported in the first columns of table 5.4. Additionally, the second last column shows the correlation coefficients berween social class and these considerations. The results show that more higher-middle class mothers mentioned that they took health into account and that children's taste could be developed, whereas working class mothers agreed more often that children might eat snacks, as long as they eat three main meals per day, and that tasty food is important to please the family. The other deliberation did not vary between the classes, except in Maastricht, where compared to working class mothers, more higher-middle class mothers agreed that their children should eat what they prepared. 
Food prescriptions and restrictions

\section{Fingure 5.2}

Class differences in the number of foods mothers restrict their children to eat

8 number of restricted roods

6

4

2

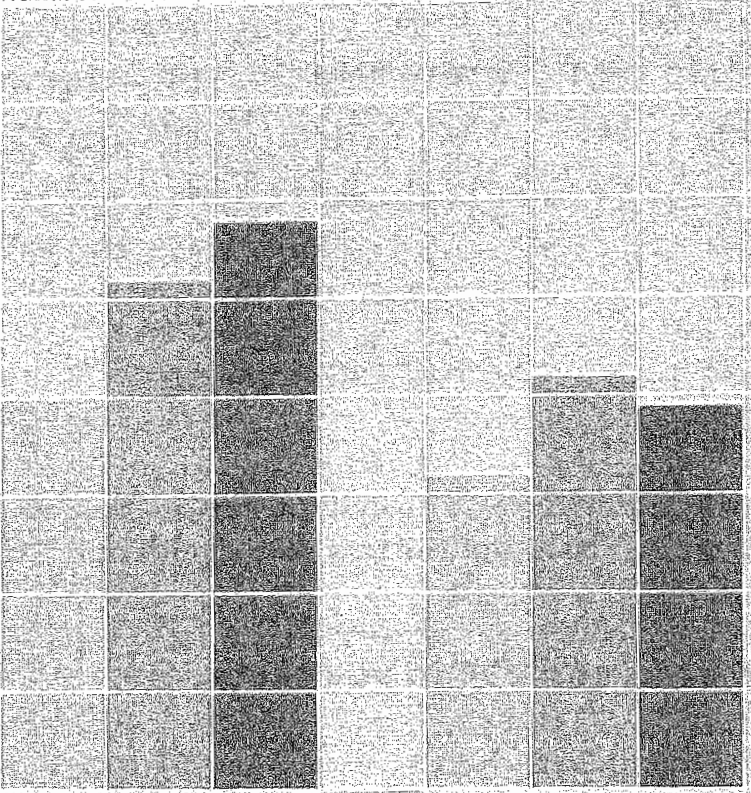

Aachen *

Liege**

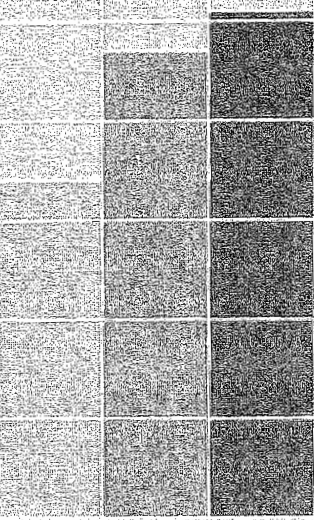

Maastricht *

socilat class:

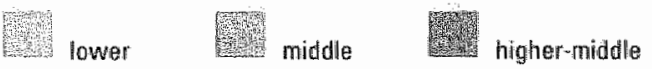

class difference, analysis of variance: $0.01<\beta<0.05$; $p<0.01$

\section{Table 5.4}

Proportion of low and higher-middle social class mothers, who agree with the following statements, and correlation coefficients $(r)$ between social class and these statements

\begin{tabular}{|c|c|c|c|c|}
\hline statements & $\begin{array}{l}\text { sociall } \\
\text { low }(\%)\end{array}$ & middle $1 \%$ & high $(\%)$ & $r$ \\
\hline take heal th into a crount & 49 & 61 & $69 \div$ & $15 *$ \\
\hline fompy has to oat what is prepared & 46 & 40 & 41 & 05 \\
\hline Ehildren may eat between neals & 27 & 16 & $10 * *$ & $-22 *$ \\
\hline children's taste can be developed & 69 & 73 & $81 *$ & 06 \\
\hline serve tasty food to please family & 79 & 69 & $63 *$ & $-14 * *$ \\
\hline
\end{tabular}

class difference, chi-square test or significant correlation: $0.01<p<0.05$, $p<0.01$ 


\section{Associations between health and taste considerations and the numbers of prescribed and restricted foods}

The correlation coefficients in table 5.5 show that mothers who considered health more often appeared to be more strict, as they both prescribed and restricted more foods. Mothers who agreed that the family had to eat what was prepared prescribed more foods. Contrary to the expectation, the correlation coefficient with the number of restricted foods indicated that these mothers restricted fewer foods. Yer, this association was probably confounded by differences between the cities, as the correlations in each city were not significant ( -.03 in Aachen, -.04 in Liège, and +.09 in Maastricht).

\section{Table 5.5}

Correlation coefficients $(r)$ between health and taste considerations, and number of prescribed and restricted foods

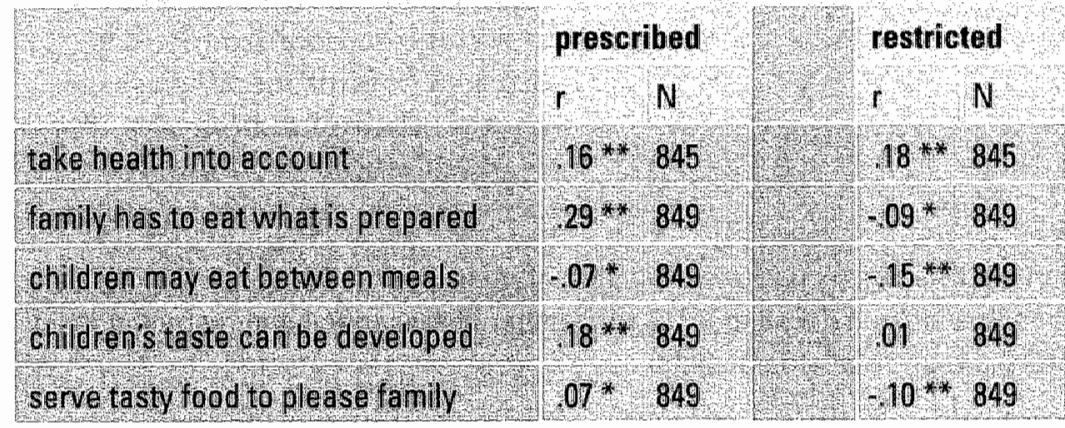

significamt correlation: ${ }^{*} 0.01<p<0.05, * * 0<0.01$

Mothers who allowed their children to eat in between meals, as long as they ate three meals per day, limited and prescribed fewer foods, and mothers who agreed that children's taste could be developed imposed more foods. Finally, mothers who found that tasty food was important to please the family restricted their children less often, but also prescribed more foods. Except for the dissimilarity mentioned above, these associations were comparable in the three cities.

\section{Associations between social class, health and taste considerations and food rules}

As there appeared to be no class differences in the number of prescribed foods, the effects of city, class, and health and taste considerations were analysed in a regression analysis (table 5.6). For mothers living in Aachen and in Liège two dummy variables were computed, taking mothers in Maastricht as a reference. As noted before, mothers in Aachen prescribed fewest foods, and mothers in Maastricht 
most Regarding we impact of healch and taste considerations, especially mothers who found that their family members had to eat what was prepared prescribed more foods. In addition, the more mothers took health into consideration, and the more they agreed that the taste of their children could be deweloped, the more foods they prescribed

As the number of testricted foodstuff differed significanty between social classes we explored wherher these class differences could be explained by health and taste considerations. Table 5.6 shows that the impact of social class on the number of restricted foods dimushed when the considerations were included. Mothers who considered hedth more often restricted more foods, whereas mothers who allowed their children to eat between meals restricted less foods. These associations partly explained the class differences in food restrictions. However, the impact of class did nor disappear when these considerations were taken into account, indicating that apart from these considerations social class still infuences food restrictions.

\section{Table 5.6}

Multiple regression of city and social class on number of restricted foods (model 1 ) and of city, social class and health and taste considerations on number of prescribed and restricted foods (model 2) (standardised regression coefficients)

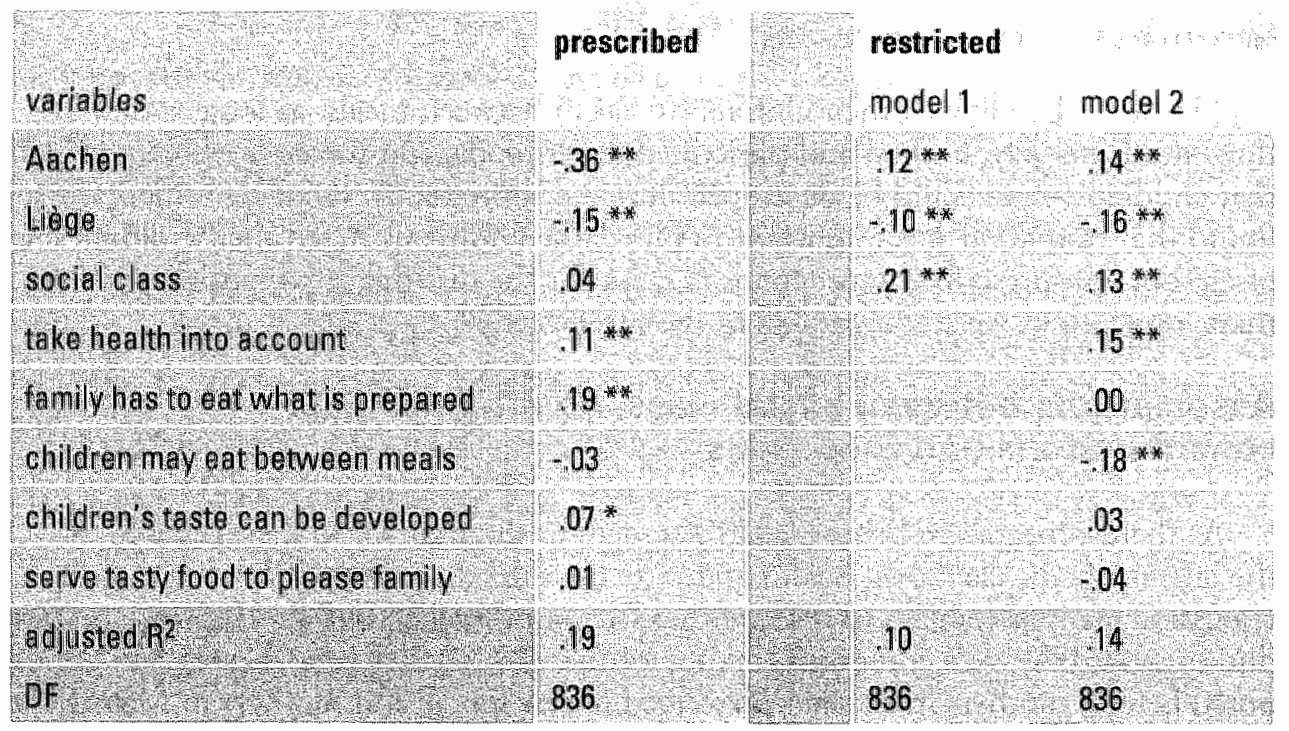

significant regression coefficient: $0.01<p<0.05, * 0<0.01$ 


\section{Discussion}

The present study showed that social class differences were apparent in the case of food restrictions, but not in the case of prescriptions. Compared to lower class mothers, higher-middle class mothers prescribed as many healthy foods, but they restricted more unhealthy foods. This latter class partern could be partly explained by the fact that higher-middle class mothers took health aspects more often into account and the food preferences of their children less often than working class mothers. Thus, our outcome suggests that food restrictions form part of the explanation of class differences in children's eating habits.

The foods that are prescribed and restricted in the present study are comparable with those reported in qualitative and quantitative studies on food practices in England (Charles \& Kerr, 1988), France (Fischler, 1986), Flanders (De Bourdeaudhuij, 1997) and the Netherlands (Van Otterloo \& Van Ogtrop, 1989). Most mothers found the foods and dishes that were served at dinner particularly important for their children's health and these foods were most often prescribed. Foods that most morhers limited either formed no component of a proper meal or could easily be substituted by a foodstuff which fitted better in a healthy diet. Yet, hardly any mother forbade these foods completely. The British study demonstrated that, in contrast to proper meals, sweet foods performed other functions than ensuring good health and development (Charles \& Kerr, 1988).

Contrary to these foods that the majority of the mothers regulated, foods that gave no rise to conflicts were generally not controlled. Many mothers permitted the consumption of, for instance, meat products and cheese with bread, dessert with dinner, and milk and fruit juice between meals. Inasmuch as mothers took health aspects into consideration when they provided these foods, most of them probably supposed that these foods were good or at least not bad for their children's health, while most children favoured these foodstuffs.

In contrast to the mainly qualitative studies about class differences in food rules, we did not find significant class differences in prescriptive food rules. However, in another quantirative study (De Bourdeaudhuij, 1997) no significant class differences in prescriptive food rules were found either. Yer, as working class mothers in the present study more often held that their family could be pleased by serving tasty food, it might be that within the category of prescribed foods lower class mothers tend to serve more often foodstuffs and meals fancied by their children. Similarly, a study among mothers in the USA on the provision of food for their family showed that lower class mothers on a tight budget bought more often foodstuffs which their family preferred than higher-middle class mothers, as they could not afford to purchase foods which might be wasted if their partner and children refused them (DeVault, 1991). Consequently, working class mothers may come less often into conflict with their children about their preferences, and less often have to impose foods which their children dislike. 
Whereas class differences in the number of prescribed foods were not apparent, class differences in the number of restricted foods were evident. Higher-middle class mothers restricted more foods than their lower class counterparts. This finding is in line with the resules of other studies (Van Otterloo \& Van Ogtrop, 1989; Charles \& Kert, 1988; De Bourdeaudhuij, 1997). Moreover, this may explain the conclusion of food consumption surveys (which are mentioned in the introduction) that highermiddle class children have healthier diets than working class children.

Finally, the foodstuffs that were prescribed or restricted varied berween the three cities, and also the number of food rules differed. Yet, despite these national variations, the present study showed that the class patterns regarding the number of prescribed and restricted foods were similar. The class differences in the health and taste considerations were comparable too.

In each city higher-middle class mothers took health more often into account in their choice of food, while lower class morhers took the preferences of their family more often into consideration, as they more often agreed that children might eat between meals, so long as they ate their main meals, and that they could please their family by serving tasty food. This association between social class and health and taste considerations corresponds with the results of qualitative studies on food practices (DeVault, 1991; Calnan, 1990; Van Otterloo \& Van Ogtrop, 1989; Charles \& Kerr, 1988; Mayall, 1986). Also the finding that mothers who considered health more often and/or taste less often applied more food rules is in line with the results of the study on food regimes of Van Otterloo and Van Ogtrop (1989).

The fact that health and taste considerations did not completely explain class differences in food rules suggests that also other pressures on behaviour might be class related. Qualitative studies on mothers' food beliefs and food practices show that lower class mothers contend with many more constraints than middle class mothers. Generally, mothers who were berter off had more resources like money and time than socially disadvantaged mothers (Van Otterloo \& Van Ogtrop, 1989; Charles \& Kerr, 1988; Mayall, 1986).

Of course, the conclusions of the present study are not wholly conclusive. First, althougli we examine food rules, we cannot draw conclusions on the effect of these rules on children's food consumption, as we do not have dara on children's eating habirs. Of the children aged berween 4 and 14 years, especially the older ones can withdraw from their mothers' food regimes, by buying foods, which their mothers (and farhers) limit, themselves. Moreover, younger children will receive sweets and snacks, which their parents limit, for instance from their grandparents or at friends' homes. Still, children's eating habits appear to be influenced by their parents' food rules. A retrospective study, which focused on the relationship between the eating habits of Belgian teenagers and the food rules their parents applied when they were 10 years old, showed that children whose parents restricted more foods still had healthier eating habits a couple of years later (De Bourdeaudhuij, 1997).

Secondly, the women's answers certainly will be coloured by social desirability. Of course they want to present themselves as capabie and competent mothers, and it 
might be that they present attitudes and behawiour they pursue rather than the behaviour they realize (Van Otterloo \& Van Ogtrop, 1989). This might be especially the case for the health and taste considerations. Yet, understanding of mothers' ideals rather than their actual attitudes and behaviour is also valuable to gain insight into their considerations concerning food.

Thirdly, there are no validated instruments available to measure health and taste considerations with help of a questionnaire. In the present study we used questions based on interview data. Analysis of data on the mothers' eating habits indicated that mothers who took account of health often and/or the preferences of their children less often had healthier food consumption patterns themselves: they consumed less fat and more fibre. Although social desirability probably has influenced the responses, this finding may support the validity of these measures.

Fourthly, it is arguable whether social class can be operationalised best by marernal educationall level. However, because of the correspondence between the mothers' education, their occupational status and their partners' schooling and profession, an alternative operationalization of social class would apparently lead to the same conclusions.

Finally, the non-response appeared to be somewhat higher in the working class districts than in the higher-middle districts. As especially people with a very low educational level may have difficulties with reading or writing and may refuse to complete the questionnaire, the non-response might be selective, which might result in an underestimation of class differences. Moreover, minimum wage-earners were underrepresented in the present study, as we decided to sample only complete families, and thus lone mothers who depended on social security benefits were not included in the sample. In the study of Van Otterloo and Van Ogtrop (1989) on food regimes, lower class mothers who themselves or their partner were (semi)skilled labourers had more in common with higher-middle class mothers than mothers from a socially more deprived background. Thus, the conclusions of the present study cannot be generalized to include the most deprived and the most welloff people. Yet, as the samples in the three cities represent the majority of lower, middle and higher-middle social class families and as the results in the three cities are comparable, the conclusions of the present study seem to be valid for the majority of these families in these cities.

To conclude, the present study indicates that class differences in restrictive food rules probably explain class differences in children's diets. Apparently, lower class mothers find it more difficult to proscribe unhealthy foods than higher-middle class mothers. Class differences in the priority given to health considerations and taste preferences of children partly explain why lower class mothers forbid unhealthy foods less often. Assuming that the importance of restrictive food rules for class differences in children's diets is confirmed in further research, nutrition education would more effectively contribute to the decrease of class differences in children's diets if it is more effectively tailored to the situation of mothers in the lower classes. Most likely this means that information about food enabling a more healthy food 
choice is not sufficient. Developing skills to resist pressures from children and to control children's food intake, especially between meals, may be as important.

\section{References}

Blaxter, M. \& Paterson, E.

(1982). Mothers and daugbiers. A three-generational study of health attitudes and behaviour. London: Heinemann.

Blaxter, M. \& Paterson, E.

(1986). The goodness is out of it: the meaning of food to two generations. In: A. Murcott (Ed.), The socialogy of food and eating. Essays on the social significance of food" (pp. 95- 105). Aldershot: Gower.

Bourdieu, P.

(1989). Distinction. A social critique of the judgement of taste. London: Rourledge \& Kegan Paul. [Originally published in French: Bourdieu, P. (1979). La distinction. Critique sociale du jugement. Paris: Les Editions de Minuit.] Calnan, $M$.

(1990). Food and health: a comparison of beliefs and practices in middle-class and working-class households. In: S. Cunningham-Burley \& N.P. McKeganey (Eds.), Readings in medical sociology (pp. 9-36). London: Rourledge.

Charles, N. \& Kerr, M.

(1986). Issues of responsibility and control in the feeding of families. In: S. Rodmell \& A. Watt (Eds.), The politics of health education: raising the issues (pp. 57-75).

London: Routledge and Kegan Paul.

Charles, N. \& Kerr, M.

(1988). Women, food and families. Manchester: University Press.

Cohen, R.Y., Brownell, K.D. \& Felix, M.R.J.

(1990). Age and sex differences in health habits and beliefs of schoolchildren. Health Psychology, 9, 208-224.

Contento, I.R., Basch, C., Shea, S., Gutin, B., Zybert, P., Michela, JL. \& Rips, J.

(1993). Rellationship of mothers' food choice criteria to food intake of preschool

children: identification of family subgroups. Health Edtucation Quarterly, 20, 243-259. De Bourdeaudhuij, I.

(1997). Family food rules and healthy eating in adolescents. Joumal of Health Psychology, 2, 45-56.

DeVault, M.L.

(1991). Feeding the family: the social organization of caring as gendered work. Chicago:

The University of Chicago Press.

De Vries, H.C.B., Lucker, T.P.C., Crenners, S.B.L. \& Katan, M.B.

(1990). Food choice and caries experience in Dutch teenagers as a function of the level of education of their parents. European Journal of Clinical Nutrition, 44, 839846. 
Donkin, A.JM, Neale, R.J. \& Tilston, $\mathrm{C}$

(1993). Childrens food purchase requests Appette, $21,291-294$

Eurostat Statistical Office of the European Communities

(1995). Demographic Statisto 1995. Luxembourg: Office for Official Publications of the European Communities.

Fischler, $C$.

(1986). Learmed versus "spontaneous" dietetics: French mothers" views of what children should eat. Soctal Sctence Information, 25, 945-965.

Golding, I., Haslum, M. \& Morris, A.C.

(1984). What do our ten-year-old children eat? Hedth Visitor, 57, 178-179.

Hulshof, K.F.A.M., Löwik, M.R.H., Kok, F.J., Wedel, M., Brants, H.A.M., Hermus, R.J.J.

\& Ten Hoor, F.

(1991). Diet and other life-style factors in high and low socio-economic groups

(Dutch Nutrition Surveillance System). European Journal of Clinical Natrition, 45 , $441-450$.

Hupkens, C.L.H., Knibbe, R.A. \& Drop, M.J.

(1997). Social class differences in women"s fat and fibre consumption: a cross-

national study. Appetite, 28,131-149.

Kennedy, E. \& Goldberg, J

(1995). What are American children eating? Implications for public policy. Nutrition Reviews, 53,111-126.

Klocke, A.

(1995). Der Einfluß sozialer Ungteichheit auf das Ernährungsverhalten im Kindes-

und Jugendalter. In: E. Barlösius, E. Feichtinger \& B.M. Köhler (Eds.), Ernährung in der Armut (pp. 185-203). Berlin: Edition Sigma.

Kromhout, D., Doornbos, G. \& Hoffmans, M.D.A.F.

(1988). Voedselkeuze, leefwijze en sterfte in relatie tot opleiding. Tijdschrift Sociale Gezondheidszorg, 66, 345-348.

Laitinen, S., Räsänen, L., Vïkari, J. \& Akerblom, H.K.

(1995). Diet of Finnish children in relation to the family's socio-conomic status.

Scandinatian jownal of Social Medicine, 23, 88-94.

Lupton, D.

(1996). Food, the body and the self. London: Sage Publications.

Mayall, $\mathbb{B}$.

(1986). Keeping children beathy. The role of mothers and professionals. London: Allen 8. Unwin.

Mennell, S., Murcort, A. \& Van Otterloo, A.H.

(1992). The sociology of food: eating diet and culture. London; Sage Publications. Murcott, A.

(1986). You are whar you eat: anthropological factors influencing food choice. In: $\mathrm{C}$.

Ritson, L. Gofton \& J. McKenzie (Eds.), The food consumer (pp. 107-125).

Chichester: John Wiley and Sons. 


\section{Menroott; $A$}

(1993). Talking of good food an empirical sudy of women's conceptualizations.

Food atsd Foodwaty, 5, 305-318.

Oalley, A, \& Rajan, L.

(1993). What did your baby cat yesterday? Social factors and infant feeding practices.

European Jownal of Public Health, 3, 18-27.

Pill, R. Peters, T.J, \& Robling, MR.

(1995). Social dass and preventive health behaviour: British example. Joumal of Epidemiology and Community Healdh, 49, 28-32.

Pràtualla, R, Berg, M.A. \& Puska, P.

(1992). Diminishing or increasing contrasts? Social dass variation in Finnish food consumption patterns, 1979-1990. European Journal of Clinical Nutrition, 46,279287.

Richardson, D.

(1993). Women, worberhood and cbildraring. Houndmills: Macmillan.

Van Berkel-Van Schaik, A.B. \& Tax, B.

(1990). Nata en standaardoperationalisatie van sociaal economische status woor epidewtologisch en social-medich onderzoek. Rijswijk: Ministerie van Welzijn, Volksgezond heid en Cultuur.

Van Der Imucht, F, \& Groothoff, J.W.

(1990). De gezondheidstoestand van de jeugd. Ongelijkheid, determinanten en gevolgen. Tijdschrifi voor Sociale Gezondheidszorg, 68, 207-214.

Van Der Lucht, F \& Groothoff, I.W.

(1995). Social inequalities and health among children aged 10-11 in the Netherlands: causes and consequences. Soctal Scienee of Medicine, 40, 1305-1311.

Van Otcerloo, A.H. \& Van Ogtrop. J.

(1989). Het regimo van veel, vet en zoet: praten met moeders oter voeding en gezondheid. Amsterdam: VU Uirgeverij.

Van Poppel, G., Schneijder, R., Maas, I.A.M., Schrijver, J., Sluiter-Van Nies, A.A.M. \& Kok, E.I.

(1989). Social-economische verschillen in voeding en voedingstoestand bij 10-11jarige jongens. Nederlands Tijdschift woor Geneeshunde, 11, 1223-1227.

Winkleby, M.A. Jatulis, D.E., Frank, E. \& Fortmann, S.P.

(1992). Socioeconomic sarus and health: how education, income, and occupation contribute to risk factors for cardiovascular disease. American Jownal of Public Health, $82,816-820$. 
Christianne L. H. Hupkens, Ronald A. Knibbe,

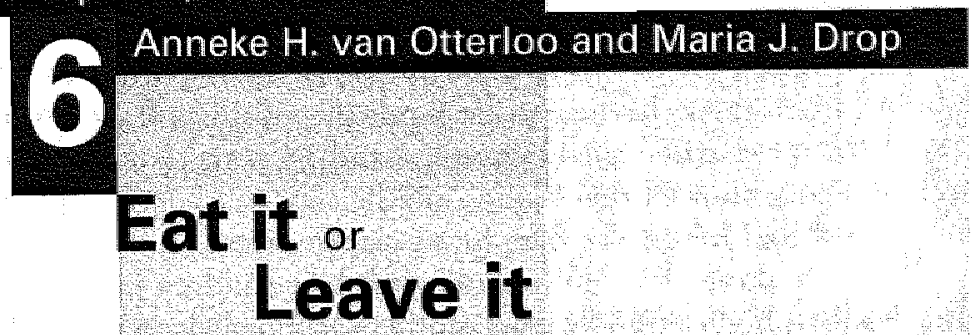

Class differences in how mothers handle children's dislikes

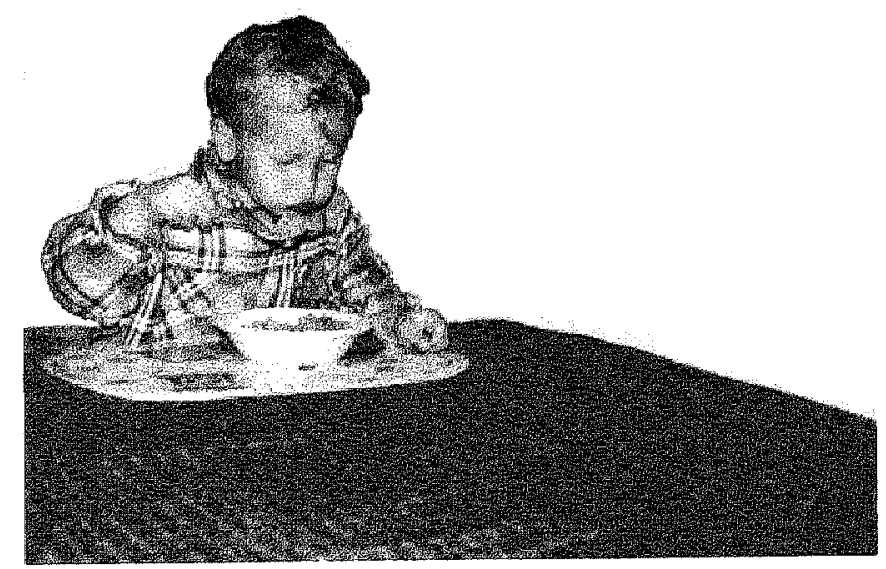




\section{Abstract}

This paper describes social class differences in the extent and manner in which mothers teach their children to eat foods they dislike. A survey among 849 mothers, who cared for children aged between 4 and 14 years in the Netherlands, Belgium and Germany, showed that higher-middle class mothers employed healthier and more consistent food rulles than lower class mothers.

While working class mothers allowed their children more frequently to eat what they wanted, higher-middle class mothers acknowledged more often that their children should learn to eat the foods they provided. The latter category of mothers reported more reasons why they taught their children to eat all foods, and they obliged their children more often to taste a little bit of the detested food. They prescribed as many foods as working class mothers, but they limited more foods, which was reflected in their own healthier dier, and probably also in their children's diets. 


\section{Introduction}

In western countries diets generally do not correspond with the dietary guidelines. Intake of too much fat and not enough fibre for instance are risk factors for major causes of death like cardiovascular disease and cancer (Willett, 1994; Hautvast, 1993; James, Ferro-Luzzi, Isaksson \& Szostak, 1988). In order to reduce the incidence of these diseases, nutrition education encourages people to consume less fat and more fibre.

Nutrition education is addressed particularly to mothers who care for young children, as they generally take care of the daily household tasks including buying food and preparing meals, even when they work outside the home (Lupton, 1996). There are two more specific reasons why these mothers form a suitable target group. Firstly, mothers consider keeping their family healthy one of their main responsibilities. Secondlly, the food rules mothers impose on their children may not only influence their children's present but also their future food habits, as eating habits developed during childhood probably influence eating habits in adulthood (Lupton, 1996; Klocke, 1995; Contento, Basch, Shea et al., 1993; Cohen, Brownell \& Felix, 1990).

However, even if someone is sufficiently knowledgeable to make a healthy food choice and intends to buy healthy foods, other important values like cost, convenience and food preferences often compete with a healthy diet (Furst, Connors, Bisogni, Sobal \& Winter-Falk, 1996; Steproe, Pollard \& Wardle, 1995; Backett, 1992). In the case of the mother who caters for her family, these restraints on food choice become even more apparent because somehow she has to take into account the wishes of her husband and children (Lupton, 1996; McKie, Wood \& Gregory, 1993; Charles \& Kerr, 1988; Van Otterloo \& Van Ogtrop, 1989).

In the upbringing of children the dilemma between healthy and tasty food is particularly apparent. Most parents and especially mothers try to promote foods that in their view are good for their children's health. In particular, foods that are part of dinner like meat and vegetables are considered necessary for children. Yer, children often dislike these foods, and thus conflicts arise about what they should eat (Fischler, 1986; Blaxter \& Paterson, 1982). Also less healthy foods like snacks, sweets and soft drinks give rise to conflicts, as the majority of mothers want to control these foods, while children favour them (Charles \& Kerr, 1988; Van Otterloo \& Van Ogtrop, 1989; De Bourdeaudhuij, 1997).

The present paper focuses on how mothers educate their children with regard to foods their children do not like. According to most women, regular consumption of proper meals is the most important element to secure that a child has a healthy diet (Charles \& Kerr, 1988; Van Otterloo \& Van Ogtrop, 1989). Especially dinner is viewed as the archetypal proper meall. However, in nuclear families dinner has more functions than providing a healthy meal. The evening meal is often the only meal which the family eats together, and therefore it has a symbolic function, as it stresses 
the family ties (Lupton, 1996). Dinner is mostly served after the husband has returned home from work and most women feel that their husband merits an appropriate cooked meal in a pleasant atmosphere. Moreover, parents and primarily mothers teach their children table manners during dinner. They educate their children, for instance, how to use their cutlery, and how to behave when they are eating. As Lupton (1996) noted, in this way "children are acculturated into the rules and norms of 'civilized' behaviour".

Based on a British study of women's accounts of their children's eating habits, Charles and Kerr (1988) formulated similar conclusions. They reported that particularly during the main meal mothers were confronted with conflicting demands and pressures: namely with their husband's right to have a proper cooked meal, the importance to teach children to appreciate this meal, and children's assertion of their own likes and dislikes. Thus, being strict and obliging children to eat the dishes that are served with dinner may lead to conflicts which disturb the ideal of a peaceful and harmonious meal. On the other hand, when mothers give in to their children's preferences, they may worry about their children's diers and feel guilty that they do not feed them properly.

Studies on food rules in different countries show that food regimes vary between social classes. Middle class mothers in the UK, the Netherlands, Belgium and Germany appeared to be more strict than their working class counterparts: they particularly testricted more unhealthy foods (Charles \& Kerr, 1988; Van Otterloo \& Van Ogtrop, 1989; De Bourdeaudhuij, 1997; Hupkens, Knibbe \& Drop, 1997a). These class patterns in food rules clarify to some extent why children in middle class families have healthier eating habirs than children in working class families (e.g. Klocke, 1995; Van Der Lucht \& Groothoff, 1995; Kennedy \& Goldberg, 1995; Laitinen, Räsänen, Viikari \& Akkerblom, 1995; Oakley \& Rajan, 1993).

According to Van Otterloo and Van Ogtrop (1989), these class patterns in food regimes were due to the position of mothers within sociery and within their families. Mothers with the slightest prospects to improve their position in society (mainly working class morhers) appeared to depend more on their role as housewife and mother to receive appreciation for their efforts. These women demonstrated their concern for their family members by providing tasty meals. Moreover, they generally experienced more constraints than middle class mothers. For instance, as working class mothers generally could spend less money on food, they tried less often new (low-fat or fibre-rich) foods, because they could not afford to buy foods their family might refuse (Van Otterloo \& Van Ogtrop, 1989; Charles \& Kerr, 1988; Mayall, 1986).

These studies also showed that middle class mothers generally had better prospects in society, as they had attained higher educational levels, and had better jobs with more responsibilities. Van Otterloo and Van Ogtrop (1989) concluded that middle dass mothers consequently had a more autonomous position both within society and within their family. Taking health aspects more often into account and the preferences of their family less often in their choice of food might represent this 
better position. In conclusion, middle class mothers seem to have more opportunities to impose unpopular food rules on their children, whereas working class mothers have less power to be strict. The present paper explores this issue by examining class differences in food rules.

The paper starts with a description of class differences in mothers' opinions regarding their children's dislikes. It is hyporhesized that higher-middle class morhers agree more often that their children should learn to eat foods they dislike, whereas working class mothers allow their children more often to eat what they like. In addition, class differences in the reasons mothers mention for these rules and the ways they try to achieve this are described.

Next, the consistency between this general food rule and two more specific rules, namely the number of foods mothers prescribe and the number of foodstuffs mothers restrict their children to eat, is studied. It is postulated that mothers who agree that their children should learn to eat the foods they serve also prescribe more healthy foods and restrict more unhealthy foods compared to mothers who permit their children to eat what they like.

Finally, in order to study whether these rules are put into practice, the correspondence between these rules and mothers' diets is studied: do mothers who apply stricter food rules have healthier eating habits themselves compared to mothers who are less strict? This might be expected as mothers probably want to ser a good example to their children. According to social cognitive learning theory, 'role models' like parents influence children's beliefs and habits (Bandura, 1986). Additionally, the mothers' food choices indicate which foods are provided within the family, like wholemeal or white bread, and full-fat or medium-fat dietary fats and oils. Indeed, diets of mothers and children are correlated (Feunekes, Stafleu, De Graaf \& Van Staveren, 1996; Oliveria, Ellison, Moore, Gillman, Garrahie \& Singer, 1992). Therefore, large and consistent differences in diet between strict and permissive mothers indicate that the application of food rules most likely effectively influences their children's diet. On the other hand, if the dietary habits of mothers are not related with their strictness, the impact of food rules on children's diets may be questioned.

A study among 1,077 Dutch families showed that the correlation in fat intake between mothers and their children was higher for foods consumed at home (mean association $r=0.46$ ) than for foods consumed elsewhere $(r=0.21)$ (Feunekes et al., 1996). The similarity between mothers and children is probably even higher for foods consumed with dinner. Therefore, the present study examines food items that are mainly eaten with dinner, like meat and vegetables. In addition, foods that are eaten with bread meals and snacks are taken into account.

Clearly, food consumption patterns vary between nations, and also the way parents educate their chilldren may differ between countries. The present scudy describes the associations between social class, food rules and food consumption in three European cities, namely Maastricht, Liège and Aachen. These cities are situated less than 50 kilometres apart in three linguistic areas, respectively the Nerherlands, 
the French-speaking part of Belgitum, and Germany. Despite national differences in eating habits and possibly also in the upbringing of children, it is hypothesized that class parterns in food rules, the consistency between different food rules and the association between food rules and mothers' diets are comparable in these cities.

In summary, the following research questions are addressed:

1 Do middle class mothers agree more often that their children should learn to eat the foods they serve, and do working class mothers allow their children more frequently to eat what they like? Do social classes differ in the reasons they mention for these rules and in their approaches to achieve this?

2 Are food rules consistent? In other words, do mothers who agree that their children should learn to eat the foods presented prescribe and restrict more foods compared to mothers who allow their children to eat what they like?

3 Is the association berween mothers' food rules and their diets consistent? Do mothers who agree that their children should learn to eat all foods and mothers who prescribe or restrict many foods have healthier eating habits than mothers who apply less stricr rules?

\section{Data and Methods}

\section{Survey}

Data on dietary and eating habits were collected from 849 women in Maastricht, Liège and Aachen between November 1993 and February 1994 , except for the period between 23 December and 9 January because of Christmas. The inclusion criteria were: (i) having a family with at least one child aged $4-14$ years who lived at home, and (ii) living together with a male partner, as we were interested in complete families.

In each city working class and higher-middlle class districts, populated by families with school-going children, were selected in order to reach enough mothers of working class and middle class backgrounds. The selection of these districts was based on demographic dara (if available), and on the advice of a municipal official. In randomly selected streets in these districts, trained female interviewers, students and graduates of the Universities of Maastricht, Liège and Aachen, approached each address. If families met the inclusion criteria, the interviewers explained how to complete the questionnaire. In addition, they made an appointment with the woman to collect the questionnaire about one week later at her home.

To obtain data about the sampling procedure and the non-response, the interviewers kept accounts of all addresses they contacted during the distribution and collection of the questionnaires. The response rate was highest in Maastricht (79\%) and Liège (78\%) and lowest in Aachen (67\%). In all three ciries the highermiddle class quarters showed the highest response (Maastricht: $82 \%$ compared with $76 \%$ in working class quarters; Liège: $83 \%$ and $73 \%$ respectively; Aachen: $73 \%$ and 
62\%). Non-response might possibly have been selective. For example, people with a low educational level may have problems with reading or writing and might have refused to collaborate for this reason. Consequently, results on class differences in the present study may be underestimated.

Characteristics of the three samples are presented in table 6.1. In general the women were about 36 years old, the majority had 2 or 3 children living at home, and on average their children were about 8 years old. In Liège a relatively large number of the women were foreign (14\%). The majority of these women originated from Italy $(7 \%)$ and orher European countries (3\%), while only $3.5 \%$ came from another continent. Finally, about half of the women had a paid or unpaid job.

\section{Table 6.1}

Population characteristics of the samples in Aachen, Liège and Maastricht

\begin{tabular}{|c|c|c|c|}
\hline & Aachen & Liege & Maastricht \\
\hline miin ber or wornen & 229 & 316 & 304 \\
\hline age gr women ye ars & $357(5)$ & $(36,4.5,4$ & $36.6[5,4]$ \\
\hline humber of ed hiner & 23.90 & 24110 & $2,[0.8]$ \\
\hline age or Ghilden lyears) & $75.6 .6)$ & 9.4. 4.01 & $8.9[3.6]$ \\
\hline Heal 1ationality (o) & 924 & 862 & 990 \\
\hline Working worien $(06)$ & 417 & 495 & 477 \\
\hline
\end{tabular}

$[x . x]$ : standard deviation

\section{Questionnaire}

The questionnaire inwolved two parts: a food frequency questionnaire and a questionnaire on food practices. The semiquantitative food frequency questionnaire was validated on the ability to rank subjects. This questionnaire was developed by Bausch-Goldbohm and Van Den Brandt for a large cohort study on diet and cancer in the Netherlands (Bausch-Goldbohm, Van Den Brandt, Van 't Veer, Sturmans \& Hermus, 1988). Both the validity and the reproducibility were tested and appeared to be satisfactory (Goldbohm, Van Den Brandt, Brants et al., 1994; Goldbohm, Van 't Veer, Van Den Brandt, Van "t Hof, Brants, Sturmans \& Hermus, 1993). T'he original questionnaire was shortened in consultation with Bausch-Goldbohm, as some questions were too extensive for the present study. The questionnaire on food practices was based on the results of a qualitative study of Van Otterloo and Van Ogtrop (1989). In collaboration with Van Otterloo, questions were formulated on, for example, meal patterns, the preparation of meals, food regimes, health considerations and preferences. 
The translated food frequency questionnaire was checked by Belgian and German dieticians and researchers for three reasons: (i) to include common Belgian or German food irems, (ii) to exclude typical Durch foods, and (iii) to improve the description of the food items, for instance by using local wordings or local brands as examples. Moreover, in collaboration with Belgian and German social scientists questions about religion, education, occupation and working situation were formulated. Next, the translation of the questionnaire as a whole was checked by interviewers who lived in Liège or Aachen. Finally, in each city the questionnaire was tested in a pilot-study to check whether the questions were comprehensible. As a result, the wording of a few questions was improved.

\section{Data}

\section{Social class}

In general, social class is based on education, occupation and/or income. Studies that compared these three measures for their power to predict health behaviour reported that educational level is usually the most consistent and reliable measure (Pill, Peters \& Robling, 1995; Winkleby, Jatulis, Frank \& Fortmann, 1992). An expert committee in the Netherlands (Van Berkel-Van Schaik \& Tax, 1990) also recommended using educational level as a measure for social class in epidemiological and social medical studies. Compared to occupational status and income, educational level has the advantage that it can be applied to everybody, and that it is less influenced by economic constraints.

Based on these arguments, social class was indicated by the highest completed education of the woman. According to the educational structure in each country, 7 educational levels were used in the Dutch and German questionnaires and 6 levels in the Belgian version. Nexr, women were classified into 3 social classes: lower social class (i.e. elementary and lower vocational training for 12-16 years old), middle class, and higher-middle class (i.e. higher vocational training for $18+$ years old and university).

\section{Learn to eat all foods}

Mothers were requested whether they thought it necessary that their children should learn to eat all foods they served or whether they thought that their children might choose themselves what they wanted to eat. The first category of mothers are referred to as 'strict' mothers, and the second category as 'permissive" mothers. Strict mothers were asked to answer two additional questions in order to understand why they found this important and how they tried to teach their children to eat foods they disliked. The formulation of these questions and of the answer categories were based on the findings of the qualitative study of Van Otterloo and Van Ogtrop (1989). First, mothers were asked what they did when their children refused something to eat. The following answer categories were provided: (1) they should clean their plate, (2) they should taste a little bit, (3) I mix it with a food they like, 
and (4) otherwise. As this latter category was not included in the analysis, and as some mothers marked more than one practice, the sum of these answers does not always add up to $100 \%$.

Secondly, the mothers were asked why they found it important that their children learned to eat all foods. The mothers could mark one or more of the following reasons: (1) I don't want to cook for everybody separately, (2) it is important that they eat a variety of foods, (3) they also have to eat what is provided, if they join in eating somewhere else, (4) it is important that they learn to obey, and (5) in this way you can develop your children's taste.

\section{Prescribed and restricted foods}

The questionnaire included a list of 20 common foods that children often eat, like meat, potatoes, cooked vegetables, raw vegetables, brown bread, white bread, cheese, milk, sweets and soft drinks. The mothers were asked to note for each food item whether they prescribed it, whether they restricted their children eating it, or whether their children were allowed to eat it whenever they wanted. Next ${ }_{s}$ of these 20 foods the number of food items mothers prescribed and the number of foods mothers restricted were computed.

\section{Food consumption}

Finally, the women's average daily consumption of a selection of food items was analyzed. Foods were chosen that were consumed mostly with dinner like meat, vegetables, potatoes, dietary oils and fats, and grains (like rice). In addition, the consumption of bread, fruit, french fries, savory snacks (like nuts and chips) and sweet snacks (including cakes and biscuits) were examined. Both meat and dietary oils and fats contribute significantly to the total intake of fat. In order to study whether mothers consumed full-far products or low- or medium-fat alternatives, the proportion of low- or medium-fat meat in total meat consumption, and the proportion of medium-fat oils and fats in the total consumption of oils and fars were studied. Similarly, for grains and bread the choice berween products that contain more fibre (like unpolished rice and brown bread) and producrs with less fibre (including polished rice and white bread) was examined.

\section{Analysis}

All analyses were performed for all respondents together, and for each city separately. Here, the overall figures of the three ciries together are presented, and dissimilarities between cities are described in the text. Only if the results of mothers in different cities showed remarkable contrasts are the results for each city presented separately. 


\section{Results}

\section{Should children learn to eat all foods?}

The proportion of mothers who agreed that their children should learn to eat the foods they served is reported in table 6.2 . While about $80 \%$ of the mothers in Liège and Maastricht agreed with this opinion, only $34 \%$ of the mochers living in Aachen subscribed to this viewpoint. Thus, two-thirds of the German mothers and less than $20 \%$ of the Belgian and Dutch mothers acknowledged that children might choose themselves what they wanted to eat. In the three cities a similar class trend was apparent: more higher-middle class mothers than working class morthers agreed that children should learn to eat everything. Yet, only in Maastricht did this class pattern reach the level of significance.

\section{Table 6.2}

Proportion of mothers who think that their children should learn to eat everything they serve according to social class in Aachen, Liège and Maastricht (\%)

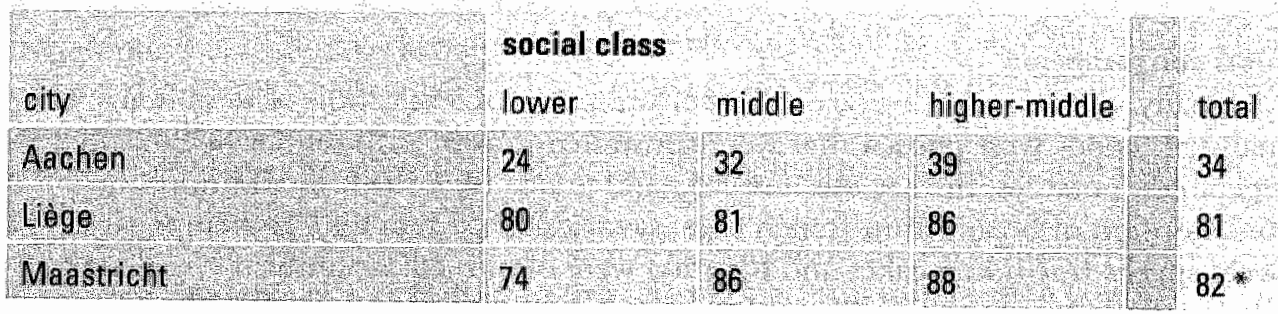

class difference, chiesquare test. "0.01<p<0.05, $p<0.01$

Table 6.3 shows the reasons mothers, who taught their children to eat all foods they served, mentioned. The great majority of mothers $(88 \%)$ stated that they found it important that their children ate a variety of foods. About half of the mothers $(49 \%)$ agrced that in this way children's taste could be developed, less than half (41\%) declared that their children had to eat what was served, when they ate somewhere else, and hardly any mother (2\%) reported that they found that their children should eat everything they served, because they should obey them. Class differences in these justifications were comparable in the three cities. Higher-middle class mothers generally mentioned more incentives than lower class mothers. Yet, compared with higher-middle class mothers, lower class mothers mentioned equally often that their children had to eat what was provided when they joined in eating somewhere else, and they reported somewhat more often that their children should obey them anyway. 


\section{Table 6.3}

Proportion of mothers who mention the following reasons to teach children to eat foods they dislike according to social class $(\%)$

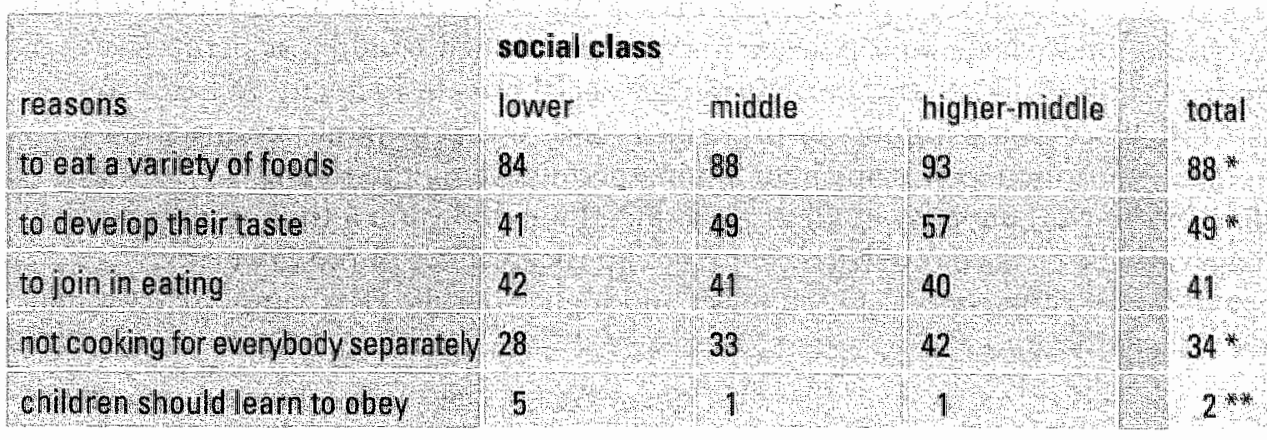

class difference, ${ }_{n}$ chi-square test: ${ }^{*} 0.01<p<0.05, * * 0<0.01$

The practices mothers applied to teach their children to eat foods they did not like is reported in table 6.4. The vast majority of the mothers (74\%) agreed that their children should at least taste a little bit of the detested food. Fewer mothers (17\%) mixed the food with another food item and only 10\% insisted that their children should clean their plate. Class patterns appeared to vary between cities. Higher-middle class mothers agreed more often that children should taste a little bit. This trend was especially apparent in Liège and to a lesser extent in Aachen and Maastricht. Lower class mothers in Maastricht reported more frequently than their higher-middle class counterparts that they mixed the food with something else. Yet, this class pattern was not apparent in Liege or in Aachen. Finally, insisting that children cleaned their plate also showed no unequivocal class pattern: in Aachen and Liège working class mothers mentioned this more often than higher-middle class mothers, while a contradictory class difference was apparent in Maastricht.

\section{Table 6.4}

Proportion of mothers who apply the following practices to teach children to eat foods they dislike according to social class (\%)

\begin{tabular}{|l|l|l|l|l|}
\hline & social class & & & \\
\hline methods & lower & middle & higher-middle & total \\
\hline they should taste a little bit & 66 & 76 & 81 & 74 ** \\
\hline mix with a food they like & 23 & 14 & 13 & 17 * \\
\hline they should clean their plate & 13 & 8 & 9 & 10
\end{tabular}

class difference, chi 1 quare 16 st $^{*} 0.01<p<0.05, p<0.01$ 


\section{Associations with other food rules}

Table 6.5 presents the number of foods strict and permissive mothers of different social classes prescribed. Mothers who insisted that their children should learn to eat everything prescribed about twice as many foods to their children as permissive mothers. This contrast was apparent in each social class in each city. Whereas no class difference in the number of prescribed foods was perceptible among strict mothers, a distinction was apparent among permissive mothers. contrary to the expectation, working class mothers prescribed more foods than their middle and higher-middle class counterparts. However, in the analyses of the three cities separately the differences between lower and higher-middle class mothers were small and not significant.

\section{Table 6.5}

Mean number of foods strict and permissive mothers prescribe their children to eat according to sacial class

\begin{tabular}{|c|c|c|c|c|c|c|c|c|}
\hline leam to eat & $\begin{array}{l}\text { social } \\
\text { lower } \\
\text { nean }\end{array}$ & $\begin{array}{c}\text { class } \\
\text { s.d. }\end{array}$ & $\begin{array}{l}\text { middle } \\
\text { mean }\end{array}$ & $\mathrm{sid}$ & $\begin{array}{l}\text { higher } \\
\text { mean }\end{array}$ & $\begin{array}{l}\text { middle } \\
\text { s.d. }\end{array}$ & $\begin{array}{l}\text { total } \\
\text { neam }\end{array}$ & \\
\hline striet? & 60 & 46 & 60 & 4.0. & 64 & 4.0 & 6.1 & 42 \\
\hline perjurssug & 3,6 & 43 & 22 & 29 & 26 & 30 & 27 & $35 \%$ \\
\hline tetal & 53 & $47 * *$ & 48 & 4.116 & 5.2 & $41 * * a$ & 50 & $43^{*}$ \\
\hline
\end{tabular}

difference between strict and permissive mothers, analysis of wariance

"class difference, analysis of variance: $0.01<p<0.05^{*} p<0.01$

The association between mothers' strictness concerning foods their children did not like and the number of foods they restricted is illustrated in table 6.6. Clearly, the insistence that children thad to learn to eat all foods was not associated with the restriction of foods deened to be bad for children: permissive mothers appeared to restrict as many foods as strict mothers. The results of the cities separately showed a comparable pattern for the samples in Aachen and Liège. However, in Maastricht stringent mothers restricted more foods than permissive mothers ( 4.5 (standard deviation s.d. $=2.2$ ) and $3.3(s . d .=2.5)$ respectively, $p<0.01)$. Finally, with regard to class differences it appeared that the higher the social class, the more foods strict and permissive mothers restricted. 


\section{Table 6.6}

Mean number of foods strict and permissive mothers restrict their children eating according to social cilass

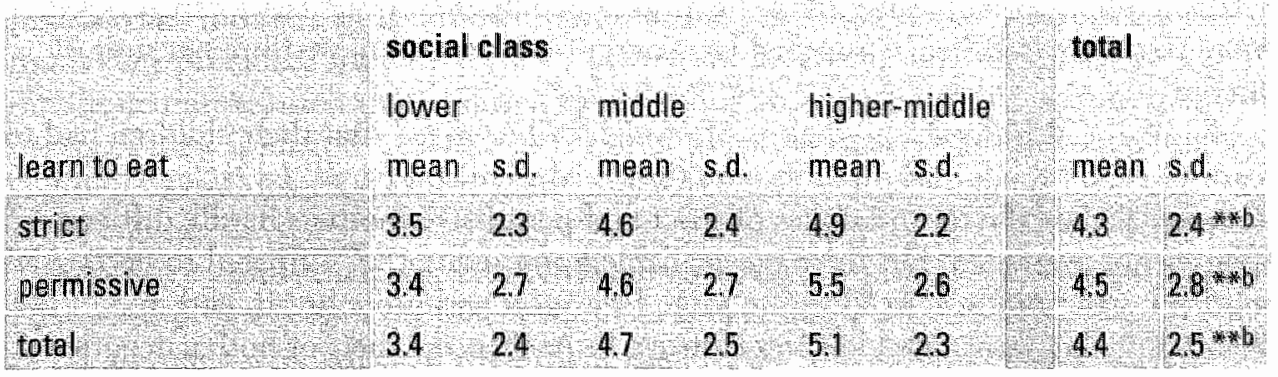

${ }^{3}$ class difference, analysis of variance: $0.01<p<0.05$, ${ }^{*} p<0.01$

\section{Associations with eating habits}

Table 6.7 shows the associations between the number of foods mothers prescribed or restricted and their eating habits. These results are presented for the three cities separately. As both mothers' rules and their eating habits varied between ciries, the overall analysis did not reflect the results in the separate cities. Although the results are presented for the cities separately, we do nor focus on cultural differences, but on the overall pattern.

In the case of the number of prescribed foods, only a few correlations appeared to differ significantly from 0 . This implied that the dietary patterns of mothers who prescribed more foods and mothers who prescribed less hardly differed: in Aachen the former category consumed more oils and fats, and especially more full-fat varieties, less wholemeal bread and more french fries. Mochers in Liège who prescribed more foods showed larger intakes of grains and bread, and in Maastricht they consumed somewhat more meat, less potatoes, and more fruit than mothers who imposed less. Thus, contrary to the hypothesis, mothers who prescribed more foods did not have healthier diets than mothers who prescribed less.

In contrast, the diers of mothers who restricted more and mothers who restricted fewer foodstuffs showed consistent differences. Generally these differences were uniform across the cities, and in line with the hypothesis. Mothers who restricted more foodstuffs consumed fewer foods that contribute to the intake of far (less meat, but relarively more lean meat, and less oils and fars) and more fibre rich foods ((Gibre rich) grains and wholemeal bread) than mothers who restricted less. The more restrictive mothers consumed less potatoes than the latter, probably because they consumed more rice and pasta. Moreover, mothers who limited more foods consumed fewer snacks (french fries, savory and sweet snacks) compared to mothers who controlled their children's consumption to a lesser extent. Only in Maastricht did mothers (and especially working class mothers) who restricted more foods consume more sweets and cookies than mothers who limited fewer foodstuffs. In 
general, mothers who restricted their children's consumption to a larger extent had healthier diers than mothers who applied fewer restrictions. Analyses of the intake of energy and the nutrients fat and fibre (these results are not shown, but these are available upon request) supported this finding: compared to the latter category, the more restrictive mothers consumed less energy and fat, and more fibre per unit of energy.

Similarly, also the dietary habits of mothers who agreed that their children had to learn to eat all foods and mothers who disagreed were compared. In each city and each social class the mean intakes of strict and permissive mothers hardly differed (figures not presented, but these are available upon request). Compared to permissive mothers, strict mothers in Liège ate more lean meat and more bread, and in Maastricht they consumed less french fries. In Aachen the diets of borh categories of mothers did not differ.

\section{Table 6.7}

Correlation coefficients between the diets of mothers and the number of foods they prescribe and restrict in Aachen, Liège and Maastricht

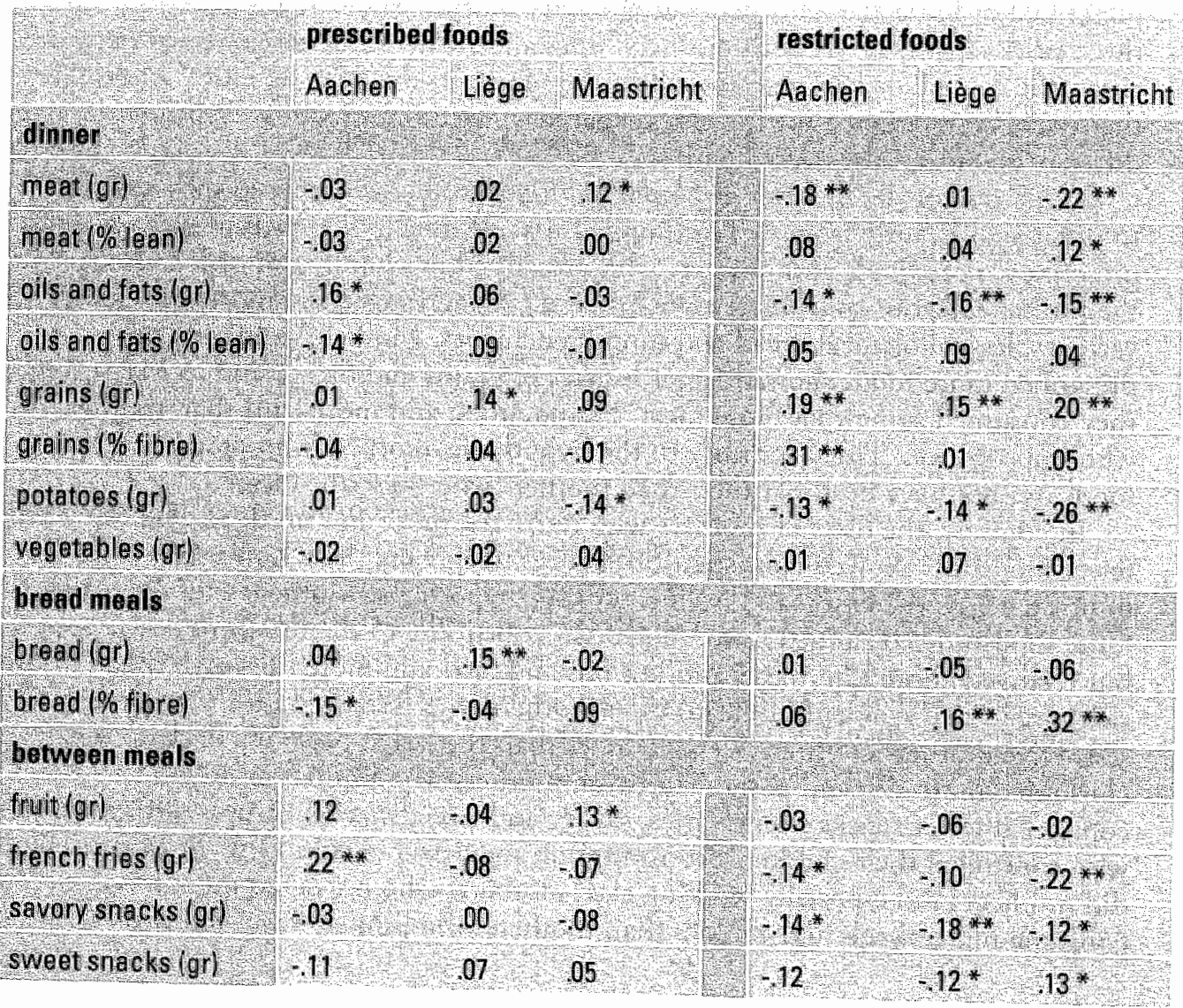

signific ant correlation: ${ }^{*} 0.01<p<0.05_{x}^{* *} p<0.01$ 


\section{Discussion}

The present study showed that, compared to working class mothers, highermiddle class morhers agreed more often that their children should learn to ear the foods they provided. Moreover, they reported more reasons, and especially mentioned more often that children's taste should be developed. Regarding the practices they applied to teach their children to eat disliked foods, they made their children taste at least a little bit more often than their counterparts of the lower social classes.

On three points there appeared to be noteworthy differences between the cities. First, class differences in the extent mothers agreed that their children should learn to eat all foods were larger in Maastricht than in the other cities. Similarly, class differences in the number of prescribed foods appeared to be larger in Maastricht than in Liège and Aachen (Hupkens, Knibbe \& Drop, 1.997a). Secondly, lower class mothers in Maastricht tended to apply less strict methods than higher-middle class mothers to teach their children to eat everything, which corresponds with the findings of the qualitative Dutch study (Van Otterloo \& Van Ogtrop, 1989). On the other hand, lower class mothers in Liège and Aachen tended to use stricter methods. A third major difference is that in Aachen a far lower proportion of the mothers agreed that their children should learn to eat everything. As the mothers in Aachen also prescribed fewer foods than the mothers in Maastricht and Liège (Hupkens, Knibbe \& Drop, 1997a), it appears that mothers in Aachen are more reluctant to prescribe what their children should eat.

With regard to the consistency between different food rules, it appeared that insisting that children eat all foods and prescribing foods were mutually related. However, these regulations were not related to the number of foods mothers restricted. Only in Maastricht, but not in the other cities, did mothers who agreed that their children had to eat all foods restrict more foodstuffs than mothers who allowed their children to eat what they wanted. Also the correlation between the number of foods mothers prescribed and the number of foods mothers restricted appeared to be insignificant (Hupkens, Knibbe, Van Otterloo \& Drop, accepted). Consequently, there seem to be at least two dimensions in food rules: prescribing foods and having children to eat all foods served on the one hand, and restricting foods which are deemed unhealthy on the other. A Belgian study on the impacr of family food rules on adolescents' eating habits demonstrated a comparable distinction between food prescriptions and restrictions (De Bourdeaudhuij, 1997).

Finally, the relation between the different types of food rules mothers apply to their children"s diets and their own dierary habits was examined. Only restricting foods appeared to be related to the mothers' eating habits: the more foods mothers restricted their children eating, the healthier their own dietary partern. As the eating habits of mothers and children are correlated (Oliveria et al., 1992; Feunekes $e t$ al., 1996), it seems safe to conclude that restricting foodstuffs allso leads to their children having a healthier diet. 
On the other hand, the results imply that differences in the extent mothers teach their children to eat all foods or differences in the extent they prescribe foods may not influence their children's diet. Evidence for these findings was presented by a retrospective study among adolescents in Belgium, which focused on the relation between the adolescents' current eating habits and the number of food prescriptions and restricrions their parents employed when they were 10 years old. That study showed that adolescents who reported more prescriptions in the past did not have heal thier eating habits than peers who mentioned fewer prescriptions, whereas adolescents who reported more restrictions had healthier eating habits than those who reported fewer restricrions. Moreover, their morhers' diets showed a similar pattern: mothers who applied more prescriptions did not have healthier eating habits than those who applied fewer rules, whereas mothers who employed more restrictions did have heal thier diets (De Bourdeaudhuij, 1997).

Concerning class differences in food rules, higher-middle class mothers in the present study applied more food rules, and especially more food restrictions, which is in line with the studies by Charles and Kerr (1988), Van Otterloo and Van Ogtrop (1989), and De Bourdeaudhuij (1997). Because, of the different types of food rules, only the number of foods mothers restricted was relared to a healthier diet in the mother, it seems likely that restrictions, rather than prescriptions, lead to a healthier diet of both mothers and their children in the higher social classes. Indeed, highermiddle class mothers had healthier eating habits, and they consumed less fat and more fibre than working class mothers (Hupkens, Knibbe \& Drop, 1997b).

This tentative conclusion does not imply that it does not make sense to prescribe children certain foods and to teach them to eat all foods. In general morhers' food prescriptions are in line with nutritional guidelines: they particularly prescribed vegetables, meat, potatoes, milk and brown bread (Hupkens, Knibbe \& Drop, 1997a; De Bourdeaudhuij, 1997). However, it is plausible that discouraging the consumption of less healthy foods, like sweets and snacks, is an effective way to improve the eating of more healthy foods. In the past decades the supply of foodstuffs has become abundant, and in particular the assortment of unhealthy snacks thas multiplied (Jobse-Van Putten, 1995; Scholliers, 1993). In addition, in the same period eating behaviour has become more individualized. More people eat bites and morsels on their own (often referred to as grazing). Also meals are being consumed less often collectively with family members or orther residents, although this trend might be less common within nuclear families thar include young children (Van Otrerloo, 1990).

A possible explanation for the fact that lower class mothers are more reluctant to restrict the food choice of their children is that especially lower class mothers have gone through the transition from relative scarcity to abundance in their youth. The majority of the parents of these mothers found the quantity of food more important than the quality. Therefore, most mothers were brought up with strict food prescriptions: they were obliged to clean their plate (Van Otterloo \& Van Ogtrop, 1989). Especially working class mothers nowadays apply fewer prescriptions than 
their parents. On the other hand, as there were fewer snacks awailable, the mothers generally experienced fewer restrictions than they employ now themselves (Van Otterloo \& Van Ogtrop, 1989), which may make it more difficult to initiate these kinds of rules.

As working cllass mothers appear to have less healthy food habits and as they employ fewer food rules than higher-middle class mothers, their children probably also have less healthy food habits. Therefore, nutrition educators should pay particular attention to lower class mothers, and not only take their knowledge and atritudes towards healthy food into account, but also increase their ability to restrict unhealthy foods.

\section{References}

\section{Backett, K.}

(1992). Taboos and excesses: lay health moralities in middle class families. Sociology of Health and Illness, 14, 255-273.

Bandura, A.

(1986). Social foundations of thought and action. A sacial cognitive theory. Englewood Cliffs: Prentice Hall.

Bausch-Goldbohm, R.A., Van Den Brandt, P.A., Van 't Veer, P., Sturmans, F. \& Hermus, R.J.].

(1988). Results of the methodological study for the clesign of a simplified, selfadministered questionnaire. In: E. Riboli \& R. Saracci (Eds.), Diet, hormontes and cancer: methodological issues for prospective studies. IARC Technical Report No. 4 (pp. 79-89). Lyon: International Agency for Research on Cancer.

Blaxter, M. \& Paterson, E.

(1982). Mothers and daughters. A three-generational study of health attitudes and behaviour: London: Heinemann.

Charles, N. \& Kerr, M.

(1988). Women, food and families. Manchester: University Press.

Cohen, R.Y., Brownell, K.D. \& Felix, M.R.J.

(1990). Age and sex differences in health habits and beliefs of schoolchildren. Health Psychology, 9, 208-224.

Contento, I.R., Basch, C., Shea, S., Gutin, B., Zybert, P., Michela J.L. \& Rips, J.

(1993). Relationship of mochers' food choice criteria to food intake of preschool children: identification of family subgroups. Healib Education Quarterly. 20, 243-259.

De Bourdeaudhuij, 1 .

(1997). Family food rules and healthy eating in adolescents. Joumal of Heath Psychology, 2, 45-56. 
Feunekes, G.I.J., Satlew, A. De Graaf, C. \& Van Staveren, W.A.

(1996). Family resemblance in fat intake in the Netherlands. In: G.L.J. Feunekes, Foods fat, family and friends: studies on the impact of the social enwiroment on dietary Fischler, $\mathrm{C}$ intake (thesis, pp. 55-72). Wageningen: Ponsen \& Looujen.

(1986). Leatned wersus 'spontaneous" dieterics: French mothers' views of what children should eat. Socral Science Information, 25, 945-965.

Furst, T., Connors, M., Bisegni, Ci.A., Sobal, I. \& Winter-falk, L.

(1996). Food choice: a conceptual model of the process: Appetite, 26, 247-266.

Goldbohm, R.A., Van Den Brandt, P.A., Brants, H.A.M., Van 't Veer, P., Al, M., Sturmans, Fi \& Hermus; R.j.J.

1994). Validation of a dietary questionnaire used in a large-scale prospecrive cohort study on diet and cancer. European Jowmal of Clinical Nutrition, 48, 253-265.

Goldbohm, R.A., Van 't Veer, P., Van Den Brandt, P.A., Van 't Hof, M.A., Brants, H.A.M., Sturmans, F. 8c Harmus, R.J.J.

(1993). Reproducibility of a food frequency questionnaire and stability of dietary habits determined from five annually repeated measurements. In: P.A. Van Den Brandt \& R.A. Bausch-Goldbohm, A prospective cohort study on diet on cancer in the Nethertands. Design, conduct, analysis and first results after 3.3 years of follow-ap (thesis, pp. 47-58). Maastricht: University Press.

Hautvast, J.G.A.J.

(1993). The future of nutrition in Europe. European Jourmal of Clmical Nutrition, 47, Suppl. 1, S96-\$100.

Hupkens, C.L.H., Knibbe, R.A. \& Drop, M.].

(1997a). Cultural and class differences in food rules in nuclear families. In: B.M. Köhler, E. Feichtinger, E. Barlösius \& E. Dowler (Eds.), Poverty and food in welfare societies. Berlin: Sigma.

Hupkens, C.L.H., Knibbe, R.A. \& Drop, M.J.

(1997b). Social class differences in women's far and fibre consumption: a crossnational study. Appetite, 28, 131-149.

Hupkens, C.L.H., Knibbe; R.A., Van Otretoo, A.H. \& Drop, M.J.

Social class differences in the food rules mothers impose on their children: a crossmational study. Social Science and Medicine, accepted.

James, W.P.T., Ferro-Luzzi, A., Isaksson, B. \& Szostak, W.B.

(1988). Healtby mutrition. Pretenting nutrition-pulated diseases in Europe. Copenhagen: WHO Regional Publications, European Series No. 24.

Jobse-Van Putten, I.

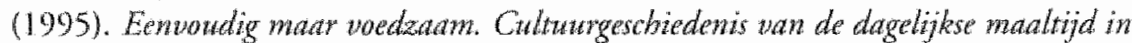

Nederland [Simple, but nourishing. Social history of the daily meal in the

Netherlands]. Nipmegen: SUN.

Kennedy, E. \& Coldberg, J.

(1995). What are American children eating? Implications for public policy. Nutrition Reviaws. 53,111-126. 
Kocke, $A$.

(1995). Der Einfluß sozialer Ungleichtheit auf das Ernahrungsverhalen im Kindesund Jugendalter [The influence of social inequality on eating habits in childhood and adolescence]. In: E. Barlosias, E. Feichtinger \& B.M. Köher (Eds.), Ermahrung in dop Armut (pp. 185-203). Berlin: Edition Sigma.

Laitinen, S., Räsänen, L., Viikari, J. \& Akerblom, H.K.

(1995). Diet of Finnish children in relation to the family's sociomeconomic status.

Scandinavian Journal of Social Medicine, 23, 88-94.

Lupton, D.

(1996). Food, the body and the self. London: Sage Publications. Mayall, B.

(1986). Keeping children bealthy. The role of mothers and professionals. London: Allen \& Unwin.

McKie, L.J., Wood, R.C. \& Gregory, S.

(1993). Women defining health: food, diet and body image. Health Education Research, 8, 35-41.

Oakley, A. \& Rajan, L.

(1993). What did your baby eat yesterday? Sociall factors and infant feeding pracrices.

European Joumal of Public Health, 3, 18-27.

Oliveria, S.A., Ellison, R.C., Moore, L.L., Gillman, M.W., Garrahie, E.J. \& Singer, M.R.

(1992). Parent-child relationships in nutrient intake: the Framingham children"s study. American Joumal of Clinical Nutrition, 56, 593-598.

Pill, R., Peters, T.J. \& Robling, M.R.

(1995). Social class and preventive health behavior: a British example. Jourmal of Epidemiology and Community Health, 49, 28-32.

Scholliers, P.

(1993). Arm en rijk aan affel. Tweebonderd jatr eetcultuw in Belgia [Poor and rich at table. Two hundred years of eating culture in Belgium]. Berchem: EPO.

Steproe, A., Pollard, T.M. \& Wardle, J.

(1995). Development of a measure of the motives underlying the selection of food: the Food choice questionnaire. Appetite, 25, 267-284.

Van Berkel-Van Schaik, A.B. \& 'Tax, B.

(1990). Natr een standandoperationalisatie van sociad- economische statur vor epidemiologisch en sociaal-medisch anderzoek [Towards a standardized operationalization of socio-economic status for epidemiological and social-medical research]. Rijswijk: Ministerie van Welzijn, Volksgezondheid en Cultuur.

Van Der Lucht, F. \& Groothoff, J.W.

(1995). Social inequalities and health among children aged 10-11 in the Netherlands: causes and consequences. Social Sience or Medicine, 40, 1305-1311.

Van Otterloo, A.H.

(1990). Eten en eetlust in Nederland (1840-1990). Een bistorisch-sociologische studic [Food and appetite in the Netherlands (1840-1.990). A historical sociological study]. Amsterdam: Bert Bakker. 
Van Otterloo, A.H. \& Van Ogtrop, J.

(1989). Het regime van veel, wet en zoet: praten met moeders over voeding en gezondheid The regime of plenty, fat and sweet: talking with mothers on food and health]. Amsterdam: Vư Uitgeverij.

Willett, W.C.

(1994). Diet and health what should we eat? Science, 264, 532-537.

Winkleby, M.A. Jarulis, D.E., Frank, E. \& Formann, S.P.

(1992). Socioeconomic status and bealth: how education, income, and occupation contribute to risk factors for cardiovascular disease. American Joumal of Public Health, $82,816-820$. 


\section{General discussion}

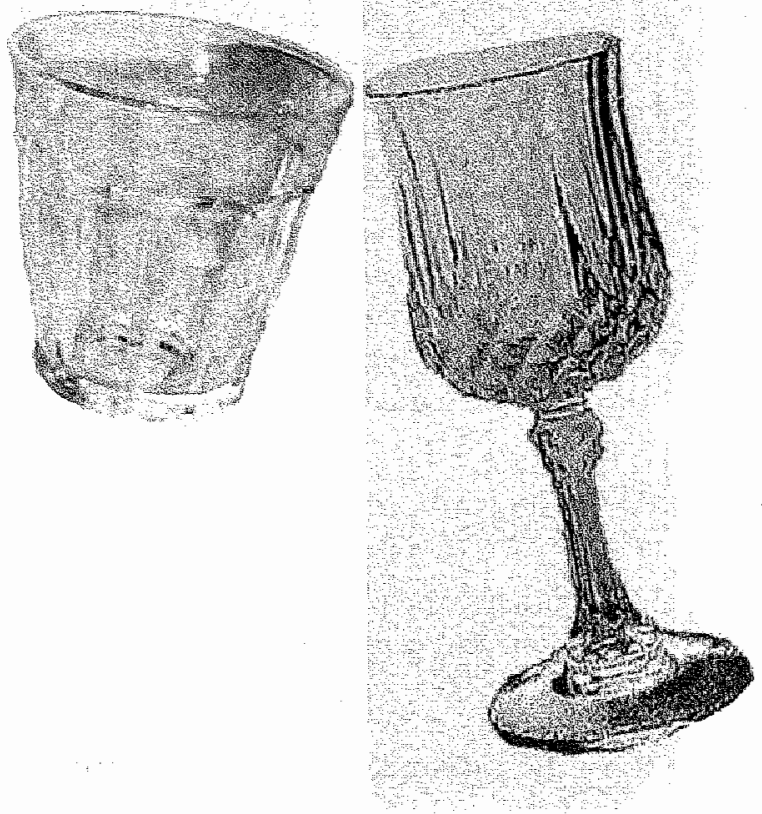


This thesis examined class differences in eating and drinking behaviour More specifically, the present study focused on the consumption of foods and drinks, food choice considerations, and the way mothers discipline their children in food matters. Two international surveys were used to explore these topics. Data of the 29 th Eurobarometer were analysed to explore patterns of drinking behaviour of men and women in twelve countries of the EC. In addition, we conducted a survey on eating behaviour among mothers with young families in Maastricht, Liège and Aachen. Both studies offered the opportunity ro compare social class patterns in eating and drinking behaviour between cultures.

This chapter starts with a brief overview of the most important results of these studies. Also international variations in food consumption patterns are discussed. Next, methodological considerations with regard to the design of the two studies, the operationalisation of social class and the influence of social desirability are deliberated. Furthermore, the theoretical relevance and implications for nutrition educarion and policy are addressed. Finally, suggestions and recommendations for further research are presented.

\section{Main findings}

The main results of the present study are summarised in figure 7.1 . This figure presents details on eating and drinking behaviour of higher-middle class people compared with lower class people.

\section{Social class differences in the consumption of foods and drinks}

The data of the Eurobarometer showed that in all countries people of higher educational levels favoured the new beverage type, while people of lower educational levels in the northern countries preferred the traditional alcoholic drink (chapter 2). In the northern countries a larger proportion of the higher educated people drank wine, and in the Mediterranean countries more higher educated people consumed beet than their lower educated counterparts. In the traditional wine countries the proportion of people who drank wine did not vary with social class, but in the traditional beer countries more lower class people consumed beer. There appeared to be not only more people of the higher social classes who drank the new beverage type, they also consumed it more frequently, whereas lower class people in the northern countries consumed the traditional beverage type (beer) more often. With respect to class differences in beer and wine consumption with meals or between meals, it appeared that in some northern countries especially higher class people took on the Mediterranean custom to consume wine with meals. 


\section{Figure 7.1}

Main results of higher-middle class people compared with lower class people

consumption of foods and drinks

chapter

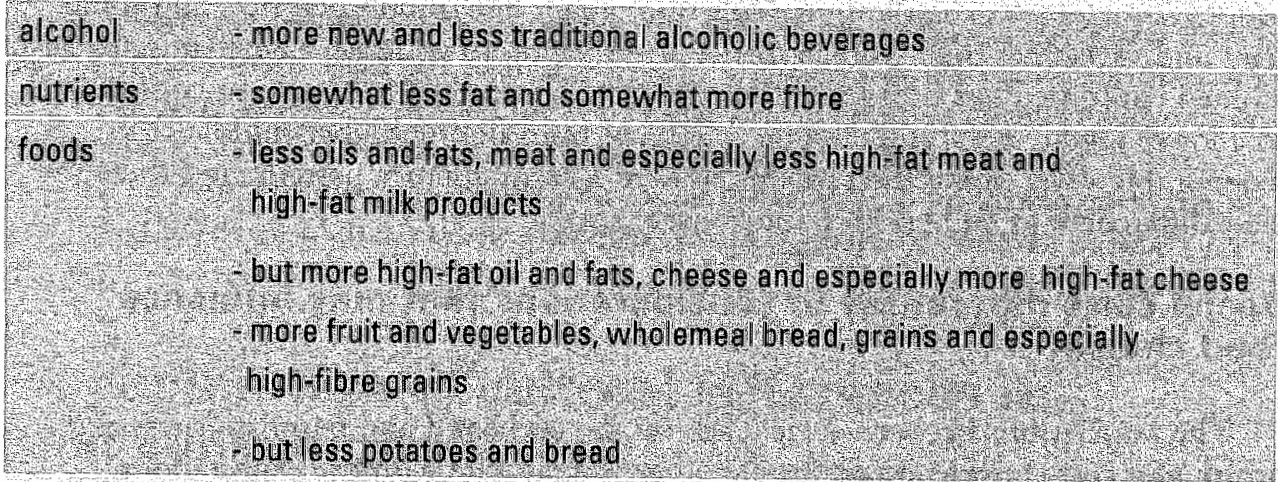

\section{considerations that may influence food choice}

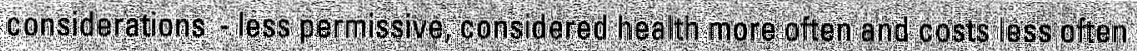

these considerations did not explain cuss difforenos in tood consumption

\section{food rules}

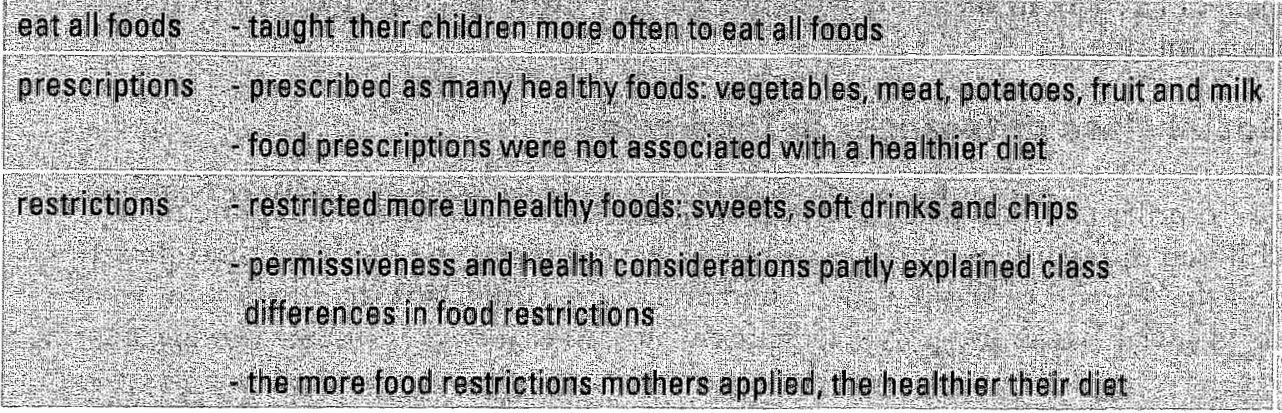

With regard to the consumption of fat and fibre, the study on eating behaviour showed that higher-middle class women in Mastricht and Liège consumed less energy and less far (in absolute amounts) and more fibre (relative to energy intake) compared to working class women. However, the differences were small, and fibre intake expressed in grams and fat intake as a proportion of energy intake did not vary between the social classes. Furthermore, the women in Aachen showed no class differences in the intake of these nutrients (chapter 3).

Class differences in the consumption of food groups were generally comparable in the three cities, but not always significant. With respect to foods that contribute to the intake of fat, higher-middle class women consumed less oils and fats, less meat and especially less high-fat meat products, and less high-fat milk products. However, 
they consumed more cheese and especially more high-fat cheese, and they more often preferred hight-fat oils and fats to alternatives with a lower fat content like lowfat margarine. With regard to foods that contain fibre, women of the higher social strata chose more often brown and wholemeal bread. In addition, they consumed more grain and particularly more high-fibre grain, like unpolished rice, and more fruit and vegetables than women of the lower strata. In contrast, higher-middle class women consumed less bread and less potatoes. Thus, most food groups contributed to a lower intake of fat and a higher intake of fibre among higher-middle class women. However, some food groups showed a contradictory pattern, and therefore class differences in fac and fibre intake were small.

\section{Social class differences in considerations that may influence food choice}

The associarions between social class on the one hand and permissiveness and health and cost considerations on the other were in line with the expectations. Mothers of the higher strata reported more frequently that they considered health in their food choice, and mothers of the lower strata mentioned more often that they considered expenses (chapter 4). Moreover, higher-middle class mothers applied more food restrictions in the education of their children, indicaring that they were less permissive than working class mothers. However contrary to the expectation, class differences in these considerations hardly explained class patterns in food consumption.

\section{Social class differences in food rules}

In order to study whether mothers of different social strata discipline their children differently with respect to food, we examined the foods mothers prescribed and the foods they limited their children eating. Foods that the majority of mothers in all social classes prescribed were foods that were served at dinner like meat, vegetables and potatoes (chapter 5). Lower class mothers prescribed as many foods as higher-middle class mothers. Foods that were limited by the majority of mothers in boch social classes were sweet foods, sofr drinks and chips. Generally, higher-middle class mothers restricted more foods than their lower class counterparts. This class difference was party explained by health considerations and opinions on the approval of children"s own preferences.

Another food rule that was examined in the present study was the mothers agreement whether their children should learn to eat all foods. Higher-middle class morhers agreed more often with this viewpoint and they obliged their children more often to taste at least a little bit, if their children did not like a food, whereas working class mothers allowed their children more frequendy to eat what they wanted and to leave foods they did not like (chapter 6). With respect to the association between food rules, it appeared chat morhers who insisted that their 
children should learn to eat all foods prescribed about twice as many foods to their children as permissive mothers. Only in Maastricht, but not in the other cities, did the former category of mothers also restrict more foods than permissive mothers.

Finally, it was tested whether stricter food rules were associated with healthier eating behawiour. Mothers' food prescriptions and their opinion that children should learn to eat all foods were not related with their own consumption, but mothers who restricted more foods for their children had healthier food consumption patterns. As mothers' and children's diets are correlated (Feunekes, Stafleu, De Graaf \& Van Staveren, 1996), this finding suggests that class differences in children's diets can be attributed partly to higher-middle class mothers being more restrictive in food choices.

\section{An exploration of cultural differences in food consumption}

Although we focused on class differences in eating behaviour in different cities, it is also interesting to examine variations in food consumption patterns between these cities. Table 7.1 presents an overview of the food consumption data in the three cities. All food groups appeared to vary significantly berween the three cities.

\section{Table 7.1}

Mean daily food consumption of women living in Maastricht, Liège and Aachen

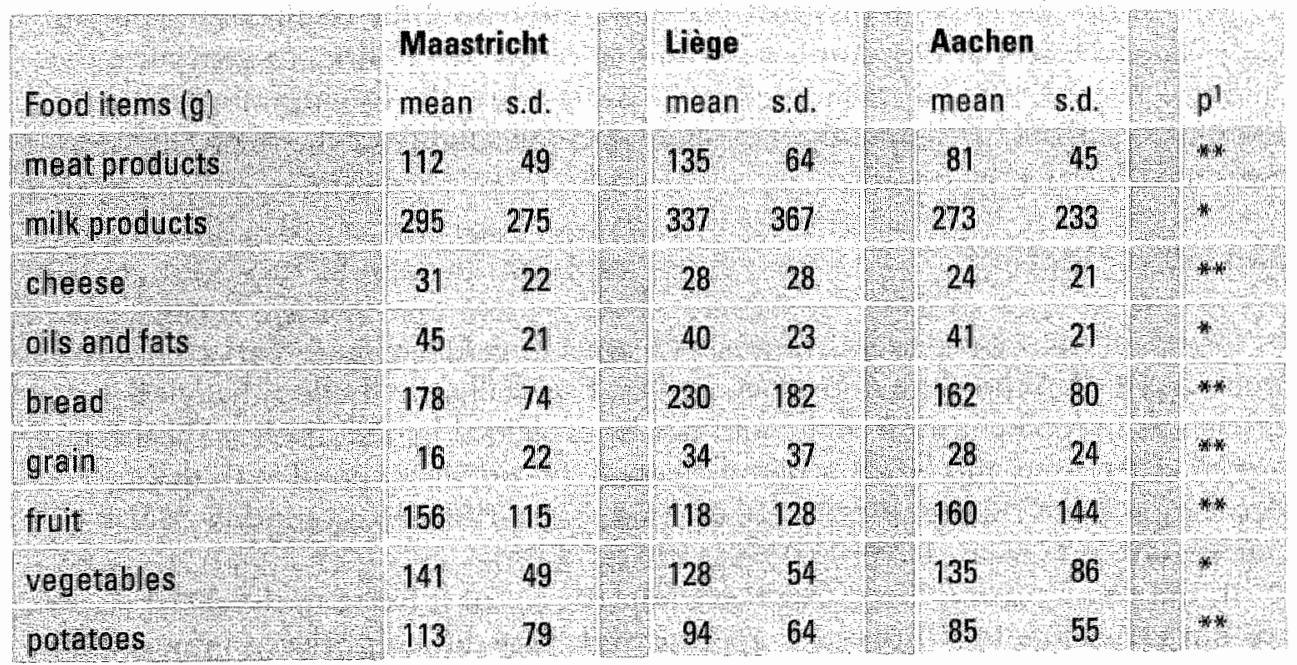

'analysis of wariance: ${ }^{*} 0.01<0<0.05, * * 0<0.01$ 
Generally the Dutch mothers showed the highest consumption of cheese, edible oils and fats, vegetables and potatoes, the Belgian mothers consumed the largest amounts of meat products, millk products, bread and grain, and the German mothers ate most fruit. Thus, food consumption waried not only between social classes, but also between cultures. In fact for some foods the differences between the cities were far larger than the differences between the lower and higher social classes within a ciry. Meat consumption, for instance, appeared to be highest in Liège and. lowest in Aachen. Although in each city meat consumption was higher among working class women than among higher-middle class women, Belgian highermiddle class women consumed more mear than Durch working class women, and Dutch higher-middle class women consumed more meat than German working class women. The consumption of bread showed a similar pattern.

Moreover, apart from social class differences, an international comparison of dietary habits is interesting. During the past decades food consumption patterns in different cultures have converged. The Seven Countries Study, for instance, showed that differences in food consumption patterns in Finland, Greece, Italy, Japan, the Netherlands, the United States and former Yugoslavia lessened in the period between 1960 and 1985 (Kromhout, Keys, Aravanis et al., 1989). Yet, in 1985 national differences between these widely divergent countries were still significant. The present study too showed that, even in such a small border region, the consumption of some foods varies considerable. Despite the shared history and the present connections between Maastricht, Liège and Aachen, national cultures appear to be very powerful.

\section{Methodological considerations}

This section describes topics that may have influenced the results of the present study. The selection of the samples may influence the possibilities to generalise the findings. The operationalisation of social class may bias the findings on class differences, and social desirability may influence the validity of the results. These issues are discussed below.

\section{Sample selection}

Generally, the class patterns in the study on eating behaviour were less pronounced than those cited in other studies. Especially the finding that class differences in food consumption could not be explained by the mothers' health and cost considerations and by their permissiveness did not correspond with the expectation based on the literature (Charles \& Kerr, 1988; Van Otterloo \& Van Ogtrop, 1989; Calnan, 1990; DeVault, 1991).

In the present survey on eating behaviour the contrast between the social classes was not very large. In all surveys it appears to be very difficult or even impossible to 
reach the upper classes and the lowest segment of the lower social classes. Moreover, in the present survey we did not select extreme lower and upper class districts. We rather chose 'common' districts, that were representative for the majority of working class and higher-middle class areas. Also the response in the three cities appeared to be somewhat lower in the working class districts than in the higher-middle class districts: $71 \%$ of the mothers in the lower class districts cooperated with the study, whereas $80 \%$ of the mothers in the higher-middle class districts participated. The non-response may have been selective. Possibly especially persons with a very low educational level, who may have difficulties with reading and writing, refused to collaborate.

In addition, we did not include incomplete families, as the number of these families probably would have been too small to justify conclusions. More than $80 \%$ of the lower class families in the three samples earned an income, and the working class women and their partners were mainly semi-skilled and skilled workers. The Dutch study on class differences in food regimes (Van Otterloo \& Van Ogtrop, 1989) showed that mothers who themselves or their partner were skilled or semiskilled labourers had more in common with higher-middle class mothers than mothers from a socially more deprived background (single mothers and families on social security). As the lower class families in the present study were comparable to the higher segment of the working class in the study of Van Otterloo and Van Ogtrop, the class contrasts in the present study were not very large. Since people from the very low and the upper classes were not represented in the study, our conclusions cannot be generalised to include the most deprived and the most welloff people, but they are valid for the majority of lower and higher-middle social class families living in Maastricht, Liège and Aachen.

The finding that the significance of the class patterns varies between the three cities may also be associated with the selection of the samples. Generally, class differences in food consumption and in food rules were smaller in Aachen than in the other two cities. The districts in Aachen appeared to be more heterogeneous with respect to the women's educational level. In the working class districts in Aachen $21 \%$ of the women had a high educational level, which was much higher than in Maastricht $(1 \%)$ and Liège ( $2 \%)$. On the other hand, in Aachen more women in the higher middle class districts had a low educational level (12\%) than in Mastricht $(6 \%)$ and Liège $(8 \%)$. One of the possible explanations is that women living in more heterogeneous districts have more contacts with people of different socio-economic backgrounds, which may influence their eating behaviour. Also the supply of foods in heterogeneous districts may differ, as shops in these districts may have adapted their assortment to a wider public.

Most studies on social class differences in eating behaviour have been performed in the UK, as this country has a long tradition in research on socio-economic health differences (Fox, 1990). The stronger hierarchy of social classes in the UK may influence lifestyle to a larger extent than in the Netherlands, Belgium and Germany. Moreover, in the UK income inequalities and the number of households living in 
powerty are larger, and thus it seems that class differences in terms of material resources are more significant (Kooiker \& Christiansen, 1995).

\section{Operationalisation of social class}

In the present study educational level was used as the indicator of social class. In comparison with other indicators of social class (occupational level and income) educational level generally shows the largest socio-economic differences in health (Rijksinstiruut voor Volksgezondheid en Milieu, 1997). Similarly, in the present study on eating behaviour the effect of five different indicators on food consumption patterns was compared: (1) educational level of the women, (2) educational level of their partners, (3) occupational status of the women and (4) of their partners, and (5) family income (a dichotomous variable: either salary or state benefit). Occupational status was classified into ten categories, based on the International Standard Classification of Occupations ISCO-88 (International Labour Office, 1990). Of these five indicators, the women's educational level appeared to show the largest differences in food consumption.

A possible disadvantage of the use of educational level is that it varies with age. Younger people are generally higher educated than older people, and thus age effects may interfere with the effects of educational level. In the present study on eating behaviour, this age effect hardly influenced social class differences, as the women belonged to the same generation: the large majority of the women in the three cities were aged between 30 and 40 years. In the study on drinking behaviour analyses for younger and older people separately showed similar results. Thus, age did not interfere with social class differences in beer and wine consumption.

\section{Social desirability}

Although it was emphasised in the food frequency questionnaire that we were interested in the general consumption of foods in the past year, and although the interviewers stressed that the answers were handled anonymously, social desirability may have biased the answers. The women may have reported opinions and practices they aspire to, but are not (yet) able to accomplish (Van Otterloo, 1995a). In so far as the results of the mother's of both social classes were coloured by social desirability, it probably would hardly affect social class differences in food consumption or underlying beliefs. Van Otterloo (1995a) reported that in the ethnographic study on food regimes the interviewers noted that especially mothers of the lower social classes 'felt the urge to present themselves as competent mothers and housewives'. If this was also the case in the present study, the actual social class differences in eating behaviour and food related beliefs and practices are even larger than those reported in the present study. 


\section{Theoretical implications}

Between 1960 and 1985 the consumption of alcohol, meat, vegetables, fruit, pastries and nuts has increased in the Netherlands, Belgium and Germany, while the consumption of bread, grain, potatoes and milk has decreased (Frank, 1987; Kromhout, De Lezenne Coulander, Obermann-De Boer, Van Kampen-Donker, Goddijn \& Bloemberg, 1990). The present study on eating behaviour showed that higher-middle class women consumed more fruit and vegetables, and less bread, potatoes and milk products than working class women. Thus, higher-middle class women displayed more modern eating habits. Exceptions were the consumption of meat, pastries and savoury snacks, which have augmented since 1960 , and were highest in the lower social strata. Probably higher-middle class women consumed less meat, as they replaced meat more often with cheese, and they apparently ate less snacks, because they were more concerned with slimming and health (Van Otrerloo, 1995a). The study on drinking behaviour clearly showed that the consumption of new beverages was higher among higher-middle class people, whereas traditional beverages were preferred in the working classes.

The results of the two studies are in line with the theories of Elias (1982), Mennell (1985) and Bourdieu (1989): higher-middle class people distinguish themselves from the working classes by their more modern eating and drinking behaviour. Women of the higher social strata display healthier habits and are more concerned with health than working class women. Thus, social class differences in food consumption may explain part of the socio-economic health differences, that have been reported in many studies (e.g. Townsend, Davidson \& Whitehead, 1988; Davey Smith, Bartley \& Blane, 1990; Lagasse, Humblet, Lenaerts, Godin \& Moens, 1990; Kirchgässler, 1990; Helmert, Mielck \& Classen, 1992; Kunst \& Mackenbach, 1994).

In addition to health considerations, notions on the quality of food also seem to be an important consideration that may differ between social classes, as the study of Van Otterloo and Van Ogtrop (1989) showed. Usually considerations on quality and health go together. To give an example: higher-middle class women bought smaller amounts of meat, but more often beef, poultry and lean cuts of meat, as these were valued because of their better quality. Working class women favoured mear because of its luxury and 'filling' nature: they bought larger portions of meat and more often cheaper types like pork and high-fat cuts. Van Otterloo (1995a) reported that working class women interpreted the quality of meat differently. According to these mothers, meat of good quality was meat that was not rotten and good-looking, whereas higher-middle class mothers valued meat with a low fat content.

However, in the case of some foods health and quality aspects may disagree. This was possibly the case with the choice of edible oils and fars. Higher-middle class women consumed less oils and fats, but they selected more often high-fat products, while working class women chose more often medium-fat alternatives, like low-fat 
maxgarine or low-fat mayonnaise. Possibly higher-middle class women try to diminish their fat intake by consuming less oils and fats, but if they consume it, they prefer butter to low-fat margarine, because they find that butter has a better quality.

Compared to women of the higher social classes, working class women rook the preferences of their family members more often into consideration and they were more often constained by their budget. This illuminates the different position of lower class and higher-middle class women in their family, which has been

elaborated by Van Otterloo and Van Ogtrop (1989). Because of the more dependent position of working class women, they may have less possibility to resist the pressures of their family members. This finding illustrates that eating behaviour cannot be detached from material and structural circumstances, as the authors of the Black Report already indicated (Townsend, Dawidson \& Whitehead, 1988).

Simillarly, studies on class differences in health attitudes reported that "coping rechniques in working class families were directed mainly toward actual problem solving, neglecting long-term prospective and preventive concern, whereas skills and cognitive patterns related to deferred gratification and long-term planning favoured preventive health attitudes in middle- and upper-class families" (Siegrist, 1989; see also Calnan, 1990). Taking health into consideration requires the ability to plan in the long term and to postpone satisfying needs, which is an aspect of the internalization of norms or the civilising process (Van Otterloo \& Gerritsen, 1991).

Whether the lower social classes adopt the eating and drinking behaviour of their higher-middle class counterparts after some time could not be examined in the present study, as we were not able to study trends. A Scandinavian study on trends in food consumption between 1970 and 1990 showed that a lower consurnption of fat and especially of saturated fat, and a higher consumption of fruit and vegetables was initiated in the higher social classes in Finland, Norway and Sweden. The lower social classes followed this pattern five to ten years later (Prättällä, 1995).

However, examination of food rules suggests that food consumption patterns may also be partly replicated from generation to generation. Working class mothers were more permissive than their higher-middle class counterparts: they agreed less often that their children should learn to eat all foods, and they restricted less often their children's eating unhealthy foods. As working class children were more often allowed to eat what they wanted than higher-middle class children, they may have less healthy food habits in their youth, and possibly also when they grow older. The association between food rules and children"s food consumption has been confirmed in a study conducted in Flanders. Adolescents who experienced more food restrictions when they were 10 years old still had healthier eating habits a couple of years afterwards (De Bourdeaudhuij, 1997).

Moreover, food consumption patterns of mothers and children appear to be associated. A study on food consumption and attitudes between three generations of women of mainly working class families showed that mothers' and daughters' eating behaviour was correlated (Stafleu, Van Staveren, De Graaf, Burema \& Hautvast, 1994). Thus, working class women may not only adopt higher-middle class eating 
behaviour, but also take on the customs they learned at home when they were young. Indeed, Van Otterloo and Van Ogtrop (1989) and Charles and Kerr (1988) illuminated that particularly working class mothers referred to the eating habits in their youth when they talked about their current eating behaviour.

With regard to future eating behaviour, the theories of Elias (1982), Mennell (1985) and Bourdieu (1989) predict that higher-middle class people keep on distinguishing themselves from the lower social classes. In line with the process of the civilising of appetite, internalisation of norms implying long-term planning and deferred gratification become more important. Thus, according to the theories of Elias and Mennell working class people will take health aspects more and more into consideration, just like their higher class counterparts, suggesting that class differences in food consumption may become smaller. In order to distinguish themselves from lower class people, people of the higher social strata may keep on changing their habits, for instance, by following the latest scientific insights concerning healthy eating. It has also been stated that social class differences become more subtle and complex. Prärtaillä (1995) suggested that 'instead of differences in the use of single foods, social classes are likely to differ in the way they talk about food, set their rables and combine foods into dishes and meals'.

\section{Implications for nutrition education and policy}

When people make food choices, they choose food items and meals rather than nutrients. Most people find it very difficult to estimate their nutrient intake. A study on the correspondence between objective assessments of dietary fat intake and selfrated fat intake showed that the majority of the respondents underestimated their fat intake. As a result, they did not follow the recommendations to eat less fat (Brug, Van Assema, Kok, Lenderink \& Glanz, 1994). More specific recommendations on the main food sources of fat like edible oils and fats, meat products, milk products and cheese might be more influential.

The results of the present study on social class differences in food consumption suggest that nutrition education may be even more effective if it is adjusted to the different social strata. In order to diminish the intake of fat, for instance, lower class people may be informed on the (small) amount of meat that is needed to perform heavy physical labour, and on products with similar qualities that may substitute meat, while people of the higher social strata may be advised to eat less cheese, and to choose more often medium-fat types of cheese. In addition, nutrition education may be more appealing, especially to people of the lower strata, if it emphasises benefits in the short term, for instance by stressing the appetising aspects of the recommended foods, besides the health benefits. In order to reduce socio-economic health differences, nutrition education may direct special attention to lower class families, for instance via general practitioners and dietitians in working class districts.

Although we could not examine the impact of mothers' food rules on their 
children's food intake, as we had no data on children's consumption, the results suggest that especially the restriction of unhealthy foods leads to a healthier diet. It appeared that mothers who restricted more foods had healthier food consumption parterns themselves, and it seems likely that their children too had healthier diets. This finding implies that nutrition education should encourage mothers to limit the consumption of unhealthy snacks. This message may be directed to working class mothers, as they limit the consumption of sweets and snacks least often.

Not only a reduction in the consumption of snacks, but also in the number of eating situations may be an important lead for nutrition education. An analogy between drinking and eating situations suggests that diminishing the number of eating situations may reduce the number of people who are overweight. When people acquire new drinking habits, addition rather than substitution takes place: new drinking habits are generally added to the already existing ones (Lemmens, 1991). If people in the northern countries, for instance, start drinking wine at meals, they generally do not diminish their consumption of beer on an evening out.

This development parallels that of earing situations. In the past twenty years the number of food items has increased explosively and also the number of eating situations has increased: eating snacks between meals and grazing (eating more often smaller meals) have become popular (Van Otterloo, 1995b). For most people it is probably easier to add a new eating situation or a new food to their consumption partern than to break with an old habit. As a result, people probably now consume a greater variety of foods on more occasions than ever before. As the extension of drinking situations in recent decades partly explains the increase of both alcohol consumption and the number of people who drink heavily, so the expansion of earing situations may have generated an increase of the number of people who are overweight. Thus, confining the number of eating situations might be an important aim of nurrition education.

Finally, not only the demand of food can be adjusted, but also the supply of foods may be changed to encourage a healthy food choice. Food industries may be stimulated to develop foods that are both tasty and that contribute to a healthy diet. The popularity of the light-products has shown that food industries are able to create sucth a demand. On a smaller scale, a supply of healthy foods in for instance canteens at schools or at work may be effective.

\section{Recommendations for future research}

First, it would be interesting to study which cultural determinants influence national food consumption patterns. For instance, are national patterns effected by differences in health education campaigns and/or in cultural identity? To comprehend cross-cultural studies on food, comparative cultural-historical research on food habits is needed. 
Secondly, in order to verify the predictions of the theories of Elias (1982), Mennell (1985) and Bourdieu (1989) it is recommended to study the consumption of foods and drinks of lower and higher class people longitudinally. Do lower class people adopt the consumption patterns of the higher classes, and do higher class people distinguish themselves from the working classes? And what are the motivations for their preferences? Specific attention could be given to foods and drinks that are first popular in one social stratum and then in the other, the so-called 'rising' and 'falling' foods and drinks.

In the present study we did not have information on the eating habits of the children. However, in order to examine the impact of mothers' (and fathers") food rules on children's consumption, it is recommended to gather data on children's eating habits in relation to that of their parents. Also in this case a longitudinal design would be interesting, as it offers the opportunity to study the development of eating habits from childhood and adolescence to adulthood. Comparing the development of eating behaviour of people who are upwardly and downwardly mobile with that of people whose social background does not change may provide insight into the impact of both the food regimes during youth and the newly achieved social status on food choice.

In order to expand the knowledge on how food choices are made within families and on social class differences in these choices, the position of the mother in the family should be studied. Although mothers generally are the gatekeepers within their families, as they mostly buy and prepare food, they do not make these decisions autonomously. The association between the mother's position in the family and their food choice may be compared in different families: single-parent families, complere families where one partner (mostly the father) has a job, and families where both partners are employed.

Finally, the present study may be extended by exploring the food regimes and eating habits of the lower segment of the lower social classes, including (singleparent) families on social security, and the upper classes in cultures with varying social distances between the social classes.

\section{References}

\section{Bourdieu, P.}

(1989). Distinction. A social critique of the judgement of taste. London: Routledge \& Kegan Paul. [Originally published in French: Bourdieu, P. (1979). La distinction. Critique sociale du jugement. Paris: Les Editions de Minuit.]

Brug, J., Van Assema, P., Kok, G.s Lenderink, T. \& Glanz, K.

(1994). Self-rated dietary fat intake: association with objective assessment of fat, psychosocial factors, and intention to change. Jouryal of Nutrition Education, 26, 218-223. 
Calnan, $M$.

(1990). Food and health: a comparison of beliefs and practices in middle-class and workingmolass households. In: S. Cunningham-Burley \& N.P. McKeganey (Eds), Reading in medical sociology (pp, 9-36). London: Routledge.

Chatles, N. \& Kerr, M.

(1988). Women, food and families. Manchester: Universicy Press.

Davey Smith, G. Bardey, M. \& Blane, D.

(1990). The Black report on socioeconomic inequalities in health 10 years on. British

Medical joumal, 301, 373-377.

De Bourdeandhui, I.

(1997). Family food rules and healthy eating in adolescents. Joumal of Health Pychology, 2,45-56.

DeVault, M.L.

(1991). Feeding the family: the social organization of caring as gendered wonk. Chicago: the Universiry of Chicago Press.

Elias, N.

(1982). Het civilisatieproces. Saciogenetische en psychogenetische anderzoekingen. Utrechr: Spectrum. [Originally published in German: Elias, N. (1939). Uber den Prozess der Zivilisation. Soziogenetische und Psychogenerische Untersuchungen. Bazel: Haus zum Falken.]

Feunekes, G.I.J., Stafleu, A., De Graaf, C. \& Van Staveren, W.A.

(1996). Family resemblance in fat intake in the Netherlands. In: G.1.J. Feunekes, Food, fat, family and friends: studies on the impact of the social enwiroment on dietary intake (thesis, pp. 55-72). Wageningen: Ponsen \& Looijen.

Fox, A.J.

(1990). Socio-economic differences in mortality and morbidity. Sandinavian Journal of Social Medicine, $18,1-8$.

Frank, ].

(1987). UK and international food consumption pattems. European food constumption and expenditure patterns, Volume 4. Bradford: University of Bradford, School of Biomedical Sciences, Food Policy Research Unit.

Helmerr, U., Mielck, A. \& Classen, E.

(1992). Social inequicies in cardiovascular disease risk factors in East and West

Germany, Social Science and Medicine, 35, 1283-1292.

International Labour Office

(1990). Intermational Stawdard Classification of Occupations: 1SCO-88. Geneva:

International Labour Office.

Kinchgässler, K.U.

(1990). Healch and social inequities in the Federal Republic of Germany. Sacial

Science and Medicine, 31, 249-256.

Kooiker, S. \& Christiansen, T:

(1995). Inequalitics in health: the interaction of circumstances and health related

behaviour. Sociology of Heath and Illvess, 17,495-524. 
Kromhout, D., De Lezenne Coulander, C., Obermann-De Boer, G.L., Van Kampen-Donker, M., Goddijn, E. \& Bloemberg, B.P.M.

(1990). Changes in food and nutrient intake in niddle-aged men from 1960 to 1985 (the Zutphen Study). American Jownal of Cliniol Nutrition, 51, 123-129.

Kromhout, D., Keys, A., Aravanis, C., Buzina, R., Fidanza, F, Simona, G., Janten, A.,

Menotti, A., Nedelikovic, S., Pekkarinen, M., Simic, B.S. \& Toshima H.

(1989). Food consumption patterns in the 1960s in seven countries. American Journal of Clinical Nutrition, 49,889-894.

Kunst, A.E \& Mackenbach, J.P.

(1994). The size of mortality differences associated with educational level in nine industrialized councries. American Jownal of Public Health, 84, 932-937.

Lagasse, R., Humblet, P.C. Lenaerts, A., Godin, I. \& Moens, G.F.G.

(1990). Health and social inequities in Belgitum. Social Science and Medicine, 31 , 237-248.

Lemmens, P.H.H.M.

(1991). Measurement and distribution of alcobol comsumption (thesis). Maastricht: Datawyse.

Mennell, S.J.

(1985). All manners of food. Eating and taste in England and France from the Middle Ages to the present. Oxford: Basil Blackwell.

Prättälä, $\mathbb{R}$.

(1995). Social class and food in the Nordic countries. Endahngasm Unschau, 42,

Beiheft, $16-20$.

Rijksinstituut voor Volksgezondheid en Milieu

(1997). Volksgezondheid Toekomst Verkenning 1997. De som der delen. Urrecht:

Elsevier/De Tijdstroom.

Siegrist, I.

(1989). Steps towards explaining social differentials in morbidity: the case of West

Germany. In: J. Fox (Ed.), Health inequalities in European countries (pp. 353-371). Aldershot: Gower.

Stafleu, A., Van Staveren, W.A., De Graaf, C., Burema, J. \& Hautvast, J.G.A.].

(1994). In: A. Stafleu, Family resemblance in fat intake, nutrition aluitudes and beliefs:

a study among three generations of women (thesis, pp. 107-121). Wageningen: Grafisch

Service Centrum.

Townsend, P., Davidson, N. \& Whitehead, M.

(1988). Inequalities in bealth. London: Penguin.

Van Otcerloo, A.H.

(1995a). Taste food regimens and fatness. A study in social stratification. In: 1. De

Garine \& N.]. Pollack (Eds.), Social aspects of obesity (pp 11 1-126). Luxembourg:

Gordon and Breach Publishers.

Van Otterloo, A.H.

(1995b). Eetsociologie. Facta, 3, 12-14. 
Van Ortenloo, A.H. \& Gerritsen, H.

(1991). Wat doer de consument met de woedingsboodschap? Voeding, 52, 246-250.

Van Otterloo, A.H. \& Van Ogtrop, J.

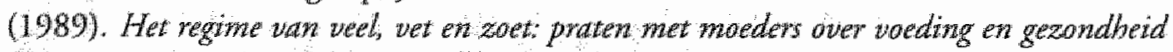
[The regime of plency, fat and sweet: talking with mothers on food and health].

Amsterdam: VU Uitgeverij. 


\section{Summary}

Over the past quarter of a century there has been a growing body of evidence in affluent countries pointing to socio-economic health differences. Generally, people of the higher social classes live longer and they spend fewer years in poor health than people of the working classes. As a high intake of fat and a low intake of fruit and vegetables appear to be associated with the main causes of death (cardiovascular disease and cancer), class differences in food consumption may explain part of these socio-economic health differences.

This thesis examines social class differences in the consumption of foods and drinks, and explores the background of these differences. It is studied whether class patterns in food choice can be untangled in terms of class differences in considerations that may underlie these choices, namely considerations regarding health, food preferences and/or costs. Finally, this study investigates food rules: do mothers of different social backgrounds educate their children differently with regard to food?

The majority of the studies on food practices within families have a qualitative design, and most studies have been performed in the United Kingdom (UK). The present study intends to extend this knowledge by analysing data that have been gathered outside the UK in two surveys: a survey on drinking behaviour in twelve European countries, and a survey on eating behaviour in three cities in the Netherlands, Belgium and Germany.

Chapter 1 describes sociological perspectives on social stratification and eating and drinking behaviour: Elias's theory on the civilising process, Mennell's philosophy on the civilising of appetire, and Bourdieu's concept of distinction. Norbert Elias studied the manners among the upper classes in Europe since the Middle Ages. He stated that when life became more predictable, foresight and selfregulation became more important for social and economic success. During this civilising process external constraints became internalised as unconscious and automatic self-restraint.

Stephen Mennell extended Elias's theory on the civilising process to the civilising of appetite. This process is characterised by distinctions between the upper and lower social classes. When food was scarce, the upper classes distinguished themselves from the lower classes by consuming large amounts of foods, and when food supplies improved, they distinguished themselves by consuming food of a better quality.

Pierre Bourdieu also examined distincrions between the social strata: he characterised the lifestyles of the higher strata as the 'taste of luxury' and of the lower strata as the "raste of necessity'. He stated that people who have greater access to economic and symbolic (implying educational) capital distinguish themselves from 
people who lack these resources in their lifestyles including preferences for music, literature, clothes, furniture and food.

These three theoriles demonstrate that people's preferences are associated with their social position. According to Elias and Mennell, this process of distinction goes on continually, and while external constraints diminish, internalised self-control increases first among the higher social strata, and then among the lower strara.

Chapter 2 analyses beer and wine consumption of more than 11,700 people in the twelve countries of the European Community in 1988. In the northern countries higher educated people drank more wine and less beer than their lower educated counterparts. In the Mediterranean countries this class pattern appeared to be reversed: higher educated people drank more beer (and as much wine) as people of lower educational level. In conclusion, people of the higher social classes in all countries adopted the customs with regard to the new beverage type more often than people of the lower classes.

The results of a survey on food consumption, food choice related considerations and food rules are described in chapters 3 to 6 . For this survey 849 mothers, who lived in working class or higher-middle class districts in Maastricht, Liège or Aachen were questioned about a wide range of food practices. Like in the study on drinking behaviour, social class was operationalised by educational level.

Chapter 3 examines the women's consumption of foods that contribute significantly to the intake of fat and fibre. Higher-middle class women appeared to consume somewhat less dietary fat and more fibre, and they are less meat, milk, and oils and fats, and more grain, fruit and vegetables. Generally, their diets were more consistent with dietary recommendations than working class women's diets. However, higher-middle class women did not always make choices that contributed to a lower intake of fat and a higher intake of fibre: they consumed less bread and potacoes and more cheese, and they chose less often medium-fat cheese and dietary fats than working class women. Although these class patterns were uniform in the three cities, they were primarily apparent in Maastricht and Liege, and to a lesser extent in Aachen.

Chapter 4 explores whether class differences in food consumption can be explained by differences in considerations that underlie food choice. Qualitative studies on food beliefs demonstrated that working class mothers took health less often into account in their choice of food, and the preferences of their family members and expenses more often. The present survey confirmed these findings. However, contrary to the expectarion, these considerations hardly explained class differences in food consumption. 
Chapters 5 and 6 describe social class patterns in how mothers discipline their children with respect to food, as class differences in food rules may explain social inequalities in children's food consumption.

Chapter 5 describes social class differences in food prescriptions and food restrictions, and analyses the association between food rules and the mothers' health considerations and attitudes towards family members' preferences. Mothers of the higher social strata prescribed as many 'healthy" foods like meat and vegetables as lower class mothers, but they restricted more sweet foods, soft drinks and snacks. Class differences in these food restrictions could be partly but not completely explained by class differences in health considerations and attitudes towards preferences.

The consistency berween different food rules, and the association berween food rules and food consumption is examined in chapter 6 . Higher-middle class mothers generally employed healthier and more consistent food rules than lower class mothers. While working class mothers allowed their children more frequently to eat what they wanted, higher-middle class mothers acknowledged more often that their children should learn to eat the foods they provided. The latter category of mothers reported more reasons why they taught their children to eat al] foods, and they obliged their children more often to taste a little bit of the detested food.

Examination of the relation between food rules and food consumption demonstrated that mothers who prescribed more foods did not eat differently compared to mothers who applied less prescriptions. However, women who restricted more foods appeared to have healthier diets than permissive mothers. Assuming a correlation between the consumption of mothers and children, this finding suggests that children, whose mothers restrict more foods, also have healthier diets.

Finally, the resuits are evaluated in chapter 7 . Cultural setting appears to be a powerful context, and in some cases cultural differences in eating and drinking behaviour exceed social class differences. The two surveys demonstrate that significant differences are not only apparent in large regions (e.g. drinking patterns in northern and Mediterranean EC countries), but also in a small border region (for instance the consumption of meat in Maastricht, Liège and Aachen).

Regarding social class differences, the surveys demonstrate that higher-middle class people consume more often new alcoholic beverages and follow more often the latest dietary recommendations. These findings are in line with the theories of Elias, Mennell and Bourdieu: higher-middle class people distinguish themselves from the working classes by their more modern earing and drinking behaviour. 
The surwey on eating behaviour showed that mothers of the higher social classes were more concerned with health. Accordingly, they had healthier diets. Working class mothers considered the preferences of their family members more often and they were more often constrained by their tight budget. This highlights the different position of lower class and higher-middle class women in their family. Because of their more deprived siruation, working class women may have less possibility to resist the pressures of their family members, and therefore they may apply fewer food rules. This finding demonstrates that eating behaviour cannor be detached from people's material and structural circumstanices. As working class children are more often allowed to eat what they want, they have less healthy eating habits when they are young, and probably also when they grow older. Thus, in working class families unhealthy eating habits may be partly replicated from generation to generation.

In conclusion, social class differences in food consumption and food rules may explain part of the socio-economic hiealth differences. The class difference in health considerations corresponds with Elias's and Mennell's notion that internalisation of norms implying long-term planning and deferred gratification are implemented first in the higher social classes. These theories suggest that in the future the lower classes will also take health more often into account, as soon as they are 'able' to postpone satisfying needs and to plan in the long term. 


\section{Samenvatting}

Steeds meer studies tonen aan dat de gezondheidstoestand van mensen in welvarende landen samenhangt met hun sociaal-economische status. Gemiddeld blijven mensen met een hogere sociaal-economische status tot op latere leeftijd gezond en leven ze langer. Aangezien een hoge consumptie van vet en een lage consumptie van groente en fruit blijken samen te hangen met de belangrijkste doodsoorzaken (hart- en vaatziekten en kanker), kunnen klasseverschillen in voedingsgewoonten eventueel een deel van de sociaal-economische gezondheidsverschillen verklaren.

Dit proefschrift beschrijft klasseverschillen in eet- en drinkgewoonten en de achtergronden van deze verschillen. Onderzocht wordt of overwegingen met betrekking tot gezondheid, smaak en financiën klasseverschillen in voedselconsumptie kunnen verklaren. Tenslotte gaat dit proefschrift in op voedingsregimes: verschillen de voedingsregels (geboden en beperkingen) die ouders hun kinderen opleggen tussen sociale klassen?

De meeste studies naar woedingspraktijken in gezinnen hebben een kwalitatieve onderzoeksopzet, en het meeste onderzoek is afkomstig uit Groot-Brittannië. Dit proefschrift daarentegen is gebaseerd op twee kwantitatieve onderzoeken, die in verschillende Europese landen zijn uitgevoerd: het ene naar drinkgewoonten in twaalf Europese landen en het andere naar voedingsgewoonten in drie steden in respectievelijk Nederland, België en Duitsland.

In hoofdstuk 1 worden drie sociologische theorieën over sociale stratificatie en eet- en drinkgewoonten beschreven: de theorieën over het civilisatieproces (Elias), de civilisatie van eetgedrag (Mennell) en distinctie (Bourdieu). Norbert Elias heeft de ontwikkeling van manieren in de hogere sociale klassen in Europa sinds de Middeleeuwen onderzocht. Hij betoogde dat naarmate her leven voorspelbaarder werd, planning en zelfregulatie belangrijker werden voor sociale en economische vooruitgang. Tijdens dit civilisatieproces werden beperkingen die voorheen van buiten werden opgelegd, geïnternaliseerd als onbewuste, automatische zelfbeperkingen.

Stephen Mennell werkte Elias' theorie uit voor eergewoonten. De civilisatie van eetgedrag wordt getypeerd door het onderscheid tussen sociale klassen. In tijden van voedselschaarste onderscheidden de hogere klassen zich van de lagere door de consumptie van enorme hoeveelheden voedsel en in de periode dat er voldoende voedsel beschikbaar kwam voor iedereen onderscheidden de hogere lagen zich door te kiezen voor voedsel met cen betere kwaliteit.

Pierre Bourdieu onderzocht verschillen in smaak tussen sociale klassen. $\mathrm{Hij}$ typeerde de leefstijl van de hogere lagen als de 'smaak van de luxe' en van de lagere 
sociale lagen als de "smaak van de noodzaak". Hij stelde dat mensen met meer economisch en symbolisch kapitaal (geld en opleiding) zich onderscheidden van mensen met minder kapitaal door middel van hun leefsrijlen, zoals voorkeuren voor imuziek, literatuur, kleding, intichting en voeding.

Deze drie theoriecen tonen aan dat de yoorkeuren van mensen samenhangen met hun maatschappelijke positie. Volgens Elias en Mennell zet dit proces van distinctie zich voortdurend voort: als er minder externe beperkingen zijn, stijgt de zelfbeheersing; eerst in de hogere sociale klassen, en vervolgens in de lagere.

Hoofdstuk 2 beschrijft sociale klasseverschillen in drinkgewoonten van ruim 11.700 mensen in twaalf Europese Janden. In de noordelijke Europese landen blijken beter opgeleide mensen meer wijn en minder bier te drinken dan mensen met een lagere opleiding. In de mediterrane landen is dit patroon omgekeerd: hoger opgeleiden drinken meer bier (en overigens evenveel wijn) als laag opgeleide mensen. Geconcludeerd wordt dat vooral mensen uit de hogere klassen de drinkgewoonten met betrekking tot de nieuwe dranksoort overnemen.

De resultaten van het onderzoek naar voedselconsumptie, voedings-gerelateerde overwegingen en voedingsregels worden beschreven in de hoofdstukken 3 tot en met 6. Voor dit onderzoek hebben 849 moeders, uit arbeiderswijken of meer gegoede wijken in Maastricht, Luik of Aken, vragenlijsten ingevuld ower allerhande voedingskwesties. Net als in het bovengenoemde onderzoek naar drinkgewoonten wordt sociale klasse in deze studie geoperationaliseerd door opleidingsniveau.

Hoofdstuk 3 onderzoekt klasseverschillen in de consumptie van produkten die veel vet en voedingsvezel bevatten. In vergelijking met vrouwen uit de lagere sociale klassen, eten vrouwen uit de hogere sociale lagen iets minder vet en meer voedingsvezel; ze eten minder vlees, melk, oliën en vetten en juist meer granen, groenten en fruit. In het algemeen komen de voedingsgewoonten van vrouwen uit de hogere saciale klassen beter overeen met de richtlijnen voor gezonde voeding. Niet al hun voedselkeuzen dragen echrer bij aan dit parroon: vrouwen uit de hogere sociale klassen eten minder brood, minder aardappels en meer kaas. Bovendien kiezen zẻ minder vaak magere kaassoorten en halfwolle vetten, zoals halvarine, als vrouwen uit de lagere sociale klassen. Hoewel deze klassepatronen in de drie steden vergelijkbaar zijn, zijn ze in Maastricht en Luik duidelijker dan in Aken. 
In hoofdstuk 4 wordt nagegaan of de klasseverschillen in voedselconsumptie verklaard kunnen worden door verschillen in overwegingen, die de voedingskeuze mogelijk beïnvloeden. Uit kwalitatiewe studies naar voedingsgewoonten blijkt dat moeders uit de arbeidersklassen gezondheid minder vaak in overweging nemen bij de keuze van voedingsmiddelen en de voorkeuren van hun gezinsleden en de prijs van voedingsmiddelen juist vaker. De studie, die voor dit proefschrift is uitgevoerd, laat vergelijkbare klasseverschillen zien. In tegenstelling tot de verwachting kunnen deze overwegingen de klasseverschillen in voedingsgewoonten echter niet verklaren.

In de hoofdstukken 5 en 6 worden klasseverschillen in voedingsregels beschreven, aangezien de manier waarop ouders hun kinderen (op) voeden een bijdrage kan leveren aan de verklaring van klasseverschillen in de eetgewoonten van kinderen.

Hoofdstuk 5 beschrijft klasseverschillen in voedingsvoorschriften en beperkingen. Moeders uit de hogere sociale lagen schrijven evenveel 'gezonde" voedingsmiddelen voor, zoals vlees en groente, als moeders uit de lagere klassen. Ze beperken echter vaker de consumptie van zoetigheid, frisdranken en snacks. Het klassepatroon in het opleggen wan deze beperkingen kan voor een deel, maar niet helemaal verklaard worden door klasseverschillen in de moeders' overwegingen ten aanzien van gezondheid en smaak.

De samenhang tussen verschillende voedingsregels onderling en tussen deze regels en voedsellconsumptie wordt onderzocht in hoofdstuk 6 . Moeders in de hogere klassen passen consistentere voedingsregels toe, die beter overeenstemmen met de voedingsrichtlijnen dan moeders in de lagere klassen. Terwijl moeders uit de arbeidersklassen vaker toestaan dat hun kinderen eten wat ze lekker vinden, vinden moeders uit de hogere sociale klassen vaker dat hun kinderen moeten eten wat hun wordt voorgezet. Die laatste moeders noemen meer redenen waarom hun kinderen alle voedingsmiddelen moeten leren eten en ze verlangen vaker dat hun kinderen in ieder geval iets proeven van wat ze nier lusten.

Analyse van de samenhang tussen voedingsregels en voedselconsumptie toont aan dat de eetpatronen van moeders die meer of juist minder voedingsmiddelen voorschrijven niet verschillen. Moeders, die meer voedingsmiddelen verbieden of inperken, eten gezonder dan toegeeflijke moeders. Gesteld dat de eergewoonten van moeders en kinderen samenhangen, hebben kinderen die meer beperkingen opgelegd krijgen waarschijnlijk ook gezondere eetgewoonten.

De theoretische implicaties van de resultaten zijn verwerkt in hoofdstuk 7 . Uit de rwee cross-culturele onderzoeken blijkt dat cultuur een krachtige context is. In sommige gevallen zijn de culturele verschillen in eet- en drinkgewoonten groter dan de klasseverschillen. De twee onderzoeken tonen bovendien aan dat culturele verschillen in eet-en drinkgewoonten niet alleen aanzienlijk zijn in een grote regio (zoals de drinkpatronen in de noordelijke en de mediterrane EG landen), maar dat 
grote variaties ook in een klein gebied als de grensstreek van Nederland, België en Duitsland aanwezig zijn (de consumptie van vlees bijwoorbeeld).

Wat de sociale klasseverschillen betreft, tonen de twee onderzoeken aan dat mensen met een hogere social-economische status vaker nieuwe dranksoorten kiezen en dat zij vaker de voedingsrichitijnen ten aanzien van vet en vezel opvolgen. Dexe bevindingen komen overeen met de theorieën van Elias, Mennell en Bourdieu: de hogere klassen onderscheiden zich wan de lagere door hun 'nieuwere' eet- en drinkgewoonten.

Het onderzoek naar voedingspraktijken toont aan dat moeders met een hogere sociaal-economische status vaker op gezondheidsaspecten letten en dat ze een gezonder voedingspatroon hebben. Moeders uit de lagere sociale klassen daarentegen houden valker rekening met de voorkeuren van hun gezinsleden. Bovendien worden hun keuzes vaker beperkt door een krap budget. Dit karakteriseert de verschillende posities van moeders in hun gezin in de hogere of juist lagere saciale klassen. Hun ongunstigere positie biedt moeders uit de lagere klassen waarschijnlijk minder mogelijkheden om weerstand te bieden aan de druk van hun gezinsleden.

Vermoedelijk passen zij daarom minder strenge voedingsregels toe. Dit toont aan dat eetgewoonten niet losstaan van materiële en structurele omstandigheden. Aangezien kinderen in de lagere klassen vaker mogen eten wat ze zelf willen, hebben ze ongezondere eetgewoonten tijdens hun jeugd en vermoedelijk ook als ze ouder worden. Ongezonde eetgewoonten worden in de lagere klassen waarschijnlijk gedeeltelijk van generatie op generatie overgedragen.

Deze klasseverschillen in voedselconsumprie verklaren mogelijk een deel van de sociaal-economische gezondheidsverschillen. Het klasseverschil in de mate waarin gezondheidsoverwegingen een rol spelen, stemt overeen met de opvattingen van Elias en Mennell dat internalisatie van normen met betrekking tot lange-termijn planning en uirgestelde behoeften het eerst optreedr in de hogere sociale klassen. Hun theorieèn suggereren dat, zodra mensen met een lagere social-economische status in staat zijn om op de langere termijn te plannen en de bevrediging van hun behoeften uit te stellen, zij ook vaker gezondheidsaspecten in hun keuzes zullen betrekken. 


\section{Appendix 1}

Selected food groups and examples of food items that are included in these groups

\begin{tabular}{|c|c|c|}
\hline food groups & fat/fibre & food items \\
\hline meat and & high-fat & pork $>15$ g fat 100 gl, meal croquette \\
\hline meat products & nedium/low-fat & beef, veal poulty, pork ( 15 g fav100 ol \\
\hline milk and & high-fat & bigh-fat (condensed) milk drinking chocolate, \\
\hline milk products & & yoghurt, coffee cream, milk pudding \\
\hline & mediumlow fat & skimmed and low-fat condensed) milk, \\
\hline & & drinking chocolate, yoghurt butternilk \\
\hline cheese & high-fiat & high fat cheese \\
\hline & low-fal & low fat cheese \\
\hline edible oils and & high-fat & oil, butter margarine, mayonnaise, cooking fat frying fat \\
\hline fats & medium-fat & low-fat butter, margarine, mayonnaise, sal ad dressing \\
\hline bread & white & White bread, currant loal \\
\hline & wholemeal & brown bread, wholemeal bread, wheat bread, rye bread \\
\hline grain & pollshed & polished rice \\
\hline & unpolished & unpolished rice, bran, wheat germs, muesli, cereals \\
\hline fruit & & oranges apples, pears, banaras, died fruit \\
\hline vegetables & & cooked raw \\
\hline potatoes & & cooked \\
\hline
\end{tabular}




\section{Dankwoord}

Iedereen die een bijdrage aan dit proefschrift heefo geleverd wil ik hartelijk bedanken. Mijn dank gaat allereerst uit naar de vrouwen uit Maastricht, Luik en Aken die aan het onderzoek hebben meegewerkt en de voedingsvragenlijsten hebben ingevuld. Merci beaucoup pour vorre participation! Vielen Dank für Ihre Mitarbeit!

Dankzij de prettige samenwerking met mijn promotor Riet Drop en mijn copromotor Ronald Knibbe, heb ik met veel plezier aan dit proefschrift gewerkt. Beste Riet en Ronald, de vrijheid die ik van jullie kreeg om dit onderzoek zo op te zetten zoals ik dat wilde en jullie vertrouwen dat dat ook zou lukken, hebben daar in belangrijke mate aan bijgedragen. De expertise die jullie in korte tijd op voedingsgebied hebben opgebouwd en jullie frisse blik op dit terrein heb ik bijzonder gewaardeerd. Onze ralrijke besprekingen over dit project (en andere onderwerpen) waren zeer inspirerend.

Anneke van Otterloo, jouw onderzoek naar 'het regime van veel, vet en zoet' vormde de basis voor het huidige onderzoek. Ik heb dankbaar gebruikt gemaakt van je adviezen en van de inzichten die uit jouw kwalitatieve onderzoek naar voren kwamen. Ik vind het prettig dat je vanaf het begin tot het eind je betrokkenheid bij dit onderzoek toonde en dat je aan twee artikelen hebr meegewerkt.

Ook de bijdrage van Sandra Bausch-Goldbohm is van onschatbare waarde. Beste Sandra, ik was al heel blij dat je me wilde adviseren hoe ik de voedselfrequentievragenlijst van de cohortstudie naar voeding en kanker het best kon inpassen in mijn vragenlijst. Dat dat heel veel extra werk voor jou betekende, omdat ook de computerprogramma's voor de invoer, verwerking en controle van de gegevens en de programma's voor de berekeningen van de nutriënten en voedingsmiddelen aangepast moesten worden, wist ik roen nog niet. Ik vind her leuk om weer met je samen te werken nu ik part-time bij TNO werk.

In addition, I am grateful to the Dutch, Belgian and German researchers and dietitians for their valuable contributions to the design of the study and the development of the questionnaire. Dr M. Bergmann, Ms H. Blochwitz, Dr H. Boeing, Dr J.V.A. Collen, Ms M.J. Deschoolmeester, Ms I. Gijsen, Dr F. Kinet, Prof. Dr O. Kuty, Dr I. Paul, Dr R. Peters, Ms C. Provoost, Prof. Dr G. ReginsterHaneuse, Prof. Dr J. Siegrist, Prof. Dr W.A. van Staveren and Dr A.J. Tuyns, thank you for your constructive comments. 
I owe special thanks to the graduates and students who actually initiated and executed the study in the three cities. Inez Bandell-Hoekstra, Françoise Bonhivers, Stephanie Göbbels, Almut Kriele, Ivonne Neves, Mona Pursey and Agnes Schuurman, I appreciated your enchusiastic and professional approach. You have made essential contributions to the success of this study.

De verwerking en de controle van de voedingsgegevens heb ik met een gerust hart kunmen overlaten aan Carolien van Tuijl. Dankzij je ervaring en je inzet, kon je snel uit de voeten met deze klus. Harry van Montfort en Tony van Montfort wil ik hartelijk danken voor hun bijdrage aan het aanpassen van de computerprogramma's.

Mijn collega's van de vakgroep Medische Sociologie wil ik bedanken voor de plezierige werksfeer. Met spijt neem ik afscheid van jullie. Sylvia en Marjoke, ik mis jullie dagelijkse aankondiging van de gezamenlijke thee-pauzes: 'Thee-ee, kom nu gezellig thee-drinken'. Rudie, veel succes met jouw promotie! Met Theo, Ypie en Maaike heb ik tussen de bedrijven door met veel plezier gesport. Maaike, leuk dat je zo'n enthousiaste paranimf bent. Je begon gelijk het feest te organiseren, toen ik informeerde of je paranimf wilde zijn.

Familie en vrienden, bedankt voor jullie belangstelling en vooral voor jullie afleiding. Madeleine, ik vind het leuk dat je mijn paranimf wil zijn.

Martijn, de vele uren die jij aan dit proefschrift hebt besteed, zijn duidelijk zichtbaar. Het is een heel mooi boek geworden, nier alleen van buiten, maar ook van binnen!

Lieve pa en ma, bedankt dat jullie er altijd voor mij zijn. Bedankt ook dat jullie de allerlaatste versie van het proefschrift helemaal hebben doorgelezen om de laatste fouten op te sporen. Dit proefschrift draag ik aan jullie op en aan Annelous en mijn grootouders, die zoveel voor mij betekenen.

Marc, tenslotte wil ik jou bedanken voor ons plezierige en afwisselende leven. Dankzij joun bereidheid om mij achterna te reizen, kan ik gaan en staan waar ik wil zonder jou te hoeven missen: van Maastricht naar Chemnitz, Antananarivo, Harare, Zeist of Heerlen! 


\section{Curriculum Vitae}

Christianne Hupkens was born on August 17, 1966 in Delft, the Netherlands. In 1984 she obtained her Gymnasium-B diploma at Stella Maris in Meerssen. In the same year she started to study Human Nutricion at the Agricultural University in Wageningen. She followed the health-relared curriculum, and she participated in a study focusing on seasonal influences on body weight and energy metabolism in Dogbo, Benin, in 1989. She graduated in August 1990 with majors in nutrition, statistics and social sciences methodology.

In August 1990 she started working at the department of Mathematics of the Agricultural University as a lecturer in statisrics. In addition, she worked as an epidemiologist at the department of Welfare and Public Health of the Municipality Arnhem. In February 1991 she started the PhD project described in this thesis at the department of Medical Sociology at the University of Maastricht.

Since September 1996 she works as a consultant to Eurostat at Statistics Netherlands in Heerlen. She explores the availability and comparability of national health interview surveys in Europe, and she participates in the European Task Force on health and health relared survey data. From November 1997 onwards she combines this function with a job at the department of Consumer Research and Epidemiology of TNO Nutrition and Food Research Institute in Zeist. She writes a research proposal to initiate a study on the relation between food consumption patterns and cancer. 